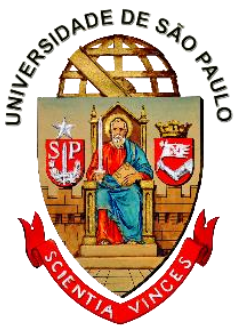

UNIVERSIDADE DE SÃO PAULO

FACULDADE DE ODONTOLOGIA DE RIBEIRÃO PRETO

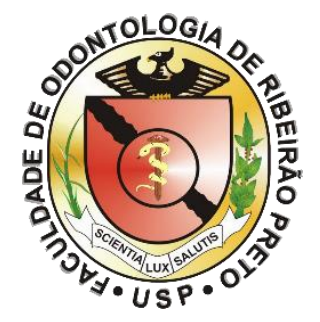

SERGIO AUGUSTO DE FREITAS VICENTE

ESTUDO DAS PROPRIEDADES FÍSICAS E MECÂNICAS DE MATERIAIS RESTAURADORES ODONTOLÓGICOS SUBMETIDOS A CONDIÇÕES DE INUMAÇÃO E AFOGAMENTO PARA FINS PERICIAIS

Ribeirão Preto 



\section{ESTUDO DAS PROPRIEDADES FÍSICAS E MECÂNICAS DE MATERIAIS RESTAURADORES ODONTOLÓGICOS SUBMETIDOS A CONDIÇÕES DE INUMAÇÃO E AFOGAMENTO PARA FINS PERICIAIS}

Dissertação apresentada à Faculdade de Odontologia de Ribeirão Preto, da Universidade de São Paulo, para a obtenção do título de Mestre no Programa de Reabilitação Oral.

Área de Concentração: Biologia Oral

Orientadora: Profa. Dra. Maria José Alves da Rocha

\section{VERSÃO CORRIGIDA}

A versão original se encontra disponível na

Faculdade de Odontologia de Ribeirão Preto - USP

\section{Ribeirão Preto}




\section{AUTORIZO A REPRODUÇÃO E DIVULGAÇÃO DO TEOR TOTAL OU PARCIAL DESTE TRABALHO POR QUALQUER MEIO CONVENCIONAL OU ELETRÔNICO, PARA FINS DE ESTUDO E PESQUISA, DESDE QUE CITADA A FONTE.}

Ficha catalográfica elaborada pela Biblioteca Central do Campus USP - Ribeirão Preto

Vicente, Sergio Augusto de Freitas

Estudo das propriedades físicas e mecânicas de materiais restauradores odontológicos submetidos a condições de inumação e afogamento para fins periciais.

130 p. : il. ; $30 \mathrm{~cm}$

Dissertação de Mestrado, apresentada à Faculdade de Odontologia de Ribeirão Preto/USP. Área de Concentração: Biologia Oral.

Versão corrigida. A versão original se encontra disponível na biblioteca da unidade que aloja o programa e na Biblioteca Digital de Teses e Dissertações da USP (BDTD).

Orientadora: Rocha, Maria José Alves da 


\section{FOLHA DE APROVAÇÃO}

Sergio Augusto de Freitas Vicente

Dissertação apresentada à Faculdade de Odontologia de Ribeirão Preto, da Universidade de São Paulo, para obtenção do título de Mestre.

Área de Concentração: Biologia Oral

Aprovado em:

\section{Banca examinadora:}

1) Prof.(a). Dr.(a).:

Instituição:

Julgamento: Assinatura:

2) Prof.(a). Dr.(a).:

Instituição:

Julgamento: Assinatura:

3) Prof.(a). Dr.(a).:

Instituição:

Julgamento: Assinatura: 



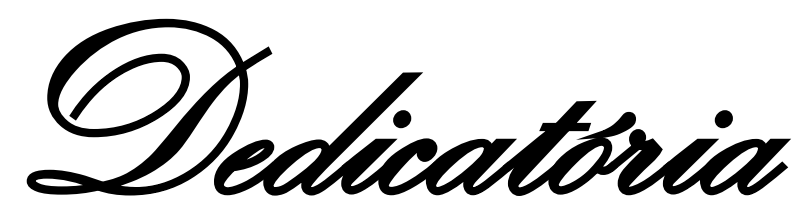



Aos meus pais, Ana Maria e Casemiro, pelo apoio em todas as escolhas que eu fiz na vida. Em quaisquer que fossem as circunstâncias, sempre tiveram paciência e confiança. Pela determinação e luta na minha formação e de meu irmão, e por sempre proverem os ensinamentos para a vida e para todas as questões, não exigindo nada em troca. Pelo exemplo de honestidade, humildade e amor incondicional. Mais do que me proporcionar uma boa infância e vida acadêmica, vocês formaram os fundamentos do meu caráter e me prepararam para a vida.

A meu irmão, Nando, pela compreensão, amizade e companheirismo em todos os momentos de minha vida, e por sempre me apoiar e incentivar.

Obrigado por serem a minha referência e incentivo, por estarem sempre presentes, e por tornarem possível mais um sonho, mais uma caminhada, mais uma vitória. Vocês sempre acreditaram em mim, me ensinaram o valor do trabalho, do sacrifício e da perseverança na conquista de um ideal e, por serem meus maiores exemplos, terão a minha eterna gratidão. Essa conquista é de todos nós. Amo vocês! 



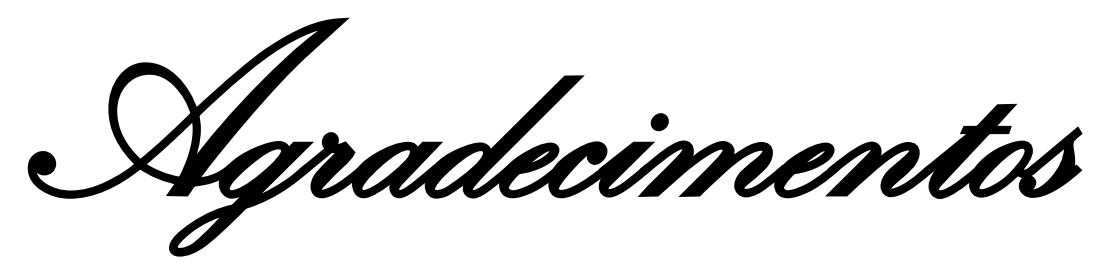



À Profa. Dra. Fernanda de Carvalho Panzeri Pires de Souza, por acreditar e apostar em mim. Seu exemplo de força, sabedoria e competência encorajou-me a resistir a tudo que pudesse me impedir de concluir essa difícil jornada. A senhora se preocupou com os meus passos, não apenas no sentido acadêmico, mas na vida. Seu exemplo profissional e ético de dedicação e compromisso me acompanhará em toda a minha carreira docente, sempre na busca pela excelência. Sua experiência foi fundamental, com conselhos e ajuda nas tomadas de decisões, para que eu pudesse ser hoje uma pessoa melhor, com ética, caráter, tolerância e paciência. Muito obrigado por não ter desistido de mim e ser grande incentivadora! À senhora, ofereço minha eterna gratidão, admiração e amizade!

Ao colega e grande amigo Roberto Cesar Biancalana, que foi muito importante para a conquista desta vitória. Não apenas no aspecto técnico e acadêmico dos laboratórios, seminários e atividades diversas, mas principalmente pela amizade e pelo exemplo de competência, determinação e superação, pelo incentivo e apoio dedicados durante toda a jornada. Não foi fácil, mas vencemos juntos. Muito obrigado! Você terá sempre minha gratidão, admiração e amizade!

À Profa. Dra. Maria José Alves da Rocha, minha orientadora, pela oportunidade, disponibilidade e paciência, em todos os momentos que precisei.

À Universidade de São Paulo e à Faculdade de Odontologia de Ribeirão Preto, na pessoa de seu diretor, Prof. Dr. Valdemar Mallet da Rocha Barros, pelas oportunidades oferecidas durante o mestrado. Me orgulho muito por realizar essa importante etapa de minha formação acadêmica nesta casa.

Ao Programa de Pós-graduação em Reabilitação Oral, na pessoa da coordenadora Profa. Dra. Fernanda de Carvalho Panzeri Pires de Souza, pela dedicação, esforço e comprometimento em buscar o crescimento do programa, incentivando e proporcionando aos alunos atividades de pesquisa e extensão, e pela garantia dos nossos direitos e deveres com a pós-graduação. 
Ao CNPq (Conselho Nacional de Desenvolvimento Científico e Tecnológico), pela bolsa concedida.

Aos professores Alma Blásida Concepción Elizaur Benitez, Ana Maria Razaboni, Andiara de Rossi Daldegan, Andréa Candido dos Reis, Bruno Spinosa de Martinis, Cláudia Helena Lovato da Silva, Evandro Watanabe, Fernanda de Carvalho Panzeri Pires de Souza, Helena de Freitas Oliveira Paranhos, Hermes de Freitas Barbosa, João Paulo Mardegan Issa, Jorge Esquiche León, José Tarcísio Lima Ferreira, Karina Fittipaldi Bombonato Prado, Mamie Mizusaki Iyomasa, Marco Aurélio Guimarães, Maria José Alves da Rocha, Marilena Chinali Komesu, Ricardo Henrique Alves da Silva, Selma Siéssere e Silmara Aparecida Milori Corona, pelos ensinamentos e conhecimentos compartilhados, em suas respectivas disciplinas, contribuindo para que essa conquista pudesse se concretizar, e pela influência que certamente terão nas próximas etapas de minha carreira.

Ao Prof. Dr. Ricardo Henrique Alves da Silva, pela supervisão no PAE (Programa de Aperfeiçoamento de Ensino).

Aos meus colegas da pós-graduação, pela amizade, companheirismo e pelos momentos compartilhados, que serão sempre lembrados.

À Indústria e Comércio de Carnes Minerva Ltda., de Barretos (SP), pela doação dos dentes bovinos utilizados neste estudo.

À Prefeitura do Campus de Ribeirão Preto, da Universidade de São Paulo, na pessoa de seu prefeito, Prof. Dr. Osvaldo Luiz Bezzon, pela autorização para a realização dos experimentos no lago do campus. 
Ao Laboratório de Limnologia, do Departamento de Biologia da Faculdade de Filosofia, Ciências e Letras de Ribeirão Preto, da Universidade de São Paulo, na pessoa da Profa. Dra. Marlene Sofia Arcifa e dos colegas pós-graduandos Bruno Barretto de Souza e Tânia Cristina dos Santos Ferreira, pela parceria na realização dos experimentos no lago do campus de Ribeirão Preto e por todo o auxílio prestado.

Ao Departamento de Materiais Dentários e Prótese, na pessoa de sua chefe, Profa. Dra. Cláudia Helena Lovato da Silva, pela autorização para a utilização dos laboratórios do departamento para a realização dos experimentos deste estudo.

À Rafaella Tonani, do Laboratório de Pesquisa "Prof. Dr. Heitor Panzeri"; à Ana Paula Macedo, do Laboratório de Pesquisa de Metrologia; e à Adriana Cláudia Lapria Faria Queiroz, do Laboratório de Estudos Biomecânicos em Prótese e Implantes. Agradeço pela amizade, dedicação, colaboração e disposição que sempre tiveram comigo, em todos os momentos. Este trabalho não existiria sem vocês.

À esquipe do LaABio (Laboratório de Análise de Biomateriais): Profa. Dra. Fernanda de Carvalho Panzeri Pires de Souza, Rafaella Tonani, Marta Maria Martins Giamatei Contente, Carla Cecilia Alandia Román, Renata Costa de Morais, Renata Espíndola Silveira, Lourenço de Moraes Rego Roselino, Francisca Daniele Jardilino Silame, Michelle Alexandra Chinelatti, Gustavo da Col dos Santos Pinto, Ana Beatriz Silva Sousa e Roberto Cesar Biancalana. Minha chegada nesse laboratório foi, certamente, determinante para o sucesso desta etapa que se encerra hoje, de uma grande jornada que ainda está por vir. Tive a sorte de conhecer pessoas tão incríveis, que me receberam de braços abertos. Muito obrigado pela acolhida (por me "adotarem"), pelo carinho, trabalho, estudos, trocas de experiências e momentos alegres compartilhados!

Ao Departamento de Estomatologia, Saúde Coletiva e Odontologia Legal, na pessoa de sua chefe, Profa. Dra. Marlívia Gonçalves de Carvalho Watanabe. Agradecimentos estendidos aos funcionários Sr. Dorival Gaspar e Sra. Antonia Ferreira. 
Aos colegas da área de Odontologia Legal: Roberto Cesar Biancalana, Marta Regina Pinheiro Flores, Laís Gomes de Araújo, Hiromi Eduardo Sakamoto, Cristhiane Leão de Queiroz, André Luiz Bergamo, Gustavo Peres Plácido, Geovane Praxedes Lavez e Thaís Uenoyama Dezem.

Às secretárias da pós-graduação Fernanda Talita de Freitas, Regiane de Cássia Tirado Damasceno, Ana Paula Xavier, Rosângela Aparecida da Silva Troca Nascimento, Isabel Cristina Galino Sola, Regiane Cristina Moi Sacilotto e Mary Possani Carmessano, pela inestimável disponibilidade, amabilidade, paciência e colaboração em todo o processo do curso de mestrado em Reabilitação Oral.

A todos os funcionários da Faculdade de Odontologia de Ribeirão Preto, da Universidade de São Paulo.

Aos meus pais, pela dedicação de suas vidas, investindo em mim, quase sempre mais do que podiam e fazendo dos meus ideais, os seus. Ao meu irmão... enfim, como sempre falamos, somos mais que uma família, somos uma equipe!

A todos que, direta ou indiretamente, contribuíram para a realização deste trabalho.

Meu eterno agradecimento! 


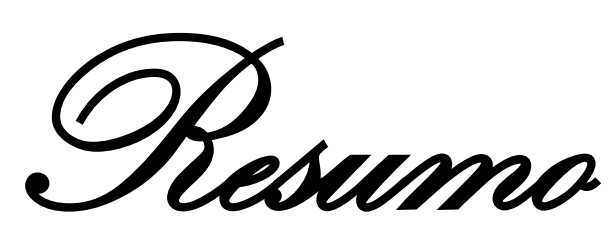



VICENTE, S. A. F. Estudo das propriedades físicas e mecânicas de materiais restauradores odontológicos submetidos a condições de inumação e afogamento para fins periciais. Ribeirão Preto, 2014. 130p. Dissertação (Mestrado em Reabilitação Oral; Área de concentração: Biologia Oral). Faculdade de Odontologia de Ribeirão Preto, Universidade de São Paulo.

\section{RESUMO}

O objetivo deste estudo foi avaliar o efeito da simulação de condições de inumação e afogamento sobre estabilidade de cor, rugosidade de superfície e microdureza de resina composta (RC), cimento de ionômero de vidro (CIV) e amálgama de prata (AM), visando fornecer elementos para diferenciação de materiais estéticos e estimativa do tempo de submissão aos agentes. Foram obtidos 60 incisivos bovinos, que receberam preparos cavitários (6 x $6 \mathrm{~mm}$ e $2 \mathrm{~mm}$ de profundidade) e foram restaurados com RC Filtek ${ }^{\mathrm{MR}} \mathrm{Z} 250$ XT (3M ESPE $\left.^{\circledR}\right)$, CIV Ketac ${ }^{\mathrm{TM}}$ Fil Plus (3M ESPE ${ }^{\circledR}$ ) e AM em cápsulas gs-80 (SDI $\left.{ }^{\circledR}\right)$. Realizaram-se as primeiras leituras, que se constituíram no baseline, de: cor, (Espectrofotômetro VITA ${ }^{\circledR}$ Easyshade), rugosidade de superfície (Rugosímetro Mitutoyo ${ }^{\circledR}$ Surftest SJ-201P) e microdureza Knoop (microdurômetro Shimadzu ${ }^{\circledR}$ Micro Hardness Tester HMV-2). Em seguida, as amostras foram separadas em dois grupos de $30(\mathrm{n}=10)$, de acordo com as condições a que foram submetidas: simulação de condições de inumação e de afogamento, por 1, 3 e 6 meses, após os quais novas leituras foram realizadas. Os valores de alteração de cor $(\Delta \mathrm{E}, \Delta \mathrm{L}, \Delta \mathrm{a}$ e $\Delta \mathrm{b})$ e demais propriedades dos materiais estéticos foram submetidos a análise estatística 3-way ANOVA, medidas repetidas, Bonferroni $(\mathrm{p}<0,05)$. Para o amálgama, foram comparados rugosidade superficial e microdureza (2-way ANOVA, medidas repetidas, Bonferroni, $\mathrm{p}<0,05$ ). Verificouse que condições de inumação e de afogamento produzem alteração de cor nos materiais restauradores estéticos, que não é tempo dependente. Não houve diferença $(p>0,05)$ na microdureza dos materiais restauradores estéticos em função dos agentes e tempos testados, apesar de apresentarem diferenças inerentes quanto a essa propriedade. Houve alteração significativa $(\mathrm{p}<0,05)$ na microdureza do $\mathrm{AM}$, após 6 meses de afogamento. Quanto à rugosidade de superfície, não houve diferença significante ( $p>0,05)$ para nenhum dos materiais, agentes e tempos testados. Concluiu-se que a contribuição desses métodos à identificação humana após inumação ou afogamento só é possível considerando-se a microdureza, sendo auxiliada pela análise da alteração de cor do material. Não é possível predizer o tempo de inumação ou afogamento de um indivíduo apenas com base nos parâmetros estudados.

Palavras-Chave: Identificação humana, Odontologia Legal, Materiais Dentários, Estabilidade de cor, Rugosidade de superfície, Microdureza 



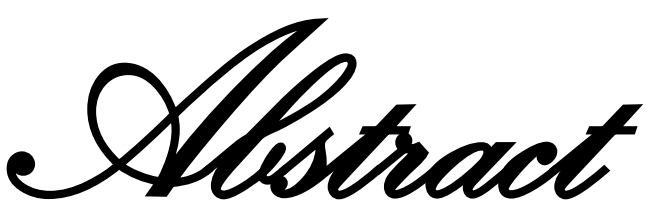



VICENTE, S. A. F. Study of physical and mechanical properties of dental restorative materials subjected to conditions of inhumation and drowning for forensic purposes. Ribeirão Preto, 2014. 130p. Dissertação (Mestrado em Reabilitação Oral; Área de concentração: Biologia Oral). Faculdade de Odontologia de Ribeirão Preto, Universidade de São Paulo.

\begin{abstract}
$\underline{\text { ABSTRACT }}$
The purpose of this study was to evaluate the effect of simulated drowning and burial conditions on color stability, surface roughness and microhardness of composite resin (RC), glass ionomer cement (CIV) and silver amalgam (AM), aiming to provide elements for differentiation of aesthetic materials and estimation of the time of the agents have been subjected to these conditions. 60 bovine incisors were prepared with a $6 \times 6 \times 2 \mathrm{~mm}$ cavity and were restored with RC Filtek $^{\text {MR }}$ XT Z250 (3M ESPE $\left.{ }^{\circledR}\right)$, CIV Ketac $^{\text {TM }}$ Fil (3M ESPE $\left.{ }^{\circledR}\right)$ and AM capsules gs-80 $\left(\mathrm{SDI}^{\circledR}\right)$. The color, surface roughness and microhardness baselines were measured using a reflectance spectrophotometer with CIE L*a*b* system (VITA® Easyshade), a surface roughness device (Mitutoyo ${ }^{\circledR}$ Surftest SJ-201P) and a micro hardness tester (Shimadzu ${ }^{\circledR}$ HMV-2). Then, the samples were separated into two groups of $30(n=10)$, in accordance with the conditions that they were subjected: simulation of burial and drowning conditions, for 1,3 and 6 months, after which further measurements were performed. Values of $\Delta \mathrm{E}, \Delta \mathrm{L}, \Delta \mathrm{a}$ e $\Delta \mathrm{b}$ and the other properties of the aesthetic materials were statistically analyzed using 3-way ANOVA, repeated measures, Bonferroni $(\mathrm{p}<.05)$. For the amalgam, only surface roughness and microhardness were compared (2-way ANOVA, repeated measures, Bonferroni, $\mathrm{p}<.05$ ). It was found that burial and drowning conditions produce color change in the aesthetic restorative materials, which is not time dependent. There was no difference ( $p>.05)$ in microhardness of aesthetic restorative materials caused by the agents and times tested, notwithstanding they have inherent differences regarding this property. There was significant change $(p<.05)$ in AM microhardness after 6 months of drowning. Regarding surface roughness, there was no significant difference ( $p>.05$ ) for any material, agents and times tested. It was concluded that the contribution of these methods to human identification after burial or drowning is only possible considering the hardness, being aided by the analysis of the color change of the material. It is not possible to predict the time of burial or drowning of an individual based solely on the studied parameters.
\end{abstract}

Keywords: Forensic Anthropology, Forensic Dentistry, Dental Materials, Color stability, Surface roughness, Microhardness 

Lista de Plussuassoes 



\section{LISTA DE ILUSTRAÇÕES}

Figura 01 Apresentação de um dente bovino .................................................... 51

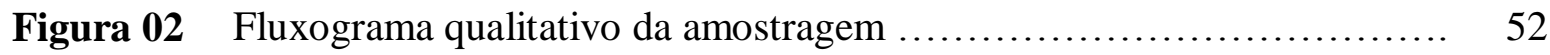

Figura 03 Etapas da confecção do preparo cavitário ................................................ 53

Figura 04 Profundidade da cavidade do preparo cavitário ........................................ 53

Figura 05 Identificação individual ....................................... 53

Figura 06 Amálgama em cápsulas gs- 80 - 2 porções $\left(\mathrm{SDI}^{\circledR}\right)$.................................. 54

Figura 07 Etapas da realização da restauração de amálgama .................................... 54

Figura 08 Ácido fosfórico a 37\% Alpha Etch $\left(\mathrm{DFL}^{\circledR}\right)$ e condicionamento ácido ........ 55

Figura 09 Adesivo Adper Single Bond $2\left(3 \mathrm{M} \mathrm{ESPE}^{\circledR}\right)$, microbrush Applicator Tips (DeTrey/Dentsply $\left.{ }^{\circledR}\right)$ e utilização ................................ 55

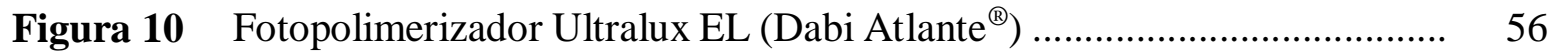

Figura 11 Resina composta Filtek ${ }^{\mathrm{MR}} \mathrm{Z} 250$ XT $\left(3 \mathrm{M}\right.$ ESPE $\left.^{\circledR}\right)$ e realização da restauração .............................................................................. 56

Figura 12 Cimento de ionômero de vidro $\operatorname{Ketac}^{\mathrm{TM}}$ Fil Plus (3M ESPE $\left.{ }^{\circledR}\right)$................... 57

Figura 13 Etapas da realização da restauração de CIV ............................................ 57

Figura 14 Início da confecção do posicionador para fotografias .............................. 58

Figura 15 Posicionador pronto para uso .................................. 58

Figura 16 Câmera Lumix DMC-FZ100 (Panasonic Corporation ${ }^{\circledR}$ ) com tripé e disparador remoto ........................................................................... 59

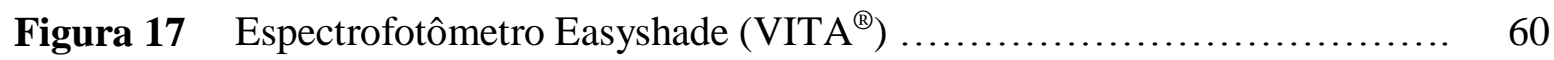

Figura 18 Esquematização do posicionamento da ponteira do espectrofotômetro sobre uma restauração estética ........................................................... 60

Figura 19 Acionamento do espectrofotômetro e apresentação dos valores no display eletrônico

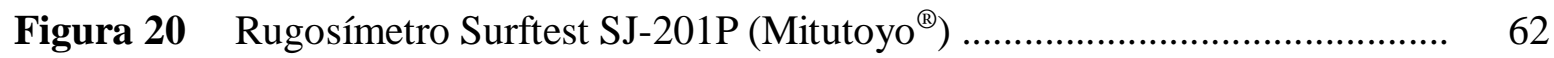

Figura 21 Realização da leitura da rugosidade de superfície ...................................... 63

Figura 22 Microdurômetro Micro Hardness Tester HMV-2 $\left(\right.$ Shimadzu $\left.^{\circledR}\right)$.................. 63

Figura 23 Focalização da superfície da restauração ................................................ 64

Figura 24 Impressão realizada pela ponta penetradora ............................................ 64

Figura 25 Cálculo e apresentação do resultado de microdureza ................................... 65

Figura 26 Acomodação dos dentes para o procedimento de enterramento .................. 66 
Figura 27 Procedimento de enterramento

Figura 28 Confecção das pequenas bolsas de poliéster para o procedimento de afogamento

Figura 29 Gaiola preparada e procedimento de afogamento

Figura 30 Representação gráfica da comparação de $\Delta \mathrm{E}$ entre materiais estéticos submetidos a inumação

Figura 31 Representação gráfica da comparação de $\Delta \mathrm{E}$ entre materiais estéticos submetidos a afogamento

Figura 32 Representação gráfica da comparação de $\Delta \mathrm{L}$ entre materiais estéticos submetidos a inumação

Figura 33 Representação gráfica da comparação de $\Delta \mathrm{L}$ entre materiais estéticos submetidos a afogamento

Figura 34 Representação gráfica da comparação de $\Delta$ a entre materiais estéticos submetidos a inumação

Figura 35 Representação gráfica da comparação de $\Delta$ a entre materiais estéticos submetidos a afogamento

Figura 36 Representação gráfica da comparação de $\Delta b$ entre materiais estéticos submetidos a inumação

Figura 37 Representação gráfica da comparação de $\Delta b$ entre materiais estéticos submetidos a afogamento

Figura 38 Representação gráfica da comparação de rugosidade de superfície entre materiais estéticos submetidos a inumação

Figura 39 Representação gráfica da comparação de rugosidade de superfície entre materiais estéticos submetidos a afogamento

Figura 40 Representação gráfica da comparação de microdureza entre materiais estéticos submetidos a inumação

Figura 41 Representação gráfica da comparação de microdureza entre materiais estéticos submetidos a afogamento

Figura 42 Comparação visual das restaurações submetidas a inumação ....

Figura 43 Comparação visual das restaurações submetidas a afogamento 
Lista de Tabelas 



\section{LISTA DE TABELAS}

Tabela 01 Médias iniciais e finais, após 1 mês, de L*, a* e b* e valores de deltas ...... 72

Tabela 02 Médias iniciais e finais, após 3 meses, de L*, a* e b* e valores de deltas . 73

Tabela 03 Médias iniciais e finais, após 6 meses, de L*, a* e b* e valores de deltas . 74

Tabela 04 Comparação das médias $\Delta \mathrm{E}$ (desvio padrão) dos agentes, para um mesmo material

Tabela 05 Comparação das médias $\Delta \mathrm{L}$ (desvio padrão) dos agentes nos diferentes tempos de ação, para um mesmo material

Tabela 06 Comparação das médias $\Delta$ a (desvio padrão) dos agentes nos diferentes tempos de ação, para um mesmo material

Tabela 07 Comparação das médias $\Delta \mathrm{b}$ (desvio padrão) dos agentes nos diferentes tempos de ação, para um mesmo material

Tabela 08 Médias de rugosidade de superfície das restaurações de resina composta submetida a inumação e afogamento, após cada um dos tempos testados .

Tabela 09 Médias de rugosidade de superfície de cimento de ionômero de vidro submetido a inumação e afogamento, após cada um dos tempos testados

Tabela 10 Médias de rugosidade de superfície de amálgama submetido a inumação e afogamento, após cada um dos tempos testados

Tabela 11 Comparação das médias de rugosidade de superfície (desvio padrão) analisadas segundo 3-way ANOVA, Bonferroni, $\mathrm{p}<0,05$

Tabela 12 Médias de microdureza Knoop de resina composta submetida a inumação e afogamento, após cada um dos tempos testados

Tabela 13 Médias de microdureza Knoop de cimento de ionômero de vidro submetido a inumação e afogamento, após cada um dos tempos testados

Tabela 14 Médias de microdureza Knoop de amálgama submetido a inumação e afogamento, após cada um dos tempos testados

Tabela 15 Comparação das médias de microdureza Knoop (KHN) (desvio padrão), analisados segundo 3-way ANOVA, Bonferroni, $\mathrm{p}<0,05$, para mesmo material - comparação entre os agentes e o tempo 

Sumario 



\section{SUMÁRIO}

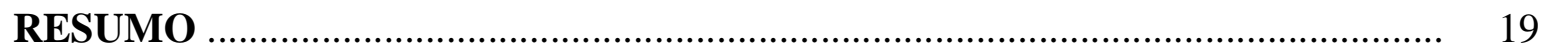

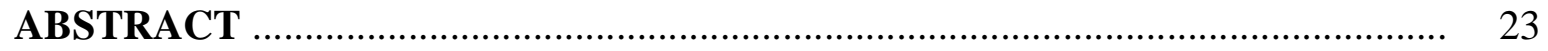

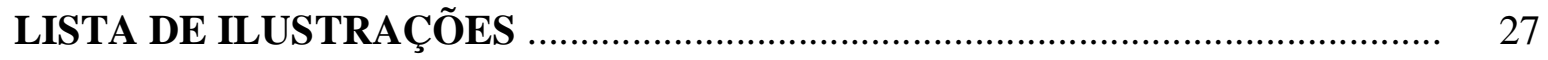

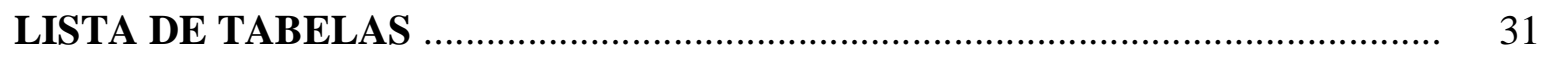

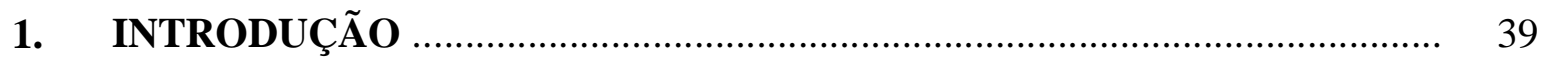

2. PROPOSIÇÃ

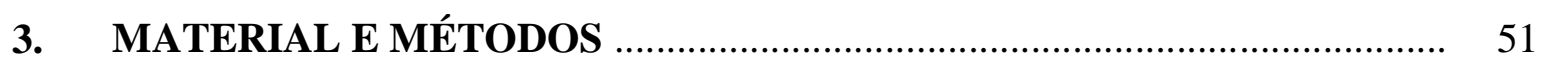

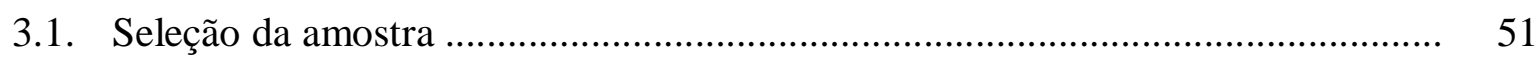

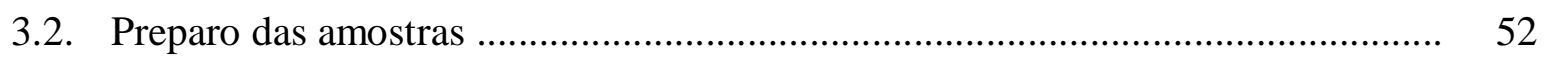

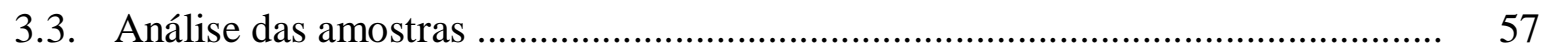

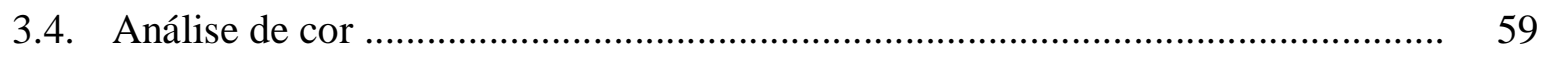

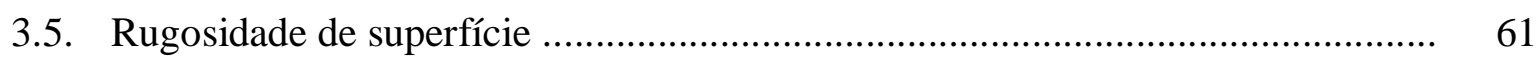

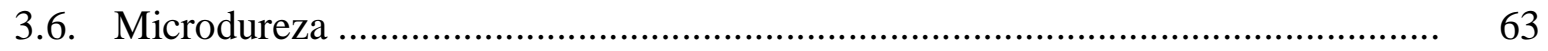

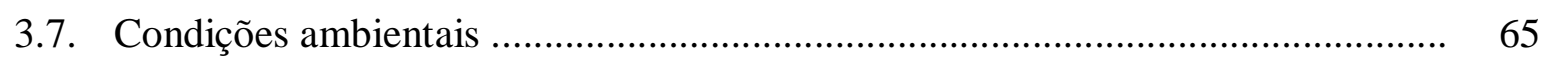

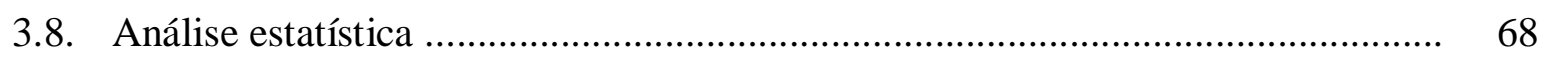

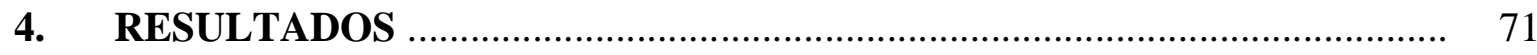

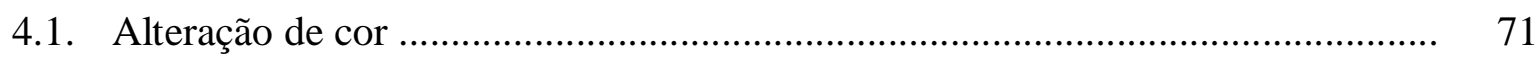

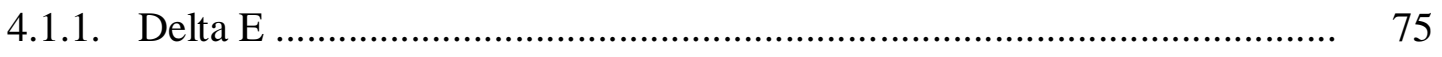

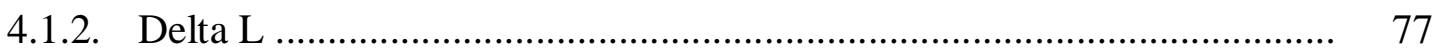

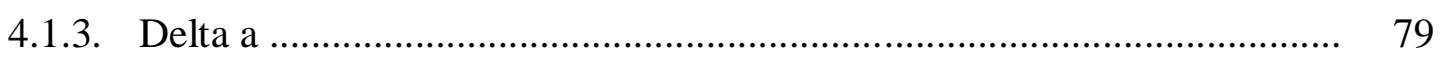

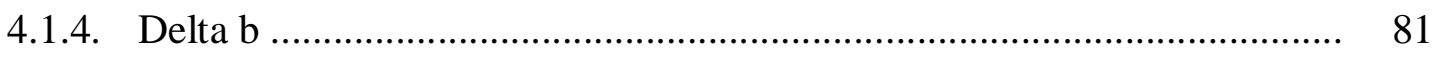

4.2. Rugosidade de superfície..................................................................... 83 


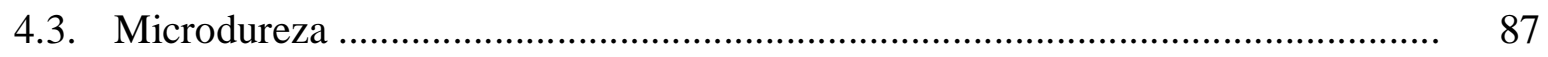

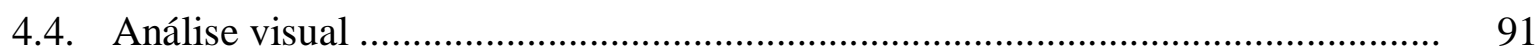

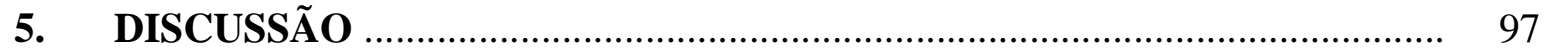

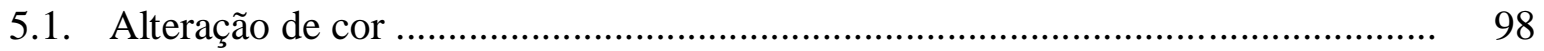

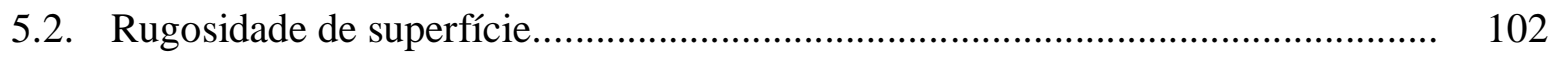

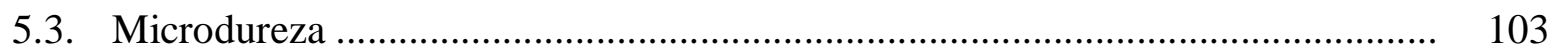

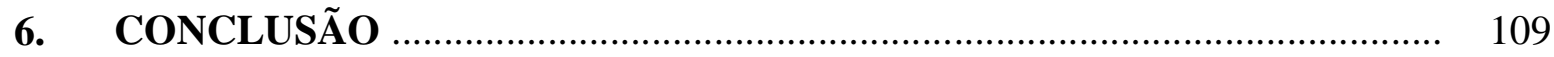

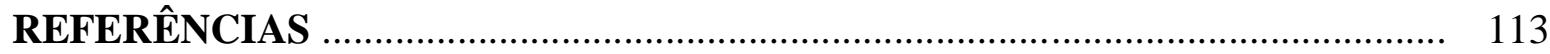

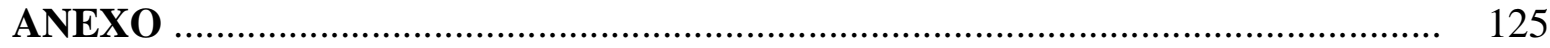


1.. Introdugấa 



\section{INTRODUÇÃO}

A Odontologia Legal é uma especialidade reconhecida e regulamentada por meio da Resolução n ${ }^{\circ}$ 63/2005 ${ }^{1}$, do Conselho Federal de Odontologia (CFO), atualizada em julho de 2012, e tem como objetivo a pesquisa de fenômenos psíquicos, físicos, químicos e biológicos que podem atingir ou ter atingido o homem, vivo, morto ou ossada, e mesmo fragmentos ou vestígios, resultando lesões parciais ou totais reversíveis ou irreversíveis.

Em âmbito forense, na maioria das vezes, a Odontologia é encarregada dos casos envolvendo análises das regiões de cabeça e pescoço (sistema estomatognático, cavidade bucal, arcos dentais, crânio), como previsto na Lei $\mathrm{n}^{\circ} 5081 / 66^{2}$, que regula o exercício da Odontologia em todo o território nacional: “Art. $6^{\circ}$. Compete ao Cirurgião-Dentista: (...) IV - proceder à perícia odontolegal em foro civil, criminal, trabalhista e em sede administrativa. (...) IX utilizar, no exercício da função de perito-odontólogo, em casos de necropsia, as vias de acesso do pescoço e da cabeça".

Dentre as áreas de competência para atuação do profissional odontólogo que exerce atividades em Odontologia Legal estão incluídas, além das anteriormente citadas, as perícias, as avaliações e os planejamentos em infortunística, as quais envolvem os acidentes de trabalho (acidentes-tipo), as doenças profissionais e doenças do trabalho; a traumatologia odontolegal; a tanatologia forense; a elaboração de documentos odontolegais, a balística forense; a perícia logística em indivíduos vivos ou mortos, íntegros ou suas partes em fragmentos; a perícia em vestígios correlatos, inclusive em manchas ou líquidos provenientes da cavidade bucal ou nesta presentes; exames por imagens para fins periciais e para fins odontolegais; a deontologia odontológica; a orientação odontolegal para o exercício profissional e a identificação humana ${ }^{1}$.

A perícia é um procedimento especial de constatação, prova ou demonstração científica ou técnica, relacionado com a veracidade de uma situação, coisas ou fato. É a procura de elementos que formem uma opinião segura e adequada sobre um determinado fato o qual se

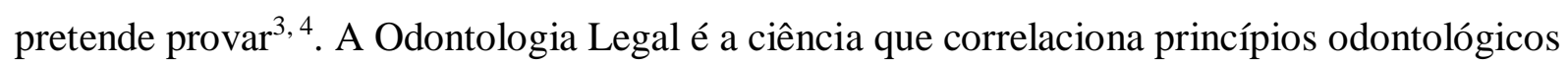
e jurídicos sob a inspiração de esclarecer dados de interesse da Justiça, incluindo o processo de identificação humana ${ }^{5-7}$. Além da sua relação com o Direito, a Odontologia Legal está intimamente ligada à Medicina Legal, devido ao seu poder de colaboração nas circunstâncias que compreendem a busca pela identificação humana ${ }^{8}$. 
A busca pela verdadeira identidade de um ser humano visa atender necessidades médico-legais, jurídicas e sociológicas, culturais e sociais, além dos complexos laços afetivos vinculados aos familiares envolvidos ${ }^{9}$. A confirmação da identidade de um indivíduo é essencial para o traçado e delineamento da investigação judicial, à família, ao Estado e para os registros públicos. Ainda sobre a importância jurídica da identificação, temos a questão sucessória de bens materiais e, até mesmo, da responsabilidade civil. Com a finalidade de que um indivíduo possa gozar de direitos e deveres, ou seja, para que faça parte de uma sociedade e do convívio social, é estritamente necessário, que ele possua um documento de identificação. Em casos de falecimento, por lei, a maioria dos países requer que o Atestado de Óbito seja emitido, não somente para revelar a causa mortis, como também para comprovar civilmente a morte e, consequentemente, solucionar problemas relacionados com pensões alimentícias, guarda de menores, seguros de vida, nova situação civil do cônjuge, aposentadorias, repasse de dívidas, heranças e outros benefícios amparados pela Lei Civil ${ }^{10,11}$.

O processo de identificação de um ser humano pode ser conduzido de diversas maneiras. No entanto, é importante distinguir os conceitos de identificação e reconhecimento. Identificação é um processo objetivo, que visa determinar a identidade de uma pessoa, por meio de fundamentos científicos, baseados na somatoscopia (variações qualitativas) e na somatometria (variações quantitativas) do corpo humano ${ }^{10}$. Por outro lado, o reconhecimento é um método subjetivo, empírico, baseado num conhecimento anterior, à época em que remanescentes do corpo encontravam-se preservados, especialmente a face ${ }^{12}$. Portanto, é afirmar ou admitir conhecer algo que antes já se conhecia ${ }^{13}$, sendo passível de erros, de boa ou má fé.

A identidade é o conjunto formado pelas características morfofisiológicas e psíquicas exclusivas de uma única pessoa, sendo, dessa maneira, capaz de individualizá-la tornando-a diferente de todas as demais ${ }^{14}$. Estabelecer a identidade de um ser humano, incontestavelmente, tem sido há muitos anos uma meta incansável. A identificação de uma pessoa requer que seja possível afirmar, com absoluta segurança e convicção, que determinado indivíduo é ele e somente ele e não uma pessoa diversa ${ }^{3}$.

Revelar a identidade de um indivíduo consiste na acepção de suas características físicas, psíquicas e biológicas que o caracterizam, tornando-o diferente dos demais. A análise necessária neste processo é a comparativa, também chamada de identificação personalista ou individual, onde é necessária a existência de um registro prévio para a comparação dos dados. 
Quando da ausência de dados comparativos, outros métodos fazem-se necessários, objetivando fornecer elementos genéricos que, juntos, podem levar a uma identificação ${ }^{15}$.

O processo de identificação envolve métodos primários e secundários de identificação humana. Considerados métodos primários, temos a Datiloscopia (exame das impressões digitais), a Odontologia Legal e a Biologia Molecular, por meio dos exames de DNA ${ }^{16-18}$. São ditos primários porque se um desses três métodos for capaz de conduzir a uma identificação positiva ou negativa de um ser humano, não existe a necessidade de recorrer-se a outro método primário para que se confirme o resultado de tal identificação. Os demais métodos (reconhecimento, tatuagens, antropologia) são considerados métodos secundários, ou seja, auxiliares para métodos primários ${ }^{18}$.

Os métodos primários de identificação são fundamentalmente comparativos, ou seja, a partir de informações existentes anteriormente à morte de um indivíduo, realiza-se comparação com as informações obtidas após a morte, que identificará ou não esse indivíduo. Para que isso seja possível, é imprescindível a existência de pelo menos um suspeito, para que essa comparação seja realizada, desde que existam informações ante mortem passíveis de comparação. Se não houver suspeitos, ou os suspeitos existentes não possuírem registros ante mortem, a identificação não é possível. Quando da não existência de suspeitos, são utilizados os métodos secundários de identificação, com o objetivo de colher a maior quantidade possível de informações a respeito do cadáver encontrado e encontrar, assim, suspeitos a serem comparados, agora sim, pelos métodos primários. Essas informações relacionam-se a sexo, idade, ancestralidade, estatura, destreza manual, hábitos e, até mesmo, condição socioeconômica do indivíduo. A Odontologia também pode ser utilizada nesse sentido, constituindo-se, então, em um método secundário de identificação ${ }^{18}$.

Entretanto, ao deparar-se com a necessidade de identificação de indivíduos mortos, em que os corpos se encontram em estado avançado de decomposição, esqueletizados, carbonizados, afogados, em que as polpas digitais foram destruídas pela ação da fauna aquática, mutilados, entre outras condições, em que a análise das impressões digitais, possivelmente, será descartada pela impossibilidade da obtenção de registros no corpo, a Odontologia Legal passa a ser o método de escolha mais viável. Existe a possibilidade, também, da utilização do exame de DNA, mas por ser um método oneroso, com dificuldades de padronização, e pelo fato de pessoal tecnicamente preparado não estar disponível em todas as localidades, muitas vezes, acaba sendo descartado ${ }^{19}$. 
Somado a esses fatores, a falta de cuidados durante a coleta, transporte ou armazenamento do material a ser periciado, pode gerar contaminação da amostra e, consequente, falha nos resultados ${ }^{20}$. Nessas situações, em que os corpos não se encontram íntegros, a Odontologia Legal pode representar o único caminho para solução dos mesmos ${ }^{21}$, propiciando redução no tempo de trabalho e custos de material, além de sua alta confiabilidade, desde que seja feito um trabalho criterioso, minucioso e organizado por profissional especialista na área.

Um único elemento dental constitui fonte fundamental de informação a respeito do indivíduo, possibilitando a determinação de características como idade, sexo e ancestralidade ${ }^{22}$. Atualmente, a viabilidade da obtenção de dados como a dieta e o habitat do indivíduo está sendo cientificamente analisada ${ }^{23}$, abrindo um novo campo de informações fornecidas pelos elementos dentais. Todas essas informações permanecem, muitas vezes, preservadas, mesmo em situações extremas de temperatura, pressão e umidade, constituindo fontes valiosas de informação para antropologistas, paleontologistas e odontolegistas ${ }^{23,24}$.

Os dentes, muitas vezes, são encontrados isolados no local de crime, situação decorrente da esqueletização do cadáver e da consequente perda dos tecidos de inserção dental. A própria manipulação pericial, tanto no levantamento do local de crime quanto no transporte dos despojos, podem contribuir para esse processo ${ }^{15}$. Esses fatores manifestam a importância em se obter dados que possam ser extraídos desses elementos isoladamente, sem considerar ainda, a relevância destes quando constituem, em seu conjunto, fonte de prova pericial.

A identificação pelo estudo dos arcos e elementos dentais é um método comparativo, por meio do qual são realizadas comparações entre informações post mortem (após a morte) e informações ante mortem (antes da morte do indivíduo) ${ }^{25}$. Na análise do crânio e seus respectivos arcos dentais, faz-se necessária a presença de dados odontológicos fornecidos pelos cirurgiões-dentistas que atendiam a vítima em vida ${ }^{26}$. Os dados ante mortem são informações provenientes do prontuário odontológico, podendo ser compostos por: fotografias da vítima, com imagens em que se possa observar o sorriso para análise da dentição; radiografias intraorais e extraorais (panorâmicas, periapicais anteriores e posteriores, interproximais, oclusais), nas quais seja possível a verificação das estruturas dentais e ósseas da maxila e mandíbula, do tamanho, da forma e do número de raízes de cada dente; modelos em gesso; placas de clareamento; fichas clínicas, com a descrição dos tratamentos realizados, plano de tratamento; 
contrato de prestação de serviços odontológicos e outras informações que possam ser relevantes ${ }^{21,27,28}$.

Uma das maiores virtudes do método de identificação pela análise dos arcos dentais é sua eficiência em situações adversas, pois os dentes são estruturas altamente mineralizadas, sendo assim, as mais resistentes do corpo humano à ação do tempo, possuindo grande durabilidade, longevidade e alta resistência a condições extremas de degradação, como alterações de pressão, temperatura e umidade ${ }^{29}$. Os elementos dentais, hígidos ou restaurados, não mudam com o passar do tempo, a não ser por fatores externos, mas que são passíveis de verificação e registro prévio $^{30-32}$.

A tanatologia é o estudo médico-legal da morte e das questões a ela relacionadas. $\mathrm{Na}$ Odontologia, são estudados os fenômenos produzidos nos dentes e tecidos anexos, relacionados às questões e circunstâncias que envolveram a morte ${ }^{33}$.

Apesar da disponibilidade de técnicas cada vez mais modernas, ainda não pode o perito consciente de suas responsabilidades estabelecer com precisão o momento em que ocorreu a morte. No máximo, deve fazer uma aproximação em uma faixa de tempo tão segura quanto possível, de modo que inclua o real momento da morte ${ }^{34}$. A estimativa do tempo transcorrido entre o óbito e o exame necroscópico é conhecida como cronotanatognose $e^{3,10,12,34}$.

Por sua vez, a tafonomia pode ser definida como o estudo dos processos geológicos e biológicos que influenciam ou contaminam materiais orgânicos após a morte. Importantes variáveis podem ser identificadas nos estudos tafonômicos, desde fatores individuais e modo de vida até variações climáticas que afetam os despojos. A avaliação tafonômica tem crescido como um componente importante e vital na análise antropológica forense. Os processos tafonômicos relacionados às variações das condições atmosféricas - como temperatura, sol, chuvas, ventos, umidade, etc. - representam uma resposta biológica ao meio ambiente imediato, auxiliando na compreensão e reconstituição do intervalo post mortem. Com relação à aplicação forense, interessam a estimativa do intervalo post mortem (tempo desde a morte) e a diferenciação entre as alterações e as traumáticas. Na prática da Antropologia Forense, considerações tafonômicas têm sido utilizadas para a interpretação global de todos os eventos que afetam os despojos entre a morte e a descoberta ${ }^{34}$.

Muitas vezes, os dentes estão restaurados com materiais odontológicos que sofrerão a ação dos mesmos agentes a que os dentes foram submetidos. Materiais restauradores estéticos estão sujeitos a alterações de cor ao longo do tempo ${ }^{35}$. Além disso, os materiais odontológicos 
apresentam propriedades físicas e mecânicas que os caracterizam e os diferenciam dos demais. Por exemplo, um material metálico possui maior ductilidade que um material cerâmico ${ }^{36}$, devido à friabilidade do segundo ${ }^{37}$. A microdureza de um material é propriedade mecânica importante para definir sua indicação ${ }^{36,38}$, mas no caso de ser necessária uma comparação cega, ou seja, em que não se conhece o material que foi utilizado na restauração, esta propriedade pode ser útil para a diferenciação.

Outra propriedade inerente aos materiais odontológicos é a sua rugosidade de superfície. Entretanto, há que se levar em consideração o papel do procedimento do polimento da restauração, após sua realização. O polimento interfere diretamente na rugosidade de superfície de uma restauração ${ }^{39-41}$. Apesar disso, quando submetido à ação de agentes externos, como imersão em soluções ${ }^{39,}{ }^{42}$, ao hábito diário da escovação ${ }^{40,41}$, hábitos parafuncionais ${ }^{43}$ e o próprio envelhecimento da restauração ${ }^{44-47}$, essa propriedade pode sofrer alteração e é material dependente ${ }^{48-50}$.

Dentre os materiais odontológicos restauradores mais utilizados na Odontologia, temos os amálgamas de prata, as resinas compostas e os cimentos de ionômero de vidro. Quando submetidos às condições impostas por este estudo, tais materiais podem sofrer modificações em suas propriedades físicas e mecânicas.

Quando os dentes são encontrados isoladamente, o confronto com as informações do prontuário odontológico dos indivíduos suspeitos muitas vezes não é suficiente para sua identificação ${ }^{15}$, principalmente devido à degradação desses materiais. Assim, o reconhecimento das alterações a que os materiais odontológicos estão sujeitos pode ter relevância para a Odontologia Legal, pois podem auxiliar na interpretação da condição a que o cadáver foi submetido (inumação ou afogamento) e, também, na estimativa do tempo a que ele foi submetido a tal condição. 


$$
\text { 2. Oropasicáa }
$$





\section{PROPOSIÇÃO}

Este trabalho teve por objetivo avaliar o efeito da simulação de inumação e afogamento sobre estabilidade de cor, rugosidade de superfície e microdureza de materiais restauradores odontológicos.

A hipótese nula testada foi que esses agentes não produziriam alterações em nenhuma das propriedades dos materiais, qualquer que fosse o tempo estudado; e que as diferenças entre os materiais permitiriam distinção entre eles, com a finalidade de auxiliar procedimentos de identificação. 



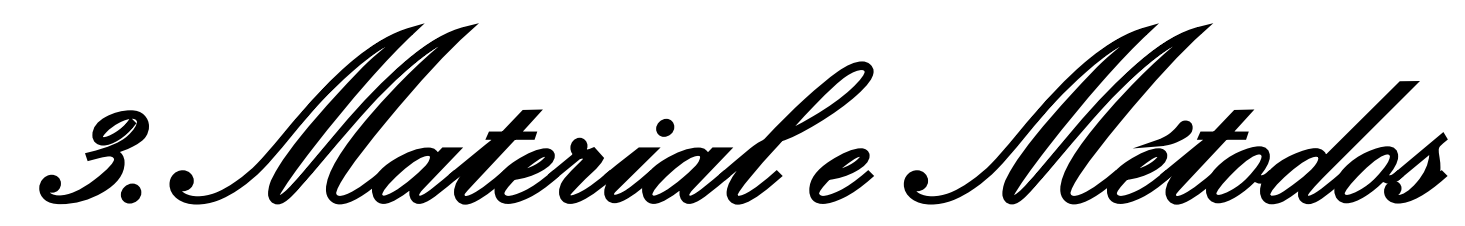





\section{MATERIAL E MÉTODOS}

\subsection{Seleção da amostra}

Para esse estudo, foram obtidos 60 incisivos bovinos (Figura 01), em frigoríficos da região do município de Ribeirão Preto (SP). Os critérios de inclusão estabelecidos foram: amostras hígidas, isentas de trincas e/ou fraturas.

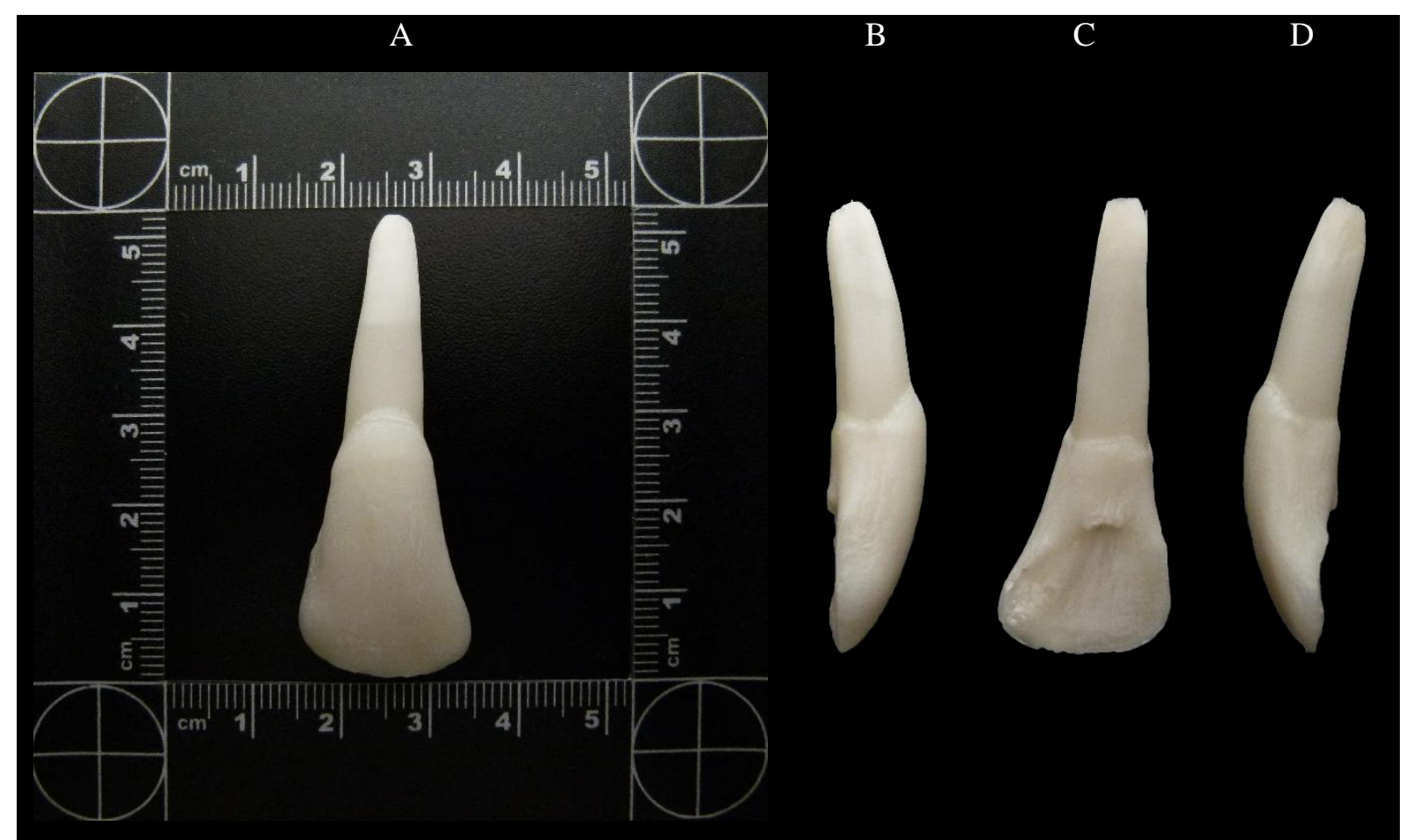

Figura 01 - Dente bovino, do grupo dos incisivos, apresentado nas faces vestibular (A), distal (B), palatina/lingual (C) e mesial (D).

Os dentes, após restaurados, foram separados aleatoriamente em 2 grupos $(n=10)$, de acordo com o tipo de condição ambiental a que seriam submetidos (inumação ou afogamento), para cada material restaurador odontológico, de acordo com o fluxograma a seguir (Figura 02). 


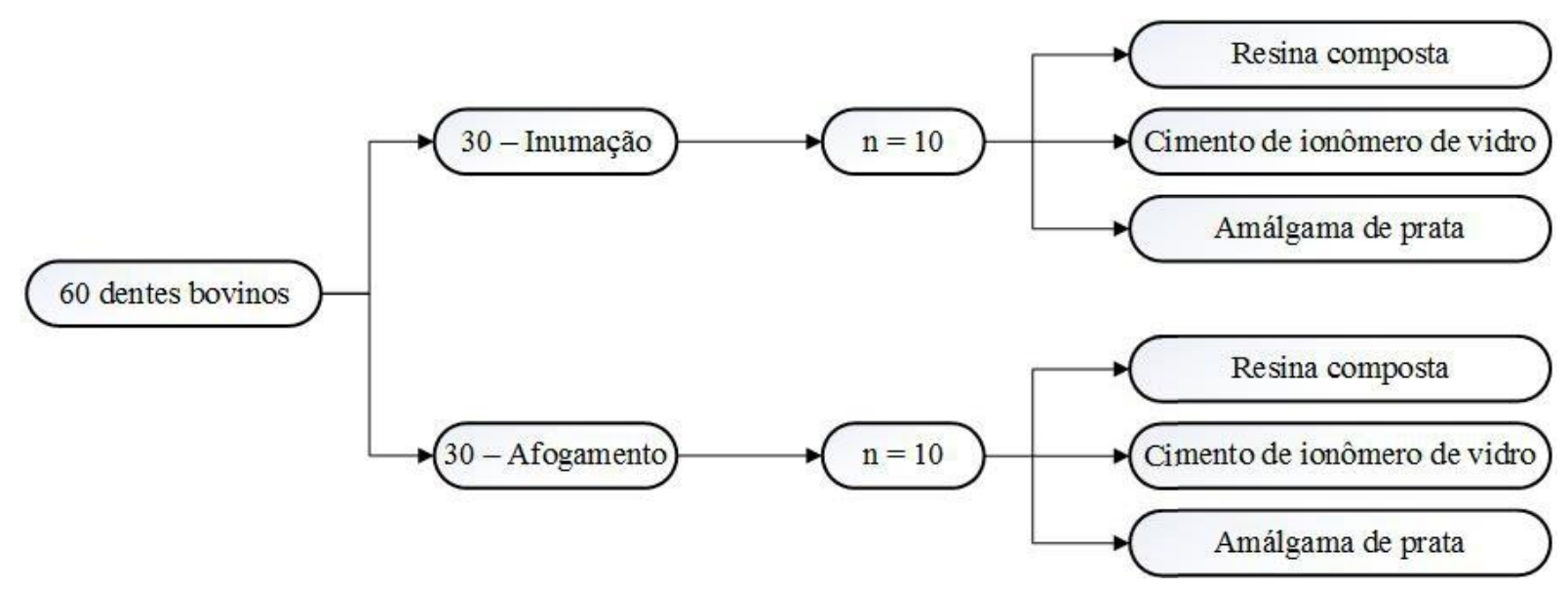

Figura 02 - Fluxograma qualitativo da amostragem.

\subsection{Preparo das amostras}

Primeiramente, os elementos dentais foram lavados em água corrente, sendo removidos todos os restos de tecidos moles e periodontais. Posteriormente, foram armazenados em recipientes de vidro contendo água destilada, sob refrigeração. Então foram realizados preparos cavitários na face vestibular de cada elemento dental, com dimensões de $6,0 \mathrm{~mm}$ de altura $\mathrm{x}$ 6,00 $\mathrm{mm}$ de largura e 2,0 $\mathrm{mm}$ de profundidade (Figura 03), realizado com broca cilíndrica diamantada $n^{\circ} 1343$ (KG Sorensen ${ }^{\circledR}$, Cotia, SP, Brasil) (Figura 04) em alta rotação (Dabi Atlante $^{\circledR}$, Ribeirão Preto, SP, Brasil). Todas as restaurações foram confeccionadas por um mesmo operador.

Os 60 dentes foram inicialmente separados em 3 grupos, e receberam numeração, realizada com broca esférica $n^{\circ} 1013$ (KG Sorensen ${ }^{\circledR}$, Cotia, SP, Brasil) (Figura 05), de acordo com o tipo de material restaurador a ser utilizado: amálgama, resina composta e cimento de ionômero de vidro. Os dentes que foram restaurados com amálgama receberam retenções adicionais nos ângulos axio-pulpares (Figura 07), realizadas com ponta diamantada roda $\mathrm{n}^{\circ}$ 1052 (KG Sorensen ${ }^{\circledR}$, Cotia, SP, Brasil) por um mesmo operador. 


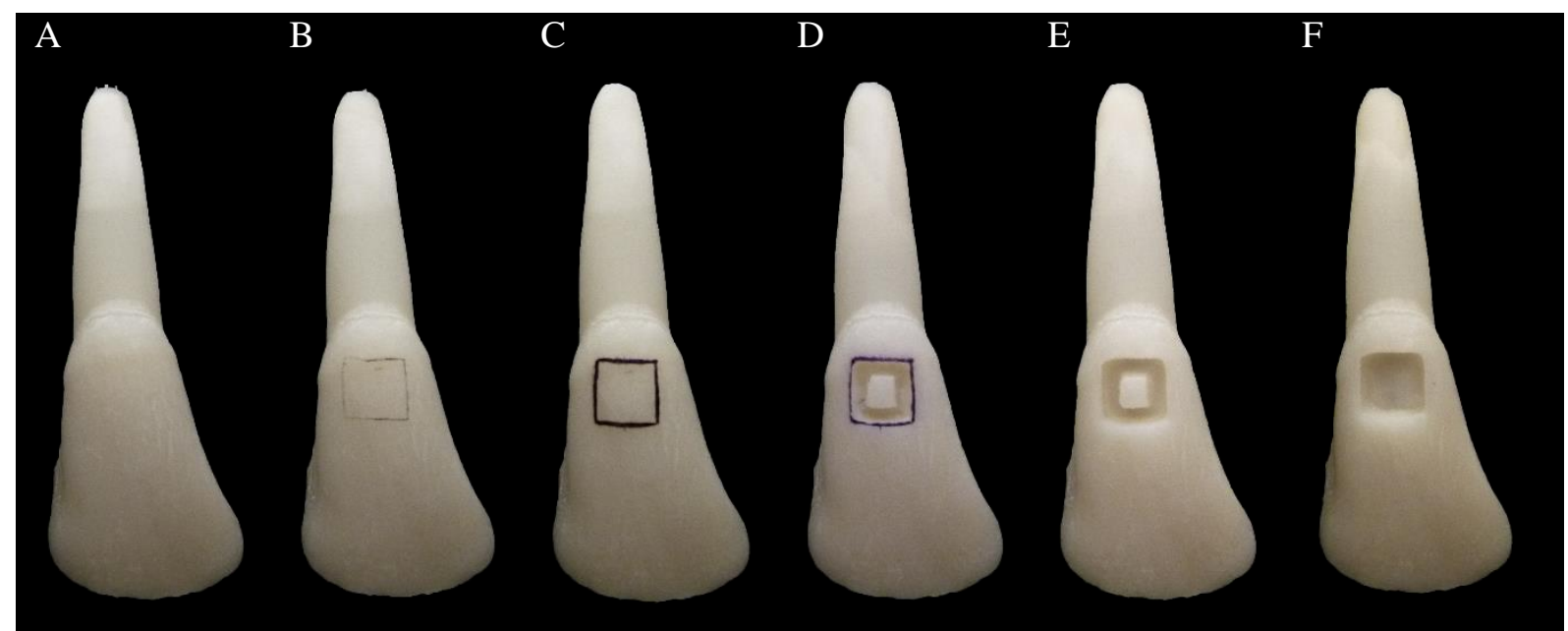

Figura 03 - Confecção do preparo: A) dente bovino selecionado; B) delimitação, a lápis, das paredes da cavidade (quadrado de 6,0mm de lado); C) delimitação, a caneta, das paredes da cavidade; D) início do desgaste do contorno da cavidade; E) contorno da cavidade concluído; e F) cavidade concluída.

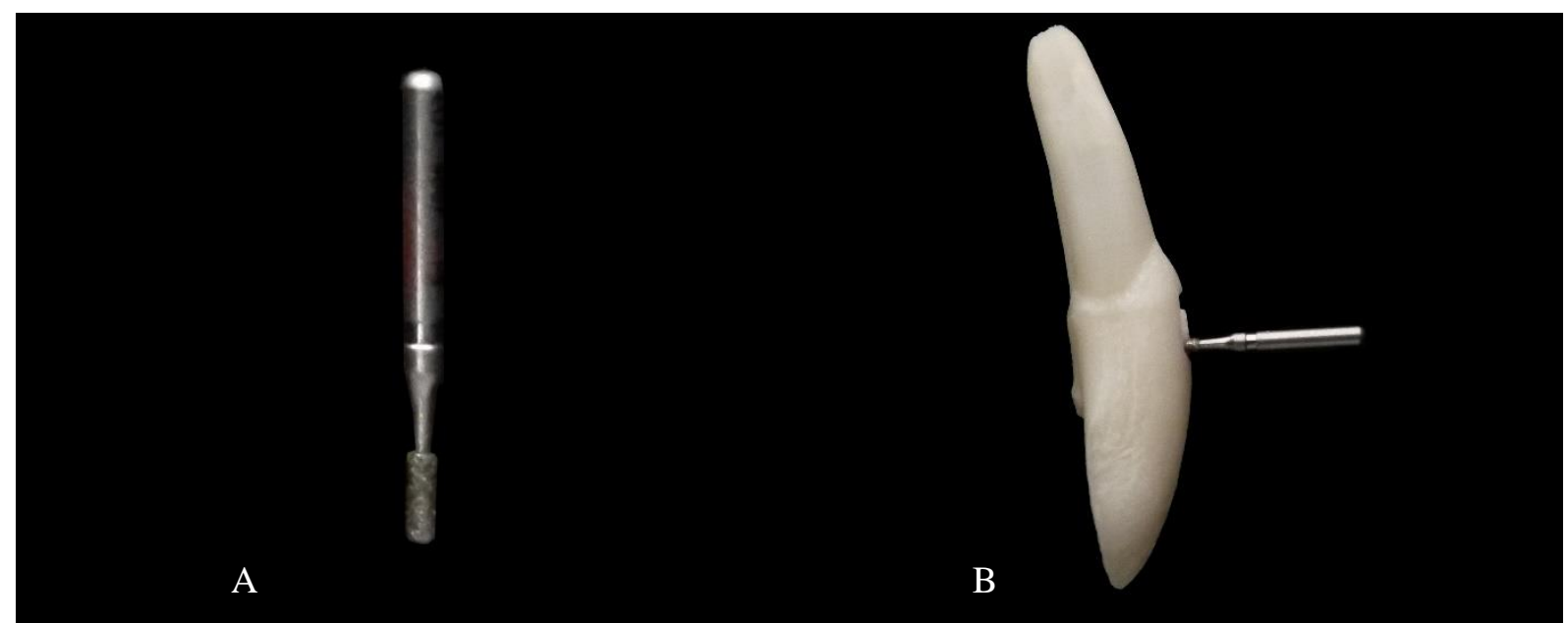

Figura 04 - A) Broca cilíndrica diamantada $n^{\circ} 1343$; e B) estabelecendo a profundidade de 2,0mm à cavidade.

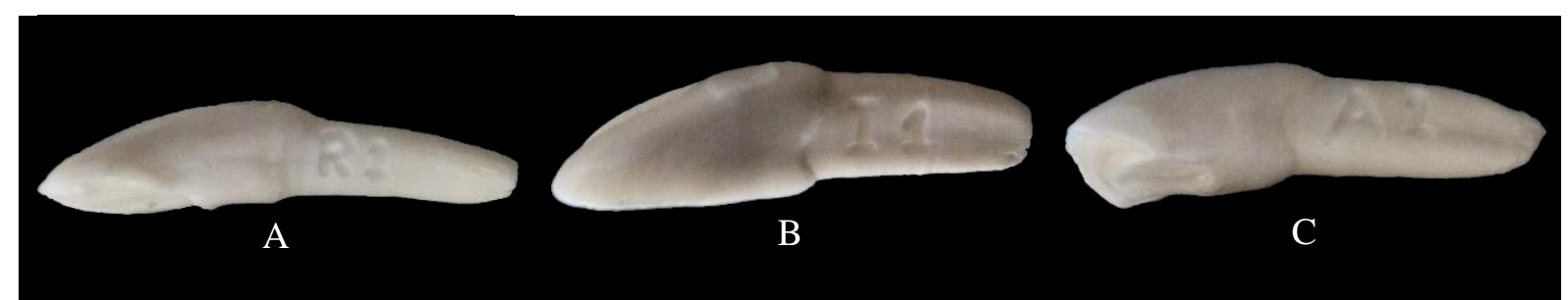

Figura 05 - Identificação individual: A) resina composta; B) cimento de ionômero de vidro; e C) amálgama de prata.

Após a confecção do preparo cavitário, foi realizada a limpeza da superfície dental com pedra pomes e água, por meio de escova Robinson (Microdont ${ }^{\circledR}$, Socorro, SP, Brasil) em baixa 
rotação, enxágue e secagem com jato de ar. Os dentes foram então restaurados com os diferentes materiais restauradores - amálgama de prata, resina composta e cimento de ionômero de vidro.

Foi utilizado o amálgama em cápsulas gs-80 - 2 porções (SDI ${ }^{\circledR}$, Bayswater, Victoria, Austrália), cuja trituração se deu por meio de amalgamador Ultramat 2 (SDI ${ }^{\circledR}$, Bayswater, Victoria, Austrália) (Figura 06), com tempo de trituração de oito segundos. Após trituração e obtenção de massa homogênea, o amálgama foi depositado e condensado na cavidade preparada. Posteriormente, foi realizada brunidura e, em seguida, o acabamento com brocas multi-laminadas de 12 lâminas FG 7901F (KG Sorensen ${ }^{\circledR}$, Cotia, SP, Brasil). Após 48 horas, foi realizado o polimento (Figura 07) com taças de borracha abrasiva em 03 granulações (marrom - grossa; verde - média; e azul - fina) - Kit polimento de amálgama Viking - 8089 (KG Sorensen ${ }^{\circledR}$, Cotia, SP, Brasil).

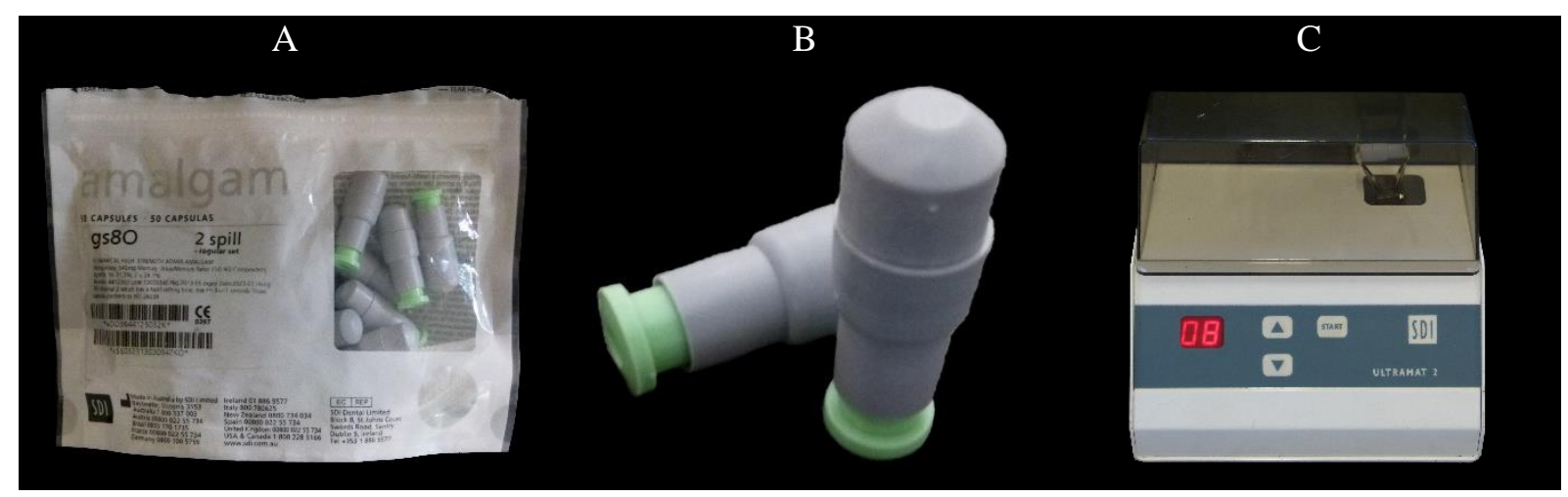

Figura 06 - A e B) Amálgama em cápsulas gs-80; C) amalgamador Ultramat 2.

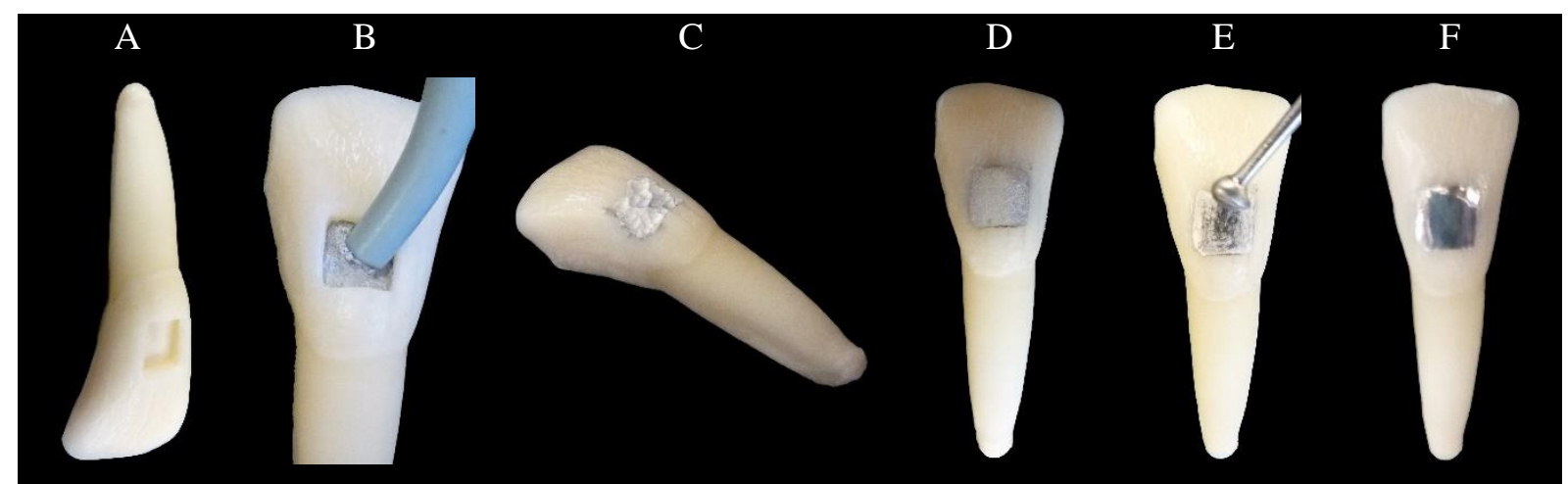

Figura 07 - A) Retenções adicionais entre as paredes delimitadoras do preparo e a parede axial; B) deposição do amálgama, em porções, na cavidade; C) condensação do amálgama; D) restauração sem acabamento; E) brunidura; e F) restauração concluída, após polimento.

Antes da confecção das restaurações em resina composta, foi realizado condicionamento ácido do esmalte e da dentina, utilizando ácido fosfórico a 37\% Alpha Etch (DFL ${ }^{\circledR}$, Rio de Janeiro, RJ, Brasil), aplicado por 15 segundos, seguido de enxágue e eliminação do excesso de 
água com leves jatos de ar, com atenção para que não houvesse desidratação da dentina (Figura 08). Na sequência, foi aplicado o adesivo de dois passos (Adper Single Bond 2 - 3M ESPE ${ }^{\circledR}$, Sumaré, SP, Brasil), em duas camadas consecutivas, por 15 segundos cada, utilizando-se pincel descartável microbrush (Applicator Tips - DeTrey/Dentsply ${ }^{\circledR}$, Konstanz, Alemanha) (Figura 09); subsequentemente, foi realizada a fotopolimerização, por 10 segundos, com fotopolimerizador Ultralux EL - Dabi Atlante ${ }^{\circledR}$, Ribeirão Preto, SP, Brasil) (Figura 10). Após a polimerização do sistema adesivo, a resina composta microhíbrida (Filtek ${ }^{\mathrm{MR}}$ Z250 XT - 3M $\mathrm{ESPE}^{\circledR}$, Sumaré, SP, Brasil), na cor A3, foi inserida na cavidade seguindo técnica incremental, com incrementos de aproximadamente $02 \mathrm{~mm}$ de espessura, e fotoativada por 20 segundos, com a ponta do aparelho fotopolimerizador o mais próximo possível do material restaurador, até o completo preenchimento da cavidade (Figura 11). O acabamento das restaurações em resina composta foi feito com a utilização de discos de lixa (Sof-Lex ${ }^{\mathrm{TM}}$ Pop-On - 3M ESPE ${ }^{\circledR}$, Sumaré, SP, Brasil), em ordem decrescente de abrasividade.

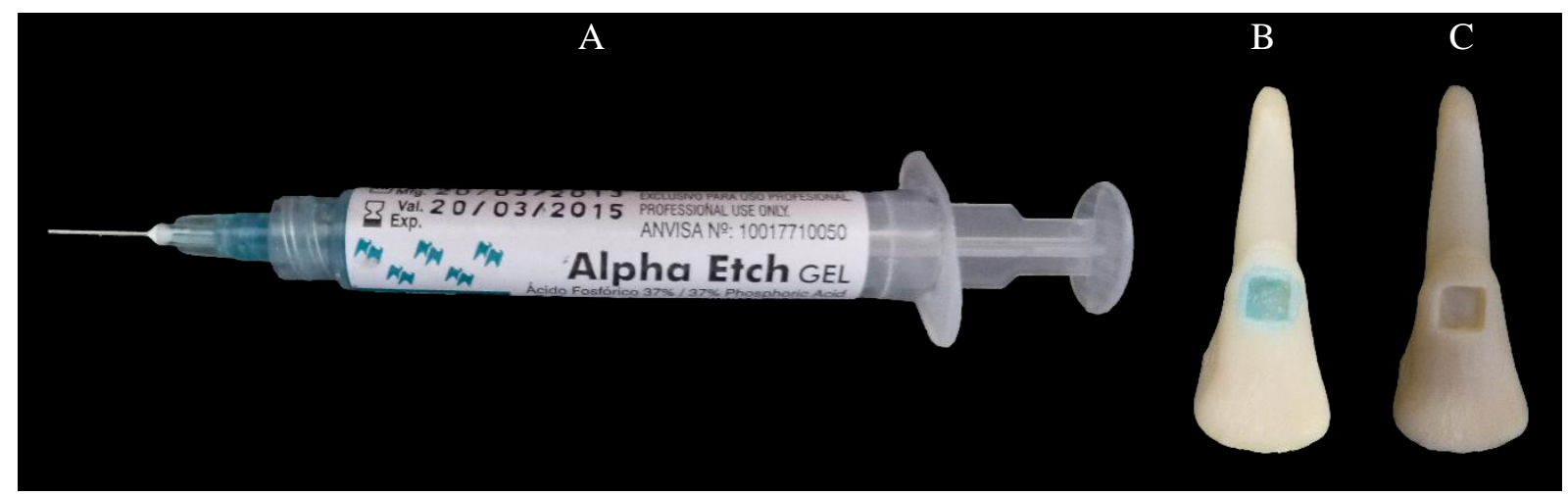

Figura 08 - A) Condicionador Alpha Etch; B) paredes recobertas pelo ácido; e C) condicionamento finalizado.

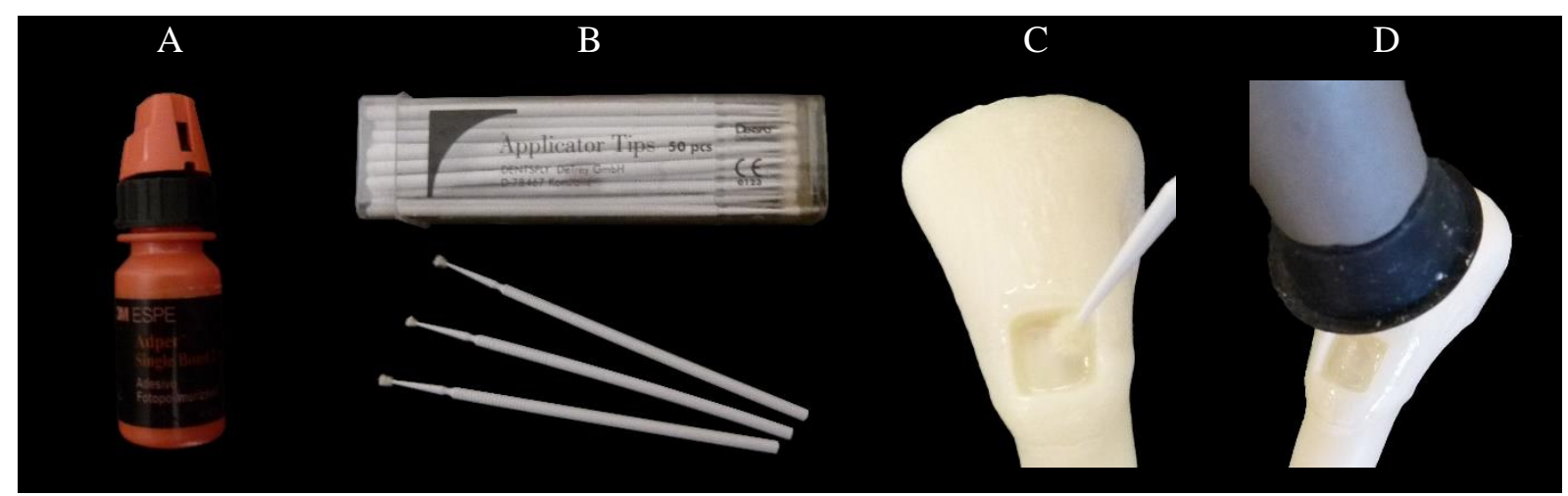

Figura 09 - A) Adesivo Adper Single Bond 2; B) microbrushes; C) aplicação; e D) fotopolimerização. 


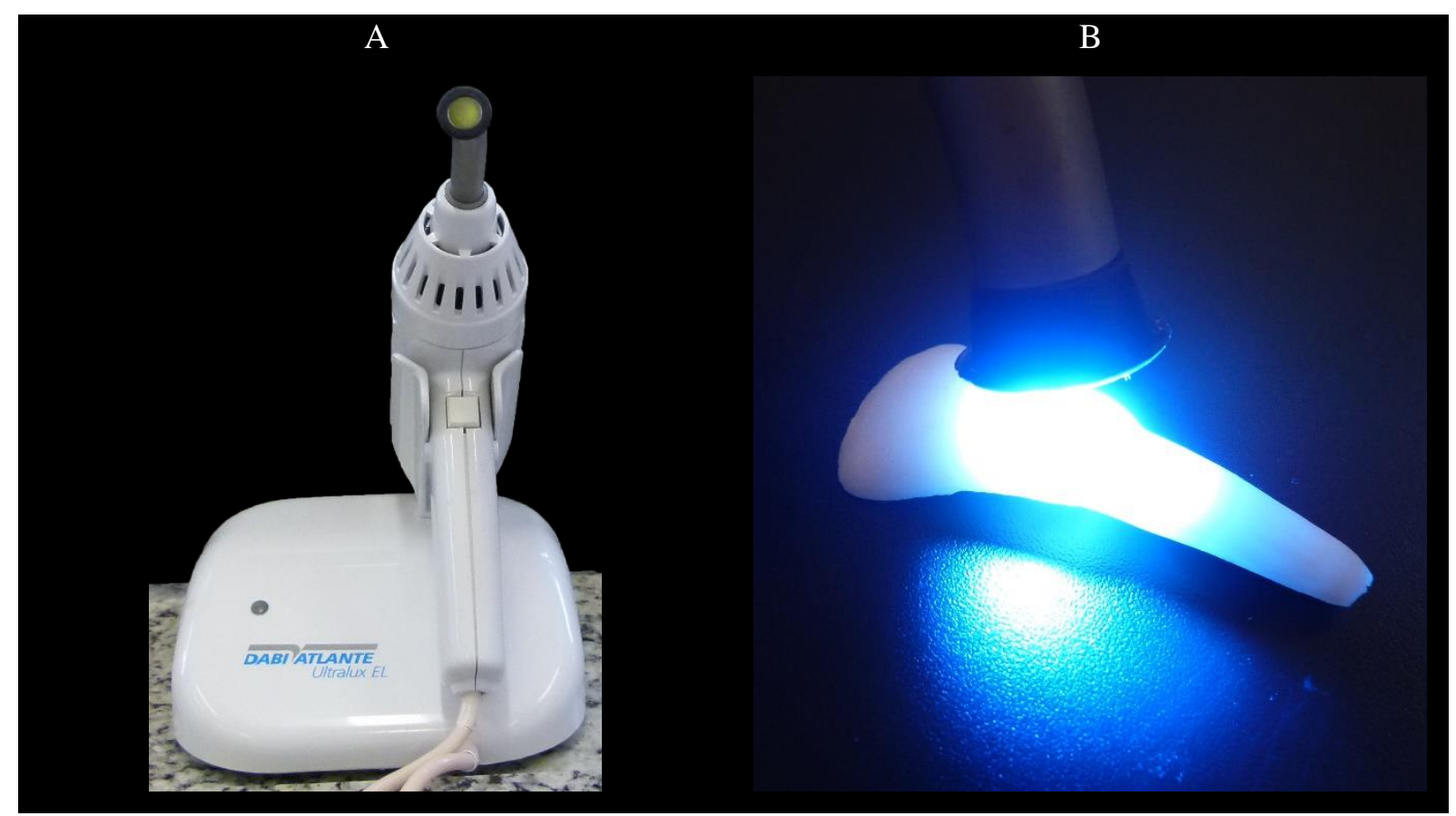

Figura 10 - A) Fotopolimerizador Ultralux EL; e B) ativação do aparelho.

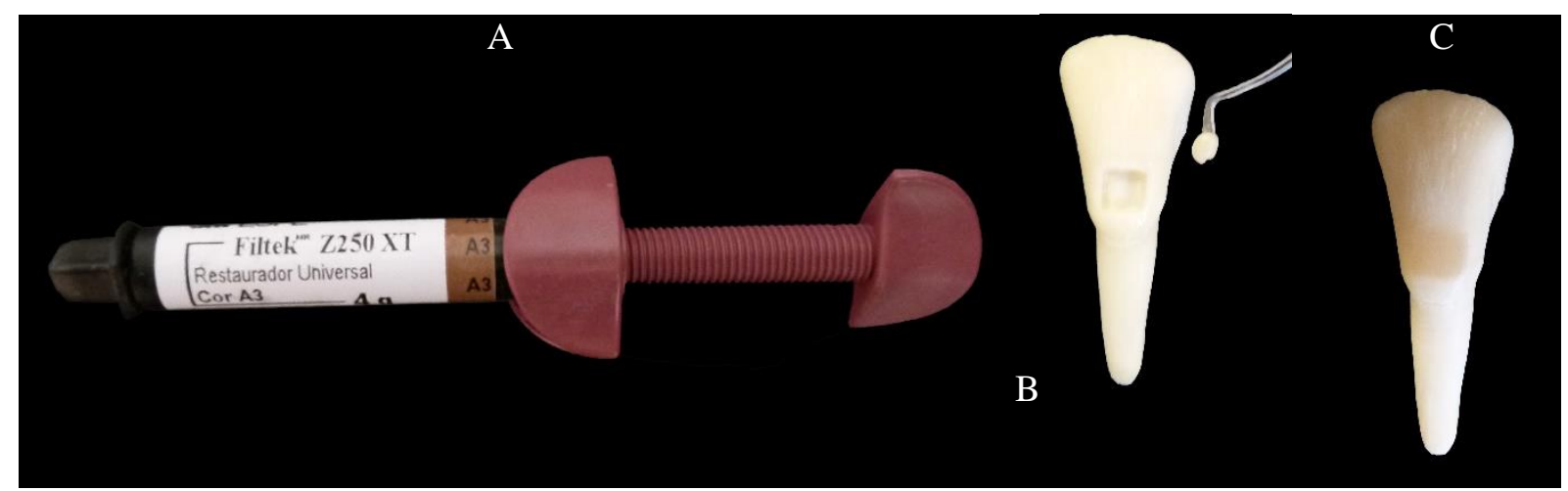

Figura 11 - A) Resina composta Filtek Z250 XT; B) inserção incremental; e C) restauração concluída.

Antes das restaurações com cimento de ionômero de vidro (Ketac ${ }^{\mathrm{TM}}$ Fil Plus - 3M $\mathrm{ESPE}^{\circledR}$, Sumaré, SP, Brasil), cor A3 (Figura 12), o material foi proporcionado segundo a recomendação do fabricante (1:1) e aglutinado até atingir a consistência de massa homogênea que, em seguida, foi aplicada em camadas, ainda brilhante, na cavidade, até seu total preenchimento (Figura 13). Após a inserção do material e preenchimento cavitário, foi realizada proteção superficial do cimento de ionômero de vidro com esmalte incolor para unhas, sem brilho. 


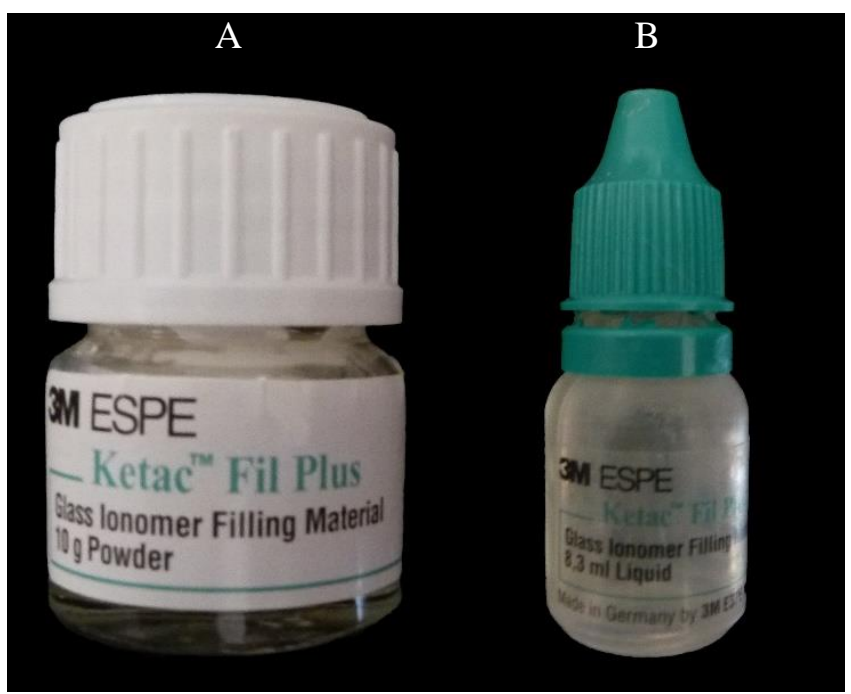

Figura 12 - CIV Ketak Fil Plus: A) pó; e B) líquido.

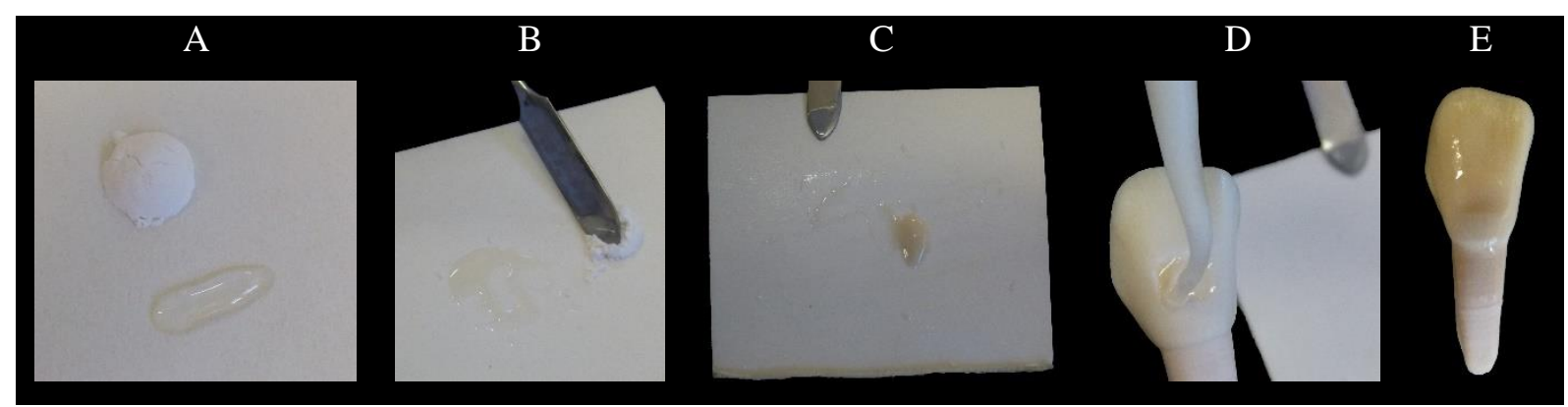

Figura 13 - A) Proporção indicada; B e C) espatulação; D) preenchimento; E) restauração concluída.

\subsection{Análise das amostras}

Após a restauração dos dentes, as amostras foram inicialmente fotografadas. Para isso, foi confeccionado um posicionador, contendo escala milimetrada, semelhante à escala $n^{\circ} 2$ da American Board of Forensic Odontology (ABFO), modificada para adaptar-se às necessidades deste estudo, com o objetivo de facilitar o posicionamento dos elementos dentais e eventuais comparações que fossem necessárias (Figuras 14 e 15).

As amostras foram analisadas por meio de fotografias padronizadas (posicionamento, iluminação, tempo de exposição, velocidade do obturador e abertura do diafragma), em vista frontal, isto é, da face vestibular dos dentes bovinos. Para isso, foi utilizada câmera reflex monobjetiva digital Lumix DMC-FZ100 (Panasonic Corporation ${ }^{\circledR}$, Kadoma, Osaka, Japão), com tripé e disparador remoto, a fim de evitar contatos e movimentações desnecessárias e prejudiciais à padronização proposta (Figura 16). A abertura de diafragma foi padronizada em f/2.8, sensibilidade em ISO-800, tempo de exposição de 1/2 segundo, com distância focal de 4,0 
mm. As fotografias foram realizadas após a confecção das restaurações (análise inicial) e em cada tempo experimental de análise (1, 3 e 6 meses após a submissão às condições impostas pelo estudo), sempre por um mesmo operador.

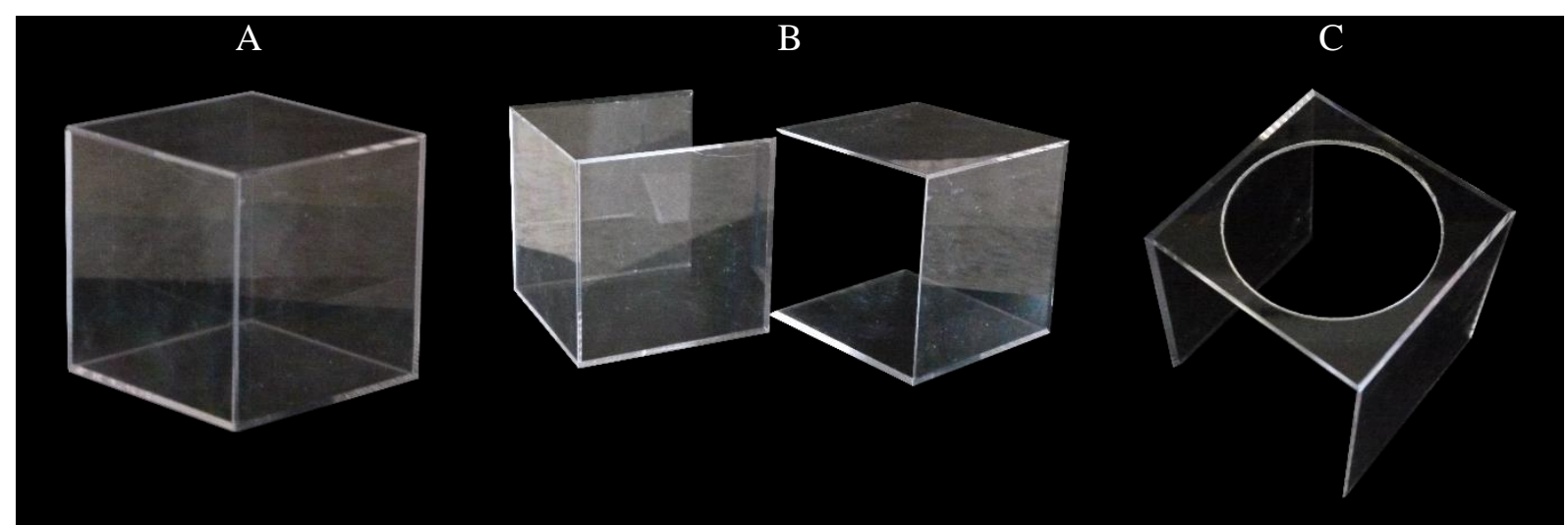

Figura 14 - A) Cubo acrílico transparente; B) duas metades que se separam; e C) corte circunferencial realizado em um dos lados.

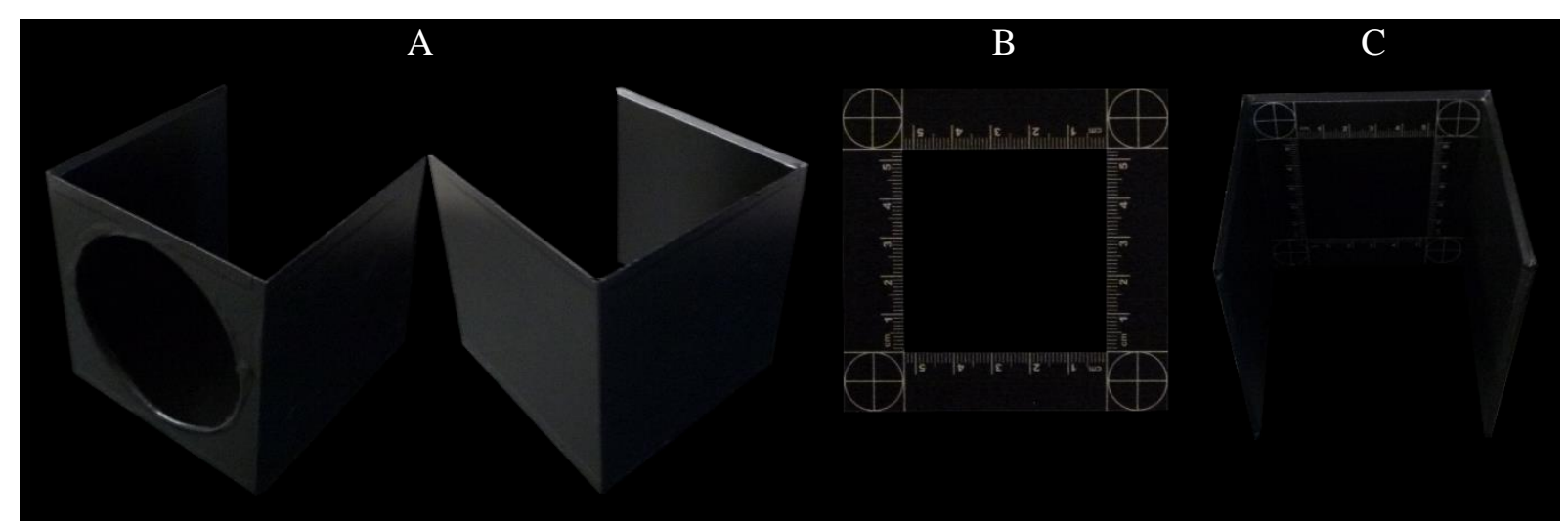

Figura 15 - A) Superfícies revestidas com contact preto fosco; B) escala milimetrada; C) escala posicionada ao fundo, em sentido oposto ao corte circunferencial realizado na outra peça. 


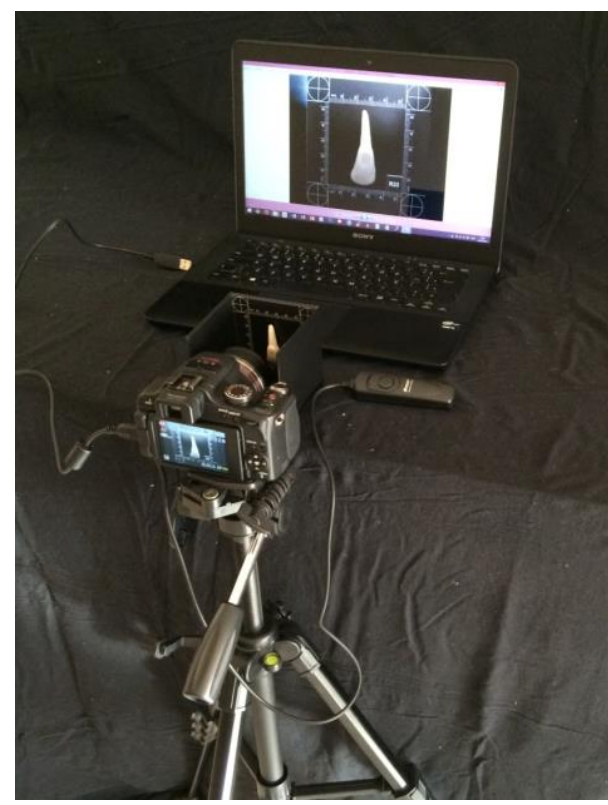

Figura 16 - Câmera Lumix DMC-FZ100, com disparador remoto, acoplada ao tripé; visualização da imagem obtida na tela do computador.

\subsection{Análise de cor}

Em seguida, leituras iniciais de cor foram realizadas (Easyshade, VITA ${ }^{\circledR}$, Bad Säckingen, Alemanha) (Figura 17) nos dentes restaurados com resina composta e cimento de ionômero de vidro. Esse equipamento possui uma ponteira digital que é posicionada sobre a restauração dos dentes e emite feixe de luz, que é transmitida por fibras ópticas, que são capazes de captar a reflexão da luz segundo coordenadas (Figuras 18 e 19).

O padrão de observação simulado pelo equipamento segue o sistema CIE L*a*b*, recomendado pela CIE (Comission Internationale de l'Éclairage) ${ }^{51}$, e que é definido por uma combinação de coordenadas cartesianas onde um ponto está associado a uma cor única. O eixo L* - coordenada de luminosidade (escala de cinza) - apresenta valores numéricos que variam de 0 (preto) a 100 (branco). Quando mais próximo de zero, mais escura é a cor do objeto, sendo que objetos claros apresentam valores numéricos para $\mathrm{L}^{*}$ próximos de 100 . Os eixos a* e b* são conhecidos como coordenadas de cromaticidade e variam de $-80 \mathrm{a}+80$. A coordenada $\mathrm{a}^{*}$ designa o eixo vermelho-verde. Quando o valor para a* for positivo (+), mostrará desvio no sentido da tonalidade vermelha; quando o valor for negativo (-), mostrará desvio no sentido do verde. Para a coordenada $b^{*}$, os valores positivos são fornecidos para os objetos da tonalidade amarela, e negativos para a tonalidade azul ${ }^{52}$.

Para a leitura da cor, os dentes restaurados foram inicialmente colocados sobre bloco com fundo padrão branco (White Standard Sphere for $45^{\circ}, 0^{\circ}$ Reflectance and Color Gardner Laboratory Inc. Bethesda, Geretsried, Alemanha). Os dentes foram acoplados ao 
espectrofotômetro e, após o acionamento, 30 lâmpadas LED com 10 cores diferentes, dispostas de forma circular, acendiam e incidiam o feixe de luz em $45^{\circ}$ com a superfície do material, utilizando iluminante padrão primário D65, que simula o espectro da luz do dia. Esse feixe era refletido em $0^{\circ}$ de volta para o aparelho e, assim, este captava e registrava os valores de $\mathrm{L}^{*}, \mathrm{a}^{*}$ e $b^{*}$ do material restaurador estético. Foram realizadas três leituras de cor para cada dente, sendo considerada como valor inicial de coordenadas, as médias desses valores.

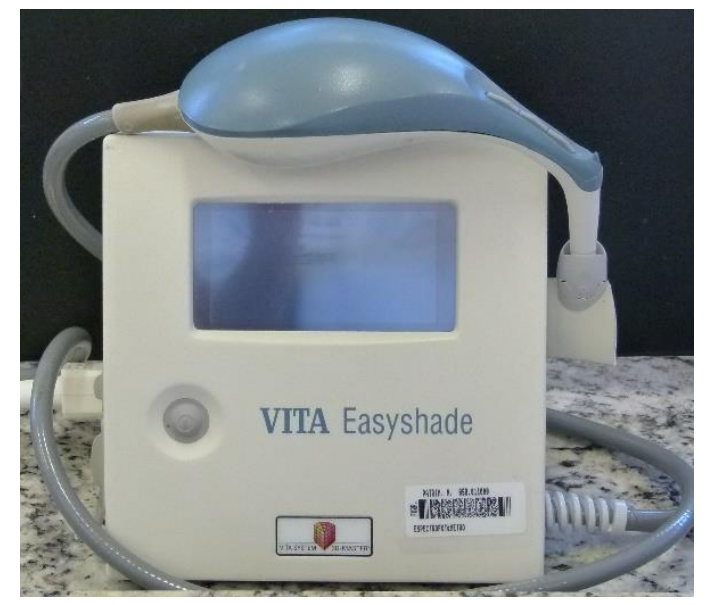

Figura 17 - Espectrofotômetro Easyshade.

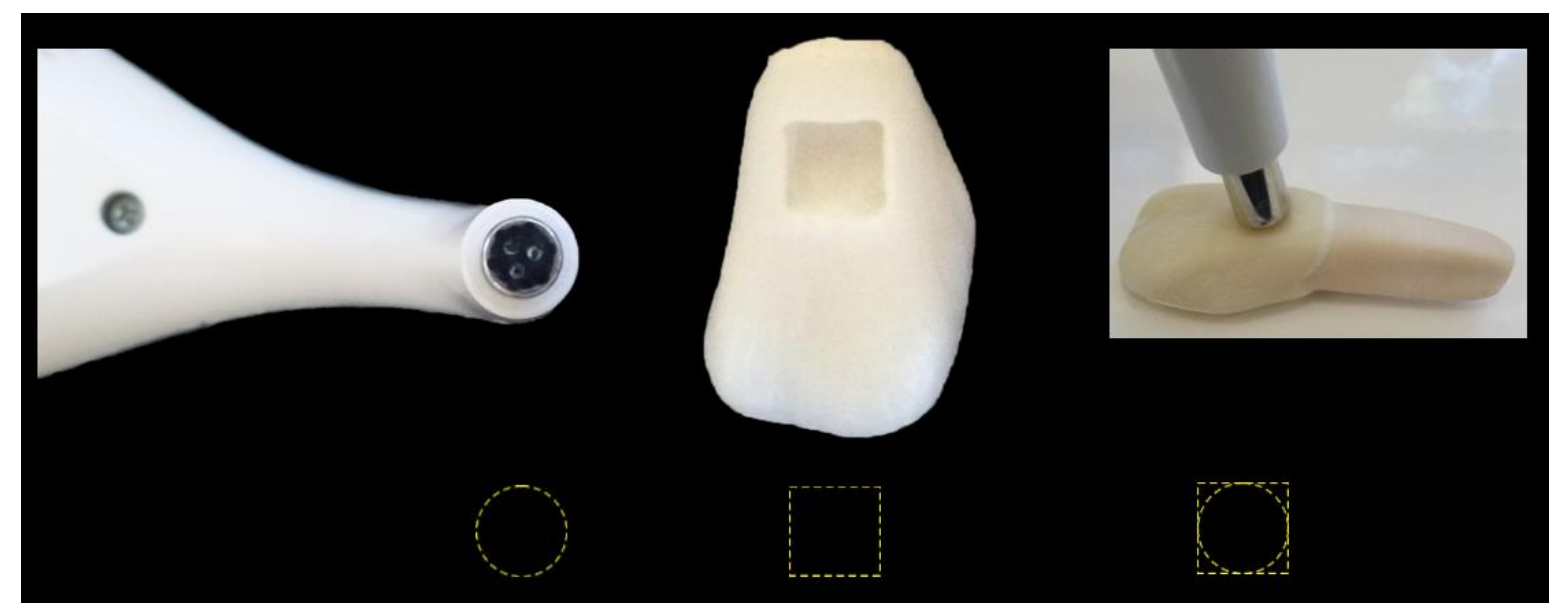

Figura 18 - Esquematização do posicionamento da ponteira do espectrofotômetro sobre uma restauração estética. 

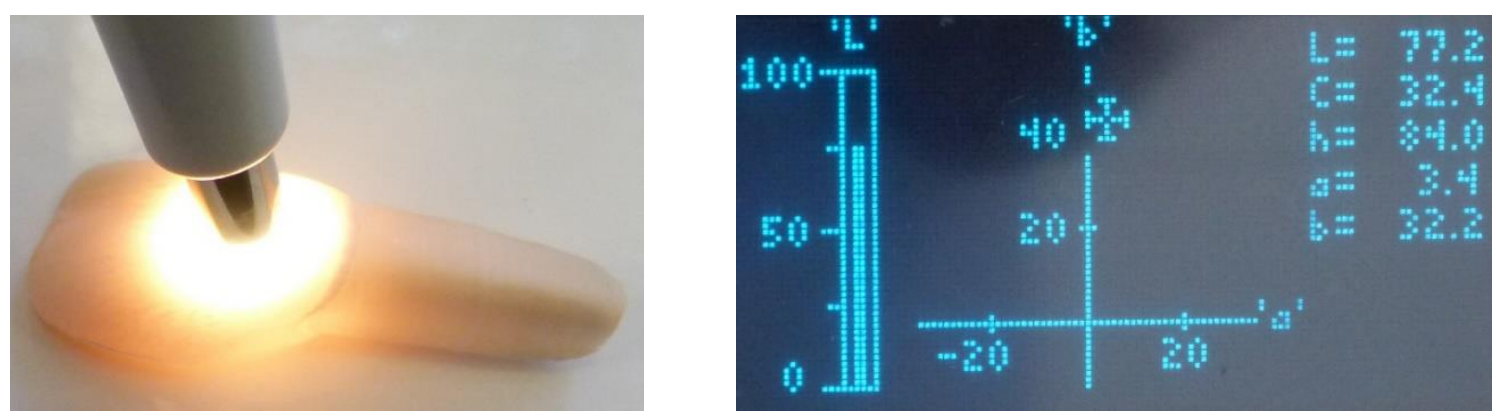

Figura 19 - Acionamento do espectrofotômetro e apresentação dos valores no display eletrônico.

\subsection{Rugosidade de superfície}

Para a avaliação da rugosidade de superfície, foi utilizado rugosímetro Surftest SJ-201P (Mitutoyo ${ }^{\circledR}$, Kanagawa, Japão). Esse aparelho permitiu a análise das condições rugosimétricas da superfície, sendo composto por duas partes principais:

- Unidade Programadora de Controle e Registro da Leitura (Figura 20, A): onde ficam localizados os comandos para o acionamento do aparelho e também o seletor do programa utilizado. No controle, foi programada a distância percorrida pela haste, de acordo com as dimensões das restaurações, e o cut-off utilizado;

- Unidade Transversal Motorizada Precursora de Leitura (Figura 20, B): composta por um motor e uma agulha, que se movimenta, realizando a sondagem da superfície da restauração de acordo com o programa pré-estabelecido. A unidade motora é fixada a uma haste vertical que, por sua vez, prende-se a uma base sólida de granito, oferecendo estabilidade ao conjunto. A base de granito fica paralela à unidade motorizada, que é passível de regulagem nos sentidos vertical e horizontal. As leituras obtidas das amostras foram expostas no display do controle. 


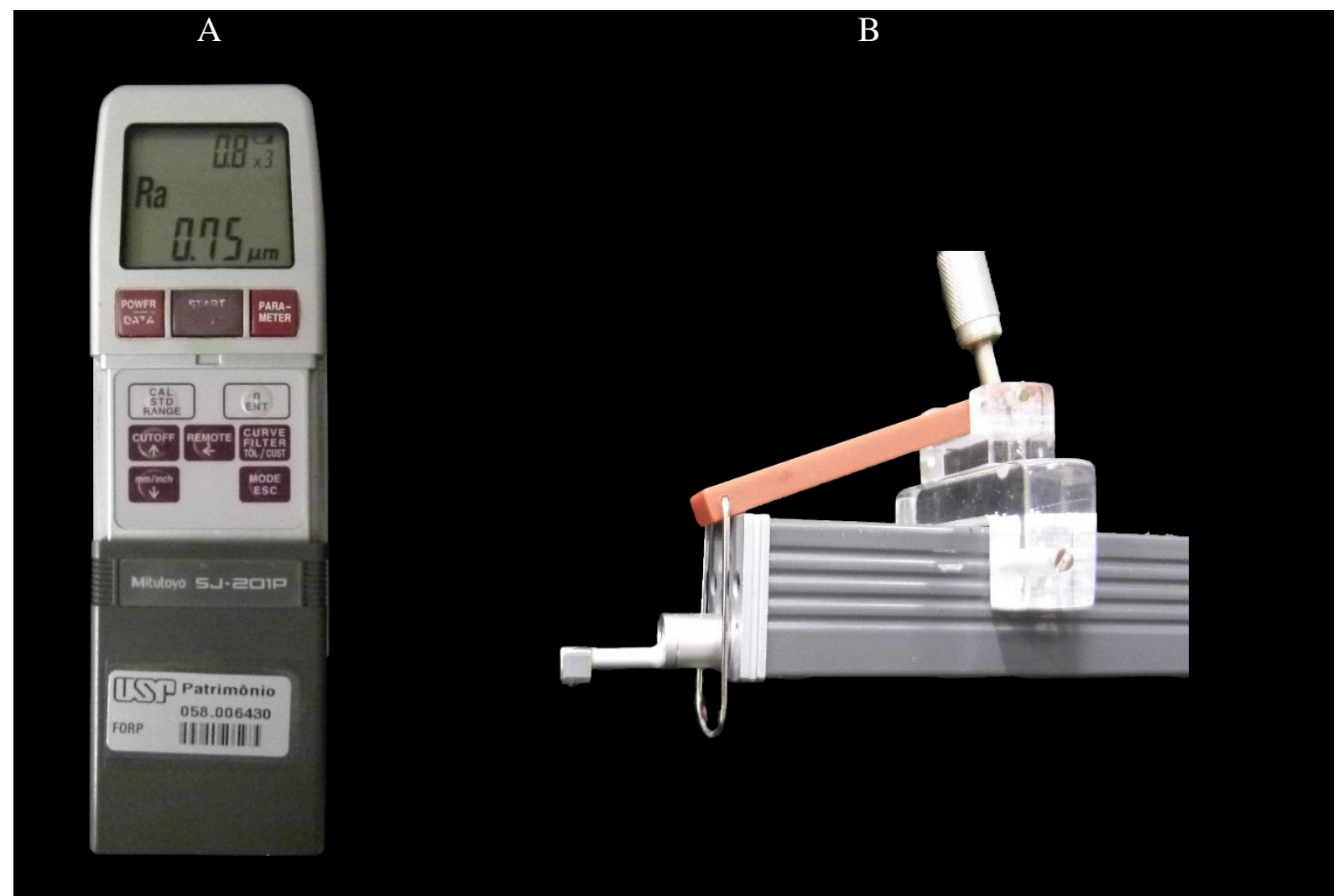

Figura 20 - A) Unidade Programadora de Controle e Registro da Leitura; B) Unidade Transversal Motorizada Precursora de Leitura.

Cada elemento dental foi posicionado com a face vestibular voltada para cima, de forma que a porção da restauração ficasse posicionada abaixo da agulha medidora de rugosidade. Ao ser acionado o aparelho, a agulha de leitura percorreu a distância de 3,2 mm, sendo 0,4 mm para a aceleração da agulha, três cut-off de $0,8 \mathrm{~mm}$, totalizando um comprimento de leitura de 2,4 mm, mais $0,4 \mathrm{~mm}$ para a desaceleração da agulha, à velocidade de 0,5 mm/s. A agulha foi movimentada em uma única direção (Figura 21), sentido inciso-cervical, detectando as irregularidades correspondentes aos picos, vales e ondas da superfície restaurada dos dentes bovinos. Esse valor foi definido como a média dos afastamentos da haste, tanto para cima como para baixo, em relação a uma linha central ${ }^{53}$. Foram realizadas três leituras, em posições distintas da superfície da restauração de cada elemento dental: uma central, ou seja, a 3 milímetros dos limites proximais, e outras duas posições, 1 milímetro à esquerda e 1 milímetro à direita, em relação à primeira marcação central. Foi considerada como leitura inicial de rugosidade de superfície (Ra) a média dessas três leituras. 


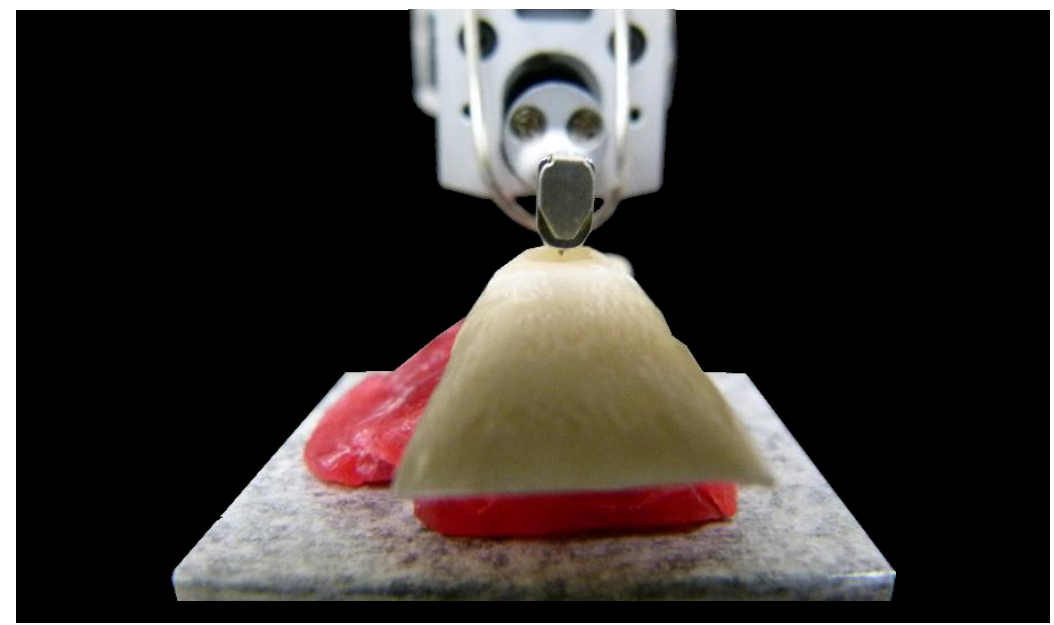

Figura 21 - Agulha posicionada sobre a superfície da restauração.

\subsection{Microdureza}

Para a análise de microdureza Knoop, foi utilizado um microdurômetro Micro Hardness Tester HMV-2 (Shimadzu ${ }^{\circledR}$, Tóquio, Japão) (Figura 22), que acionou uma ponta penetradora de diamante com forma piramidal de base losangular sob carga vertical estática de $25 \mathrm{~g}$ aplicada por 5 segundos. As leituras foram realizadas com a objetiva de 40x, para resina composta e amálgama, e de 10x, para o cimento de ionômero de vidro (Figura 23).

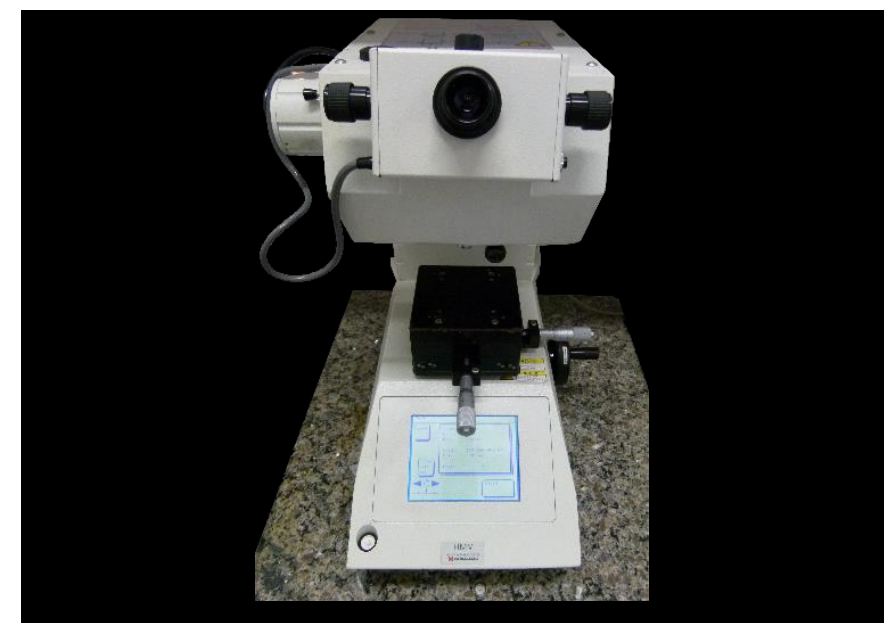

Figura 22 - Microdurômetro HMV-2. 


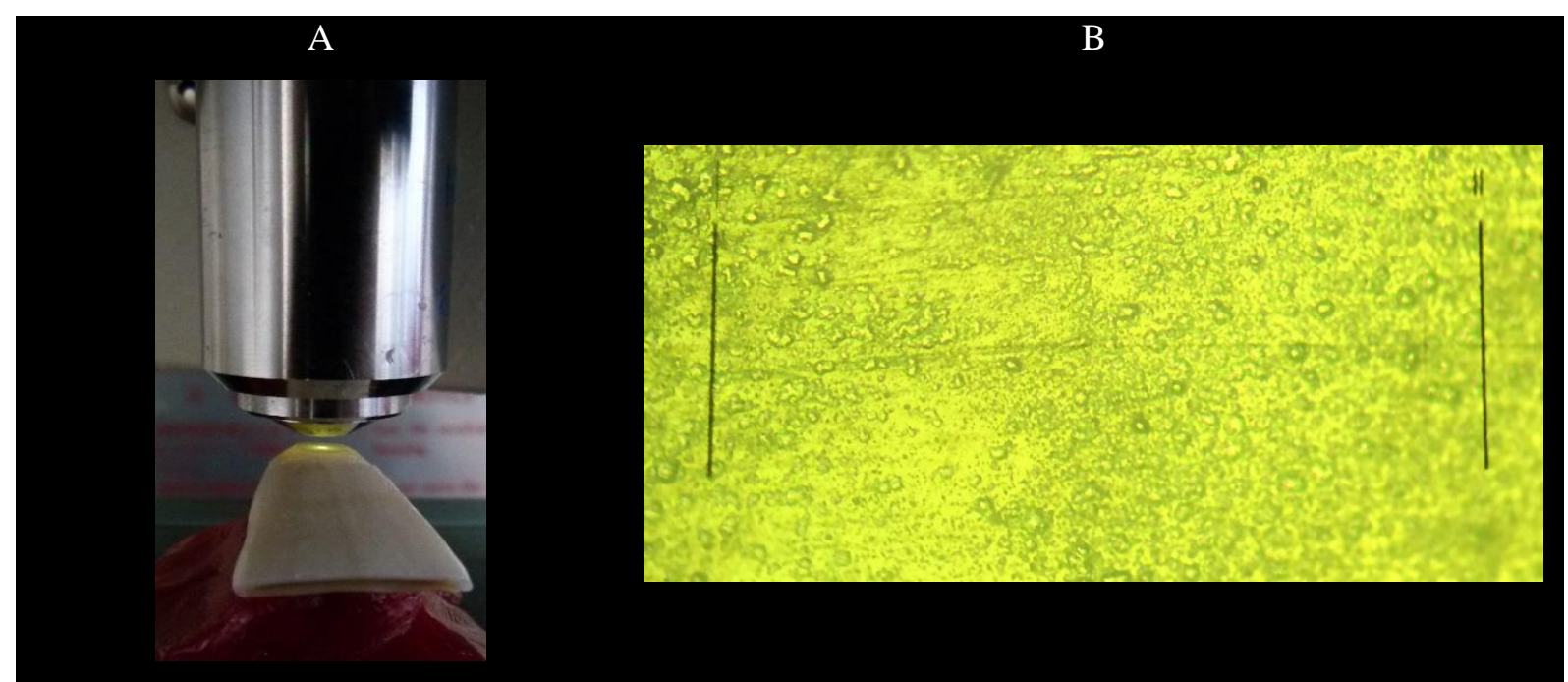

Figura 23 - A) Objetiva de 40x focalizando a região onde serão feitas as impressões; B) visualização da superfície da restauração.

Quando acionada, a ponta penetradora realizou uma compressão na superfície da amostra, gerando uma figura geométrica em forma de pirâmide inversa, visualizada pelo contraste entre a impressão e a superfície (Figura 24).

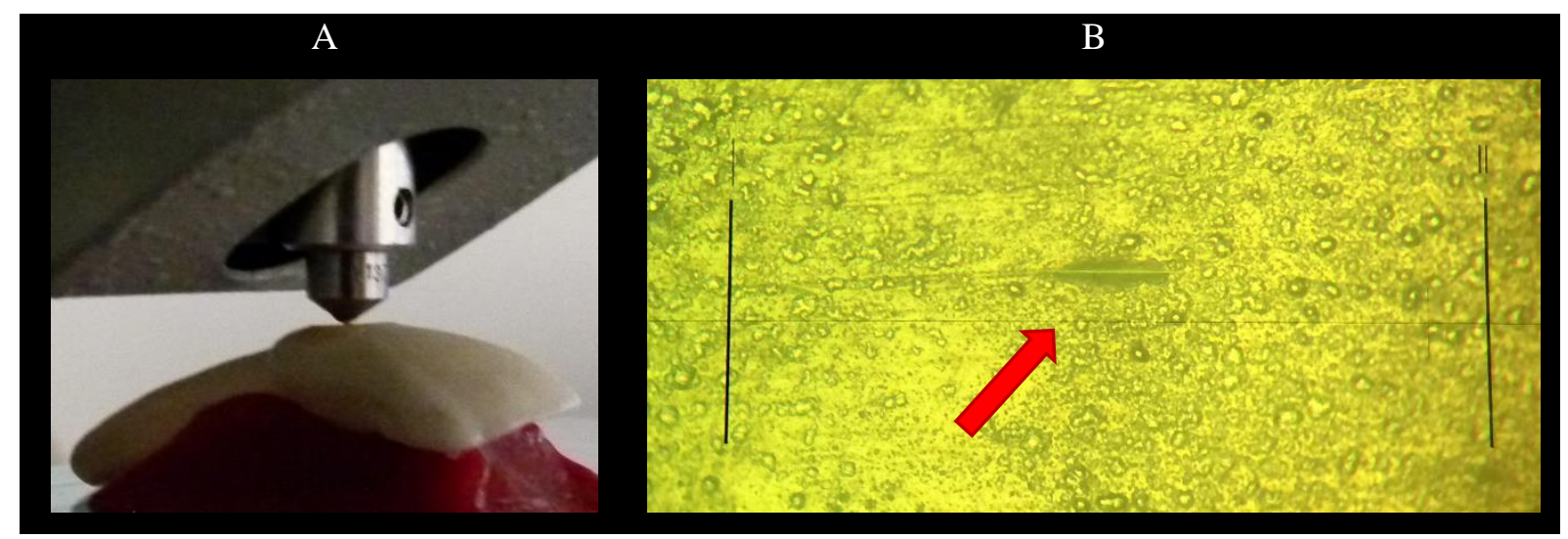

Figura 24 - A) Ponta penetradora realizando a compressão; B) figura geométrica obtida.

O losango possibilita a determinação da microdureza superficial do material a partir da mensuração de sua maior diagonal, cujo valor é aplicado em uma fórmula matemática para obtenção de resultados. O microdurômetro utilizado neste estudo realiza os cálculos automaticamente, a partir da medida obtida por uma régua com duas referências verticais, paralelas entre si, interligadas por uma referência horizontal, que é sobreposta à maior diagonal do losango, enquanto as referências verticais são posicionadas nas extremidades da impressão, 
para obtenção do comprimento (Figura 25). Assim, o resultado da dureza Knoop aparece na tela do aparelho, por meio do cálculo realizado, pelo software, da seguinte equação:

$$
\mathrm{KHN}=\frac{1,451 \mathrm{~F}}{\mathrm{~d}^{2}}
$$

Onde:

$\mathrm{KHN}=$ valor de dureza Knoop (Knoop Hardness Number)

$\mathrm{F}=25$ gramas

$\mathrm{d}=$ comprimento da maior diagonal da indentação

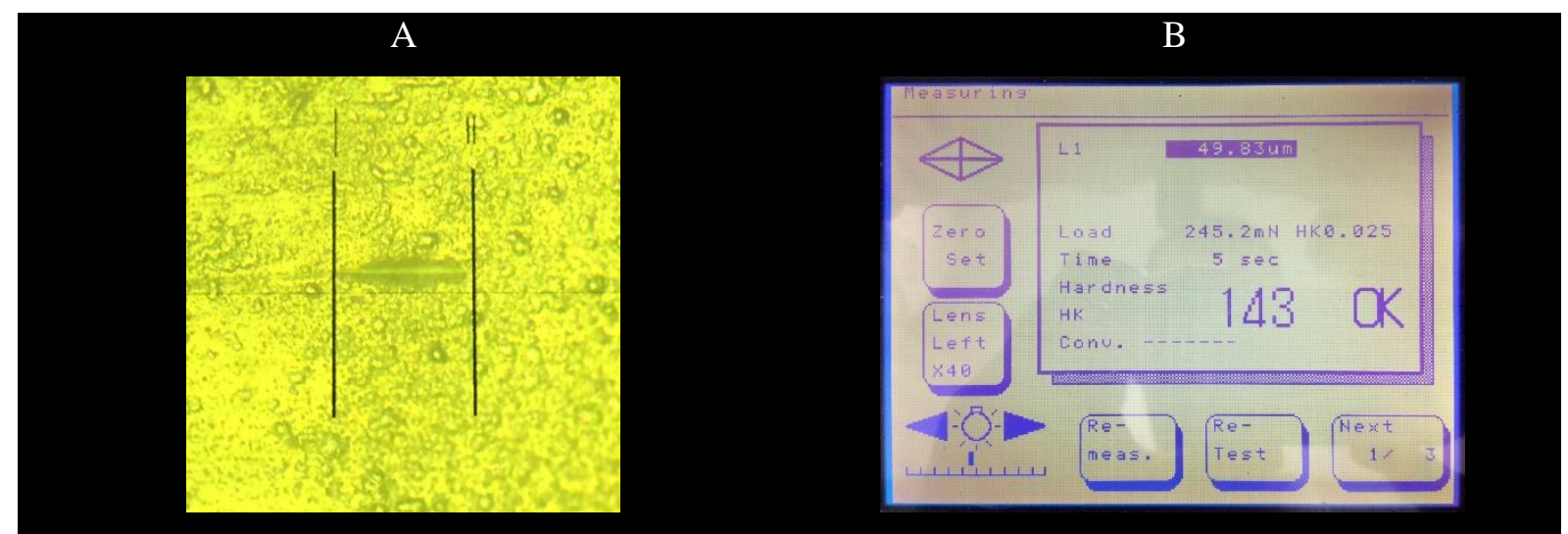

Figura 25 - A) Referências verticais perpendiculares à maior diagonal do losango; B) apresentação do resultado obtido.

Foram realizadas três leituras, em posições distintas da restauração: uma central, outra a $1 \mathrm{~mm}$ de distância, à esquerda, e outra a $1 \mathrm{~mm}$ à direita, em relação à marcação central. A média das três leituras foi considerada como valor inicial de microdureza.

Após todas as análises iniciais (baseline), os dentes restaurados foram separados aleatoriamente em 2 grupos $(n=10)$, de acordo com o tipo de condição ambiental a que seria submetido: inumação ou afogamento.

\subsection{Condições ambientais}

Para simular a condição de inumação, os dentes foram inseridos em uma bolsa de tecido com tramas abertas, reticulares, confeccionada em nylon, e foram colocados dentro de uma 
escavação com profundidade de 1,0 metro, em área delimitada e identificada para a pesquisa, e cobertos por terra (Figuras 26 e 27).

A

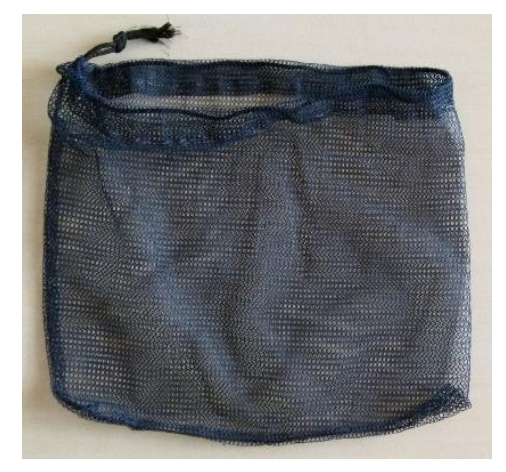

B

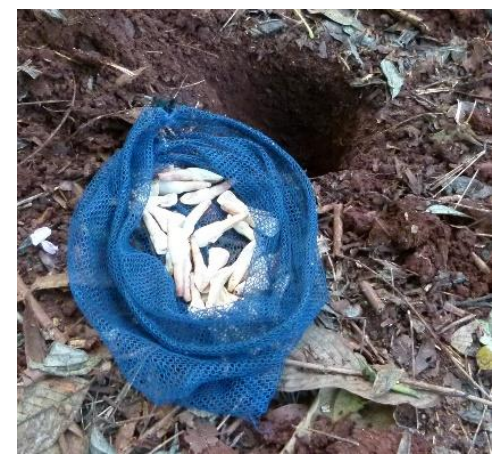

$\mathrm{C}$

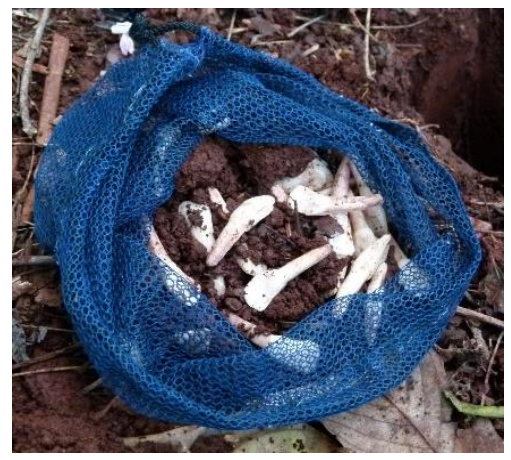

Figura 26 - A) Bolsa de nylon; B) dentes inseridos na bolsa; e C) colocação de terra dentro da bolsa.
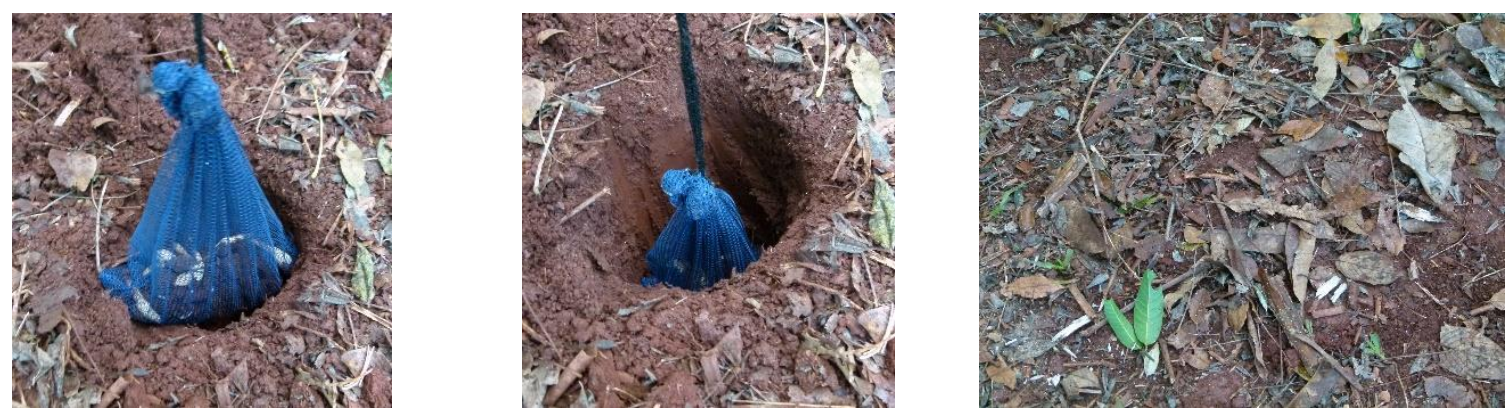

Figura 27 - Enterramento.

Para simular a condição de afogamento, os dentes foram separados, por grupos, em pequenas bolsas confeccionadas em tecido de poliéster tramado em rede, com furos hexagonais, simulando transparência. As bolsas apresentavam, ainda, um velcro, cuja função era manter os dentes no interior da bolsa, sem se perderem, mas com a possibilidade de serem facilmente removidos, quando desejado (Figura 28).

As bolsas foram colocadas em uma gaiola, do tipo alçapão, identificada com os dados referentes à pesquisa, que foi acorrentada em ponto fixo e mergulhada na água (Figura 29). 


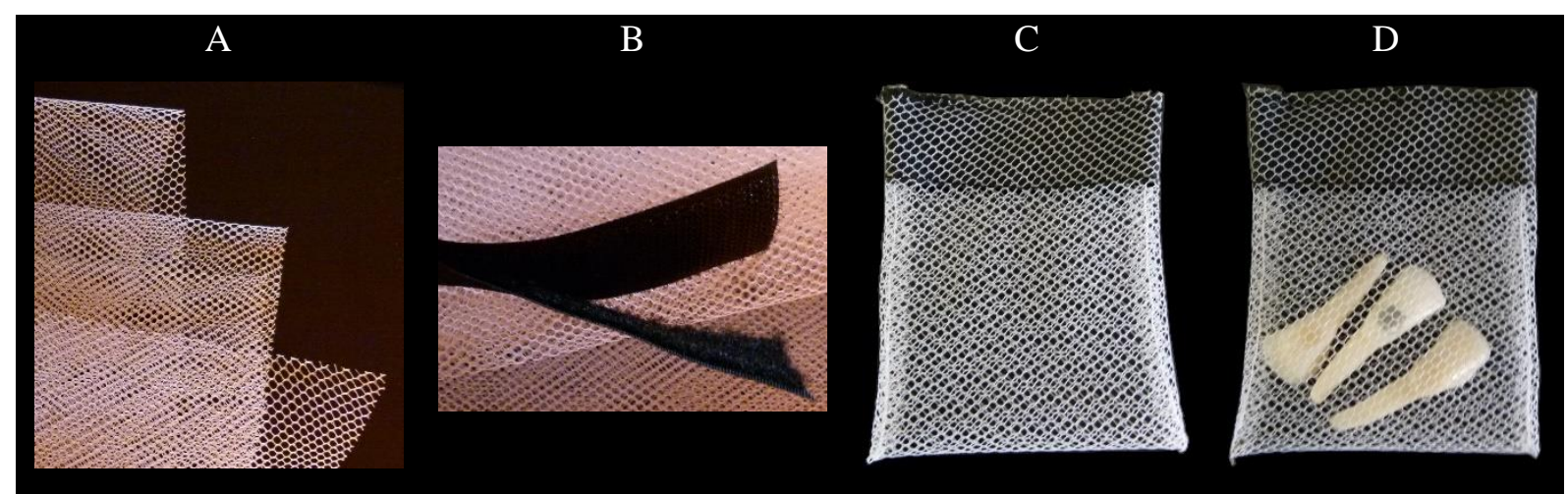

Figura 28 - A) Tecido de poliéster com tramas hexagonais; B) velcro; C) bolsa pronta; e D) dentes posicionados.

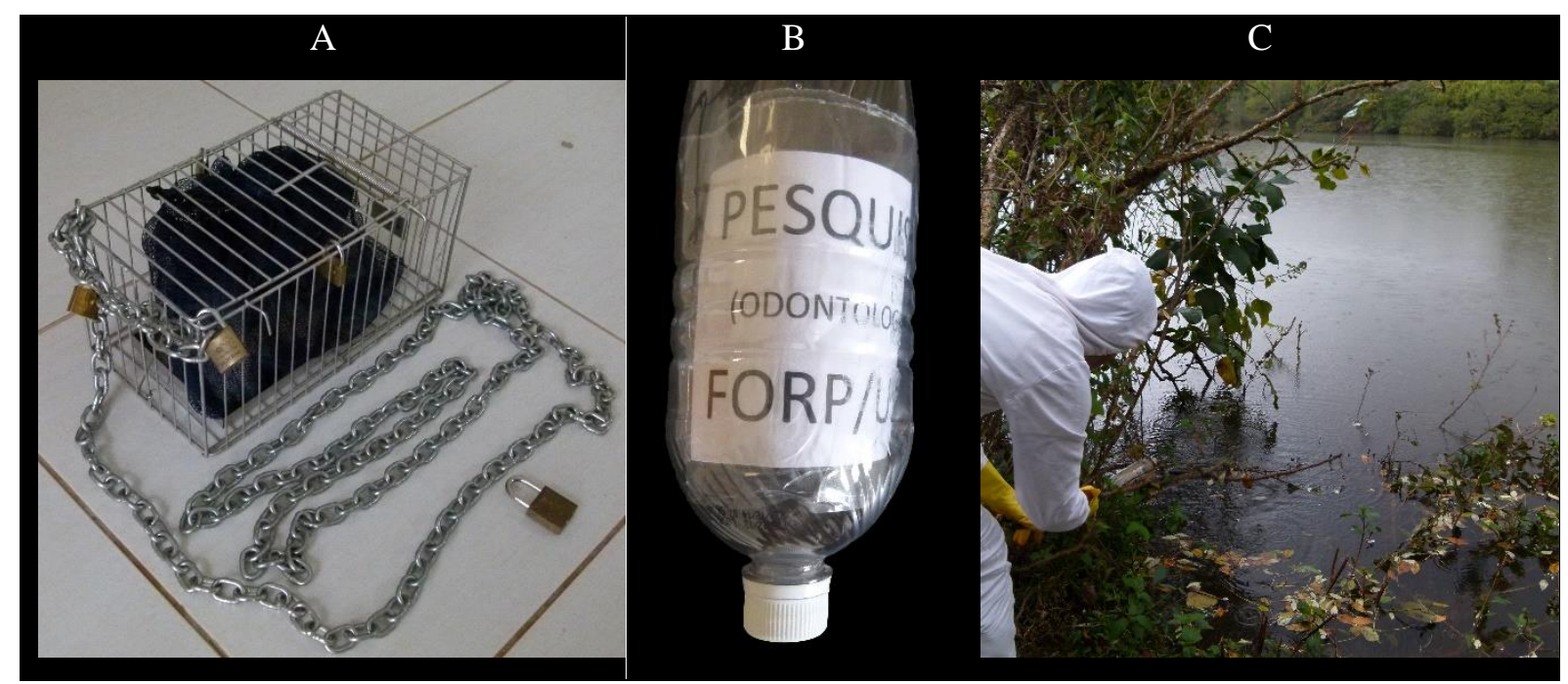

Figura 29 - A) Gaiola preparada; B) identificação flutuante; C) imersão no lago.

Em seguida, foram inseridos no interior do Lago do Campus de Ribeirão Preto, da Universidade de São Paulo, após autorização da sua Prefeitura (protocolo $\mathrm{n}^{\circ}$ 13.5.326.58.7, Anexo). Assim, os elementos dentais foram submetidos a todas as condições naturais oferecidas pelo meio ambiente do lago, mas estiveram protegidas de animais e outras situações impróprias, que inviabilizariam a pesquisa.

Após 1, 3 e 6 meses, as amostras foram retiradas das condições ambientais a que foram submetidas e novas leituras de cor, rugosidade de superfície e microdureza foram realizadas, sempre pelo mesmo operador que realizou as leituras iniciais. A estabilidade de cor dos materiais restauradores estéticos foi calculada a partir da fórmula ${ }^{54}$ : 


$$
\Delta \mathrm{E}=\sqrt{\left(\Delta \mathrm{L}^{*}\right)^{2}+\left(\Delta \mathrm{a}^{*}\right)^{2}+\left(\Delta \mathrm{b}^{*}\right)^{2}}
$$

Onde:

$$
\begin{aligned}
& \Delta \mathrm{L}^{*}=\mathrm{L}^{*}-\mathrm{L}^{*}{ }_{\mathrm{i}} \\
& \Delta \mathrm{a}^{*}=\mathrm{a}_{\mathrm{f}}-\mathrm{a}^{*}{ }_{\mathrm{i}} \\
& \Delta \mathrm{b} *=\mathrm{b}_{\mathrm{f}}-\mathrm{b}^{*}{ }_{\mathrm{i}}
\end{aligned}
$$

Sendo $L *^{*}, a^{*}{ }_{i}$ e b ${ }^{*}$ referidos como medição inicial da cor, e $L^{*}{ }_{f}, a^{*}{ }_{\mathrm{f}}$ e b* ${ }^{*}$, como medição de cor após os tempos de análise testados. Para análise da estabilidade de cor nos diferentes tempos experimentais, os valores foram sempre comparados aos valores obtidos em baseline.

Da mesma forma, após cada tempo experimental de análise, os novos valores obtidos nas leituras de rugosidade de superfície e microdureza foram comparados aos valores estabelecidos inicialmente em baseline.

\subsection{Análise estatística}

Os valores de $\Delta \mathrm{E}$ e das alterações ocorridas em todas as coordenadas ( $\left.\Delta \mathrm{L}^{*}, \Delta \mathrm{a}^{*} \mathrm{e} \Delta \mathrm{b}^{*}\right)$, para materiais estéticos, foram submetidos a análise estatística (3-way ANOVA, medidas repetidas, Bonferroni, $\mathrm{p}<0,05)$. Os fatores de variação avaliados foram tempo, material e condições ambientais a que os materiais foram submetidos. A mesma análise estatística (3-way ANOVA, medidas repetidas, Bonferroni, $\mathrm{p}<0,05)$ foi realizada para rugosidade de superfície e microdureza, com os mesmos fatores de variação, com exceção de quando comparados os valores do amálgama, que foram analisados estatisticamente segundo 2-way ANOVA, medidas repetidas, Bonferroni, $\mathrm{p}<0,05$, sendo os fatores de variação: tempo e condição ambiental a que foi submetido. Isso ocorreu devido ao fato de esse material ser facilmente diferenciado dos materiais estéticos. 


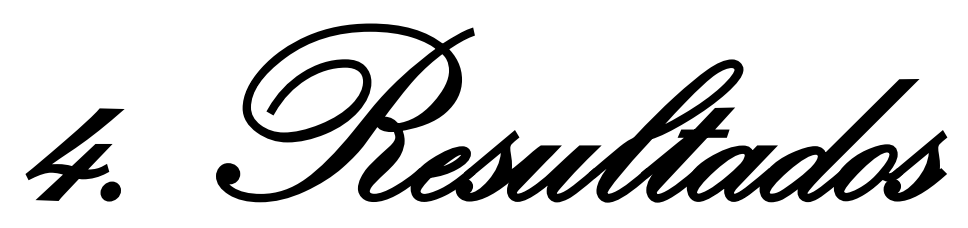





\section{RESULTADOS}

\subsection{Alteração de cor}

Nas tabelas 1, 2 e 3, são apresentados os valores de leituras iniciais e finais de cor dos materiais estéticos, após os tempos testados, bem como os valores de alteração de cor $(\Delta \mathrm{E})$ e da alteração de suas coordenadas $\left(\Delta \mathrm{L}^{*}, \Delta \mathrm{a}^{*}\right.$ e $\left.\Delta \mathrm{b}^{*}\right)$. As médias foram analisadas estatisticamente segundo 3-way ANOVA (fatores de variação: material, tempo e condição ambiental), medidas repetidas, teste de Bonferroni, com nível de significância de $95 \%$. 
Tabela 1 - Médias iniciais e finais, após 1 mês, de L*, a* e b* e valores de deltas ( $L^{*}, a^{*}, b^{*}$ e E).

\begin{tabular}{|c|c|c|c|c|c|c|c|c|c|c|c|}
\hline \multirow[t]{2}{*}{ Material } & \multirow[t]{2}{*}{ Agente } & \multicolumn{3}{|c|}{$\begin{array}{l}\text { Leituras iniciais } \\
\text { médias }\end{array}$} & \multicolumn{3}{|c|}{$\begin{array}{l}\text { Leituras médias } \\
\text { finais (após } 1 \text { mês) }\end{array}$} & \multirow[t]{2}{*}{$\Delta \mathrm{L}$} & \multirow[t]{2}{*}{$\Delta \mathrm{a}$} & \multirow[t]{2}{*}{$\Delta \mathrm{b}$} & \multirow[t]{2}{*}{$\Delta \mathrm{E}$} \\
\hline & & $\mathrm{L}^{*}$ & $a^{*}$ & $\mathrm{~b}^{*}$ & $\mathrm{~L}^{*}$ & $a^{*}$ & $\mathrm{~b}^{*}$ & & & & \\
\hline \multirow{20}{*}{ 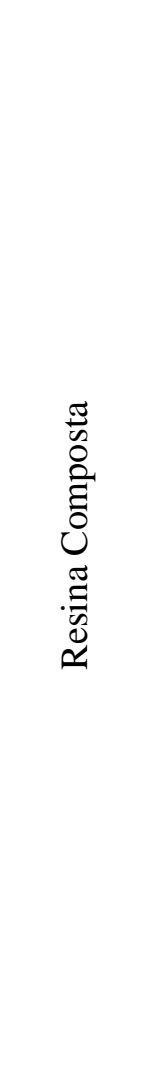 } & \multirow{10}{*}{ Terra } & 77,10 & 0,90 & 30,50 & 77,93 & 3,10 & 31,90 & 0,83 & 2,20 & 1,40 & 2,74 \\
\hline & & 80,37 & 1,30 & 31,47 & 79,63 & 2,80 & 32,50 & $-0,73$ & 1,50 & 1,03 & 1,96 \\
\hline & & 77,57 & 1,33 & 30,70 & 79,50 & 3,40 & 33,60 & 1,93 & 2,07 & 2,90 & 4,05 \\
\hline & & 76,37 & 1,70 & 30,83 & 76,40 & 3,70 & 32,60 & 0,03 & 2,00 & 1,77 & 2,67 \\
\hline & & 78,83 & 1,10 & 31,00 & 79,80 & 2,63 & 32,50 & 0,97 & 1,53 & 1,50 & 2,35 \\
\hline & & 78,53 & 1,03 & 32,00 & 80,30 & 3,10 & 33,10 & 1,77 & 2,07 & 1,10 & 2,93 \\
\hline & & 78,97 & 1,37 & 31,53 & 80,30 & 3,40 & 33,30 & 1,33 & 2,03 & 1,77 & 3,01 \\
\hline & & 77,67 & 0,90 & 30,40 & 79,30 & 3,03 & 32,73 & 1,63 & 2,13 & 2,33 & 3,56 \\
\hline & & 79,50 & 2,10 & 32,70 & 81,57 & 4,10 & 34,83 & 2,07 & 2,00 & 2,13 & 3,58 \\
\hline & & 78,37 & 1,23 & 31,83 & 80,40 & 3,50 & 34,37 & 2,03 & 2,27 & 2,53 & 3,96 \\
\hline & \multirow{10}{*}{ Água } & 79,87 & 1,30 & 31,80 & 78,77 & 3,33 & 35,30 & $-1,10$ & 2,03 & 3,50 & 4,19 \\
\hline & & 76,00 & 1,67 & 31,20 & 73,60 & 3,60 & 35,43 & $-2,40$ & 1,93 & 4,23 & 5,24 \\
\hline & & 77,97 & 1,30 & 30,83 & 77,87 & 2,90 & 33,80 & $-0,10$ & 1,60 & 2,97 & 3,37 \\
\hline & & 75,73 & 1,90 & 31,70 & 73,73 & 3,20 & 33,87 & $-2,00$ & 1,30 & 2,17 & 3,22 \\
\hline & & 76,43 & 0,90 & 30,27 & 73,00 & 2,50 & 33,23 & $-3,43$ & 1,60 & 2,97 & 4,81 \\
\hline & & 77,50 & 0,90 & 31,40 & 77,53 & 1,83 & 31,80 & 0,03 & 0,93 & 0,40 & 1,02 \\
\hline & & 76,83 & 1,50 & 31,70 & 76,03 & 2,10 & 31,57 & $-0,80$ & 0,60 & $-0,13$ & 1,01 \\
\hline & & 80,83 & 1,20 & 33,23 & 79,67 & 3,23 & 36,40 & $-1,17$ & 2,03 & 3,17 & 3,94 \\
\hline & & 78,97 & 1,63 & 32,53 & 75,70 & 3,27 & 34,80 & $-3,27$ & 1,63 & 2,27 & 4,30 \\
\hline & & 78,33 & 1,10 & 30,80 & 73,73 & 2,53 & 33,03 & $-4,60$ & 1,43 & 2,23 & 5,31 \\
\hline \multirow{20}{*}{ 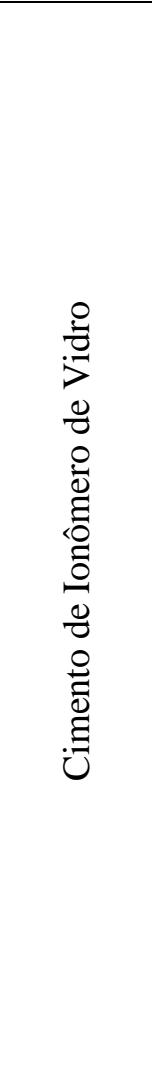 } & \multirow{10}{*}{ Terra } & 84,13 & 3,13 & 35,87 & 84,30 & 2,90 & 33,70 & 0,17 & $-0,23$ & $-2,17$ & 2,19 \\
\hline & & 81,30 & 3,97 & 37,87 & 81,23 & 2,80 & 34,43 & $-0,07$ & $-1,17$ & $-3,43$ & 3,63 \\
\hline & & 82,97 & 2,47 & 33,73 & 81,60 & 2,40 & 31,37 & $-1,37$ & $-0,07$ & $-2,37$ & 2,73 \\
\hline & & 82,10 & 1,40 & 30,97 & 85,77 & 1,50 & 31,13 & 3,67 & 0,10 & 0,17 & 3,67 \\
\hline & & 81,87 & 2,63 & 34,73 & 82,03 & 2,50 & 33,13 & 0,17 & $-0,13$ & $-1,60$ & 1,61 \\
\hline & & 84,27 & 2,40 & 34,23 & 78,17 & 3,40 & 35,23 & $-6,10$ & 1,00 & 1,00 & 6,26 \\
\hline & & 83,17 & 3,00 & 34,97 & 85,17 & 3,00 & 34,50 & 2,00 & 0,00 & $-0,47$ & 2,05 \\
\hline & & 79,17 & 3,93 & 37,23 & 82,00 & 3,30 & 35,50 & 2,83 & $-0,63$ & $-1,73$ & 3,38 \\
\hline & & 87,43 & 0,13 & 27,90 & 87,40 & 1,30 & 28,87 & $-0,03$ & 1,17 & 0,97 & 1,52 \\
\hline & & 85,63 & 1,40 & 32,43 & 84,37 & 1,50 & 30,47 & $-1,27$ & 0,10 & $-1,97$ & 2,34 \\
\hline & \multirow{10}{*}{ Água } & 83,03 & 1,40 & 31,00 & 70,13 & 2,40 & 29,27 & $-12,90$ & 1,00 & $-1,73$ & 13,05 \\
\hline & & 85,33 & 0,00 & 25,83 & 74,20 & 0,80 & 24,03 & $-11,13$ & 0,80 & $-1,80$ & 11,31 \\
\hline & & 79,83 & 2,10 & 32,90 & 77,53 & 2,50 & 31,87 & $-2,30$ & 0,40 & $-1,03$ & 2,55 \\
\hline & & 85,37 & 1,60 & 31,60 & 80,87 & 2,10 & 30,87 & $-4,50$ & 0,50 & $-0,73$ & 4,59 \\
\hline & & 83,57 & 1,40 & 31,40 & 75,57 & 1,40 & 29,20 & $-8,00$ & 0,00 & $-2,20$ & 8,30 \\
\hline & & 84,13 & 2,60 & 33,90 & 73,53 & 3,33 & 31,73 & $-10,60$ & 0,73 & $-2,17$ & 10,84 \\
\hline & & 83,50 & 3,00 & 35,73 & 80,97 & 2,30 & 32,70 & $-2,53$ & $-0,70$ & $-3,03$ & 4,01 \\
\hline & & 84,67 & 1,50 & 31,73 & 77,53 & 2,50 & 31,60 & $-7,13$ & 1,00 & $-0,13$ & 7,20 \\
\hline & & 83,77 & 2,10 & 32,43 & 82,13 & 1,60 & 31,13 & $-1,63$ & $-0,50$ & $-1,30$ & 2,15 \\
\hline & & 83,73 & 1,43 & 31,43 & 75,77 & 2,20 & 29,13 & $-7,97$ & 0,77 & $-2,30$ & 8,33 \\
\hline
\end{tabular}


Tabela 2 - Médias iniciais e finais, após 3 meses, de $L^{*}, a^{*}$ e b* e valores de deltas $\left(L^{*}, a^{*}, b^{*}\right.$ e E).

\begin{tabular}{|c|c|c|c|c|c|c|c|c|c|c|c|}
\hline \multirow[t]{2}{*}{ Material } & \multirow[t]{2}{*}{ Agente } & \multicolumn{3}{|c|}{$\begin{array}{c}\text { Leituras iniciais } \\
\text { médias }\end{array}$} & \multicolumn{3}{|c|}{$\begin{array}{l}\text { Leituras médias } \\
\text { finais (após } 3 \text { meses) }\end{array}$} & \multirow[t]{2}{*}{$\Delta \mathrm{L}$} & \multirow[t]{2}{*}{$\Delta \mathrm{a}$} & \multirow[t]{2}{*}{$\Delta \mathrm{b}$} & \multirow[t]{2}{*}{$\Delta \mathrm{E}$} \\
\hline & & $\mathrm{L}^{*}$ & $a^{*}$ & $b^{*}$ & $\mathrm{~L}^{*}$ & $\mathrm{a}^{*}$ & $\mathrm{~b}^{*}$ & & & & \\
\hline \multirow{20}{*}{ 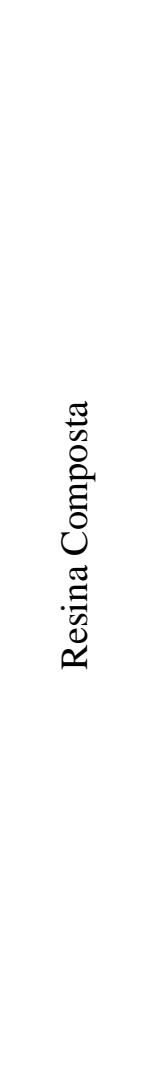 } & \multirow{10}{*}{ Terra } & 77,10 & 0,90 & 30,50 & 77,30 & 2,20 & 30,57 & 0,20 & 1,30 & 0,07 & 1,32 \\
\hline & & 80,37 & 1,30 & 31,47 & 79,30 & 2,17 & 31,33 & $-1,07$ & 0,87 & $-0,13$ & 1,38 \\
\hline & & 77,57 & 1,33 & 30,70 & 78,10 & 2,40 & 31,80 & 0,53 & 1,07 & 1,10 & 1,62 \\
\hline & & 76,37 & 1,70 & 30,83 & 75,97 & 3,40 & 32,07 & $-0,40$ & 1,70 & 1,23 & 2,14 \\
\hline & & 78,83 & 1,10 & 31,00 & 79,33 & 1,50 & 30,10 & 0,50 & 0,40 & $-0,90$ & 1,10 \\
\hline & & 78,53 & 1,03 & 32,00 & 78,53 & 2,20 & 31,40 & 0,00 & 1,17 & $-0,60$ & 1,31 \\
\hline & & 78,97 & 1,37 & 31,53 & 79,70 & 2,97 & 32,80 & 0,73 & 1,60 & 1,27 & 2,17 \\
\hline & & 77,67 & 0,90 & 30,40 & 78,37 & 2,20 & 31,03 & 0,70 & 1,30 & 0,63 & 1,61 \\
\hline & & 79,50 & 2,10 & 32,70 & 79,47 & 2,90 & 32,50 & $-0,03$ & 0,80 & $-0,20$ & 0,83 \\
\hline & & 78,37 & 1,23 & 31,83 & 79,87 & 2,83 & 32,93 & 1,50 & 1,60 & 1,10 & 2,45 \\
\hline & \multirow{10}{*}{ Água } & 79,87 & 1,30 & 31,80 & 79,17 & 2,80 & 33,63 & $-0,70$ & 1,50 & 1,83 & 2,47 \\
\hline & & 76,00 & 1,67 & 31,20 & 76,60 & 3,10 & 32,47 & 0,60 & 1,43 & 1,27 & 2,00 \\
\hline & & 77,97 & 1,30 & 30,83 & 78,83 & 2,50 & 32,03 & 0,87 & 1,20 & 1,20 & 1,91 \\
\hline & & 75,73 & 1,90 & 31,70 & 76,50 & 2,70 & 32,33 & 0,77 & 0,80 & 0,63 & 1,28 \\
\hline & & 76,43 & 0,90 & 30,27 & 75,30 & 2,30 & 32,07 & $-1,13$ & 1,40 & 1,80 & 2,55 \\
\hline & & 77,50 & 0,90 & 31,40 & 80,00 & 2,00 & 32,20 & 2,50 & 1,10 & 0,80 & 2,85 \\
\hline & & 76,83 & 1,50 & 31,70 & 77,30 & 2,50 & 32,07 & 0,47 & 1,00 & 0,37 & 1,16 \\
\hline & & 80,83 & 1,20 & 33,23 & 82,50 & 3,10 & 35,50 & 1,67 & 1,90 & 2,27 & 3,39 \\
\hline & & 78,97 & 1,63 & 32,53 & 79,87 & 2,60 & 33,00 & 0,90 & 0,97 & 0,47 & 1,40 \\
\hline & & 78,33 & 1,10 & 30,80 & 77,23 & 2,10 & 31,70 & $-1,10$ & 1,00 & 0,90 & 1,74 \\
\hline \multirow{20}{*}{ 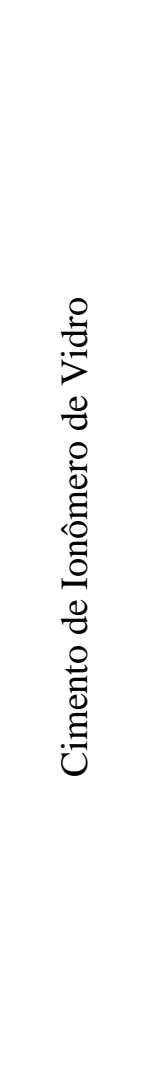 } & \multirow{10}{*}{ Terra } & 84,13 & 3,13 & 35,87 & 80,20 & 3,20 & 34,20 & $-3,93$ & 0,07 & $-1,67$ & 4,27 \\
\hline & & 81,30 & 3,97 & 37,87 & 80,87 & 3,37 & 36,00 & $-0,43$ & $-0,60$ & $-1,87$ & 2,01 \\
\hline & & 82,97 & 2,47 & 33,73 & 80,00 & 2,60 & 32,67 & $-2,97$ & 0,13 & $-1,07$ & 3,16 \\
\hline & & 82,10 & 1,40 & 30,97 & 81,97 & 1,50 & 30,97 & $-0,13$ & 0,10 & 0,00 & 0,17 \\
\hline & & 81,87 & 2,63 & 34,73 & 68,40 & 3,80 & 31,73 & $-13,47$ & 1,17 & $-3,00$ & 13,85 \\
\hline & & 84,27 & 2,40 & 34,23 & 77,73 & 4,23 & 36,30 & $-6,53$ & 1,83 & 2,07 & 7,09 \\
\hline & & 83,17 & 3,00 & 34,97 & 84,43 & 2,50 & 33,63 & 1,27 & $-0,50$ & $-1,33$ & 1,91 \\
\hline & & 79,17 & 3,93 & 37,23 & 78,37 & 3,30 & 35,10 & $-0,80$ & $-0,63$ & $-2,13$ & 2,36 \\
\hline & & 87,43 & 0,13 & 27,90 & 79,97 & 1,57 & 28,83 & $-7,47$ & 1,43 & 0,93 & 7,66 \\
\hline & & 85,63 & 1,40 & 32,43 & 82,53 & 1,50 & 30,80 & $-3,10$ & 0,10 & $-1,63$ & 3,51 \\
\hline & \multirow{10}{*}{ Água } & 83,03 & 1,40 & 31,00 & 76,80 & 2,30 & 32,17 & $-6,23$ & 0,90 & 1,17 & 6,41 \\
\hline & & 85,33 & 0,00 & 25,83 & 81,90 & 2,10 & 31,90 & $-3,43$ & 2,10 & 6,07 & 7,28 \\
\hline & & 79,83 & 2,10 & 32,90 & 82,13 & 2,10 & 33,10 & 2,30 & 0,00 & 0,20 & 2,31 \\
\hline & & 85,37 & 1,60 & 31,60 & 78,87 & 2,73 & 32,80 & $-6,50$ & 1,13 & 1,20 & 6,71 \\
\hline & & 83,57 & 1,40 & 31,40 & 81,50 & 1,40 & 31,53 & $-2,07$ & 0,00 & 0,13 & 2,07 \\
\hline & & 84,13 & 2,60 & 33,90 & 80,37 & 2,80 & 34,10 & $-3,77$ & 0,20 & 0,20 & 3,78 \\
\hline & & 83,50 & 3,00 & 35,73 & 82,60 & 2,20 & 33,47 & $-0,90$ & $-0,80$ & $-2,27$ & 2,57 \\
\hline & & 84,67 & 1,50 & 31,73 & 80,77 & 2,20 & 32,37 & $-3,90$ & 0,70 & 0,63 & 4,01 \\
\hline & & 83,77 & 2,10 & 32,43 & 74,33 & 3,60 & 34,13 & $-9,43$ & 1,50 & 1,70 & 9,70 \\
\hline & & 83,73 & 1,43 & 31,43 & 79,10 & 2,40 & 31,27 & $-4,63$ & 0,97 & $-0,17$ & 4,74 \\
\hline
\end{tabular}


Tabela 3 - Médias iniciais e finais, após 6 meses, de $L^{*}, a^{*}$ e b* e valores de deltas $\left(L^{*}, a^{*}, b^{*}\right.$ e E).

\begin{tabular}{|c|c|c|c|c|c|c|c|c|c|c|c|}
\hline \multirow{2}{*}{ Material } & \multirow[t]{2}{*}{ Agente } & \multicolumn{3}{|c|}{$\begin{array}{l}\text { Leituras iniciais } \\
\text { médias }\end{array}$} & \multicolumn{3}{|c|}{$\begin{array}{l}\text { Leituras médias } \\
\text { finais (após } 6 \text { meses) }\end{array}$} & \multirow[t]{2}{*}{$\Delta \mathrm{L}$} & \multirow[t]{2}{*}{$\Delta \mathrm{a}$} & \multirow[t]{2}{*}{$\Delta \mathrm{b}$} & \multirow[t]{2}{*}{$\Delta \mathrm{E}$} \\
\hline & & $\mathrm{L}^{*}$ & $a^{*}$ & $\mathrm{~b}^{*}$ & $\mathrm{~L}^{*}$ & $a^{*}$ & $\mathrm{~b}^{*}$ & & & & \\
\hline \multirow{20}{*}{ 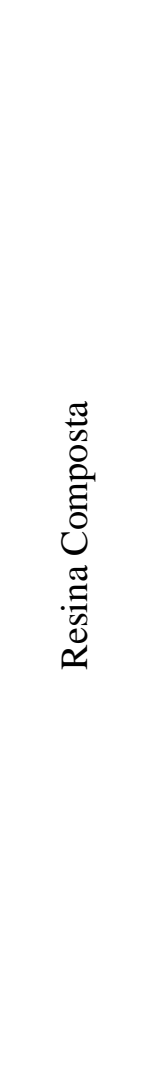 } & \multirow{10}{*}{ Terra } & 77,10 & 0,90 & 30,50 & 77,93 & 3,17 & 32,50 & 0,83 & 2,27 & 2,00 & 3,14 \\
\hline & & 80,37 & 1,30 & 31,47 & 79,90 & 3,00 & 32,97 & $-0,47$ & 1,70 & 1,50 & 2,31 \\
\hline & & 77,57 & 1,33 & 30,70 & 79,83 & 3,80 & 34,70 & 2,27 & 2,47 & 4,00 & 5,22 \\
\hline & & 76,37 & 1,70 & 30,83 & 77,03 & 4,83 & 34,17 & 0,67 & 3,13 & 3,33 & 4,62 \\
\hline & & 78,83 & 1,10 & 31,00 & 80,17 & 2,80 & 32,57 & 1,33 & 1,70 & 1,57 & 2,67 \\
\hline & & 78,53 & 1,03 & 32,00 & 80,00 & 3,50 & 34,10 & 1,47 & 2,47 & 2,10 & 3,56 \\
\hline & & 78,97 & 1,37 & 31,53 & 81,20 & 3,60 & 34,57 & 2,23 & 2,23 & 3,03 & 4,38 \\
\hline & & 77,67 & 0,90 & 30,40 & 80,50 & 3,57 & 34,10 & 2,83 & 2,67 & 3,70 & 5,37 \\
\hline & & 79,50 & 2,10 & 32,70 & 81,63 & 3,97 & 34,77 & 2,13 & 1,87 & 2,07 & 3,51 \\
\hline & & 78,37 & 1,23 & 31,83 & 80,90 & 4,10 & 35,57 & 2,53 & 2,87 & 3,73 & 5,35 \\
\hline & \multirow{10}{*}{ Água } & 79,87 & 1,30 & 31,80 & 81,53 & 4,33 & 37,63 & 1,67 & 3,03 & 5,83 & 6,78 \\
\hline & & 76,00 & 1,67 & 31,20 & 77,30 & 4,80 & 37,37 & 1,30 & 3,13 & 6,17 & 7,04 \\
\hline & & 77,97 & 1,30 & 30,83 & 79,93 & 4,10 & 35,77 & 1,97 & 2,80 & 4,93 & 6,00 \\
\hline & & 75,73 & 1,90 & 31,70 & 77,77 & 3,90 & 36,37 & 2,03 & 2,00 & 4,67 & 5,47 \\
\hline & & 76,43 & 0,90 & 30,27 & 80,07 & 3,50 & 35,90 & 3,63 & 2,60 & 5,63 & 7,19 \\
\hline & & 77,50 & 0,90 & 31,40 & 78,90 & 2,60 & 34,63 & 1,40 & 1,70 & 3,23 & 3,91 \\
\hline & & 76,83 & 1,50 & 31,70 & 77,00 & 3,17 & 34,10 & 0,17 & 1,67 & 2,40 & 2,93 \\
\hline & & 80,83 & 1,20 & 33,23 & 82,30 & 4,00 & 37,87 & 1,47 & 2,80 & 4,63 & 5,61 \\
\hline & & 78,97 & 1,63 & 32,53 & 80,20 & 3,67 & 36,00 & 1,23 & 2,03 & 3,47 & 4,20 \\
\hline & & 78,33 & 1,10 & 30,80 & 78,73 & 2,90 & 34,00 & 0,40 & 1,80 & 3,20 & 3,69 \\
\hline \multirow{20}{*}{ 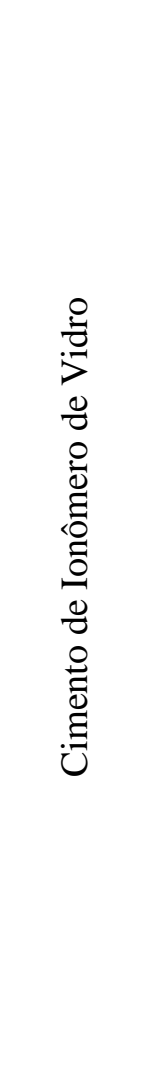 } & \multirow{10}{*}{ Terra } & 84,13 & 3,13 & 35,87 & 80,43 & 3,80 & 35,43 & $-3,70$ & 0,67 & $-0,43$ & 3,78 \\
\hline & & 81,30 & 3,97 & 37,87 & 79,00 & 4,60 & 37,83 & $-2,30$ & 0,63 & $-0,03$ & 2,39 \\
\hline & & 82,97 & 2,47 & 33,73 & 75,33 & 4,90 & 35,93 & $-7,63$ & 2,43 & 2,20 & 8,31 \\
\hline & & 82,10 & 1,40 & 30,97 & 85,63 & 2,00 & 33,20 & 3,53 & 0,60 & 2,23 & 4,22 \\
\hline & & 81,87 & 2,63 & 34,73 & 77,37 & 3,40 & 34,13 & $-4,50$ & 0,77 & $-0,60$ & 4,60 \\
\hline & & 84,27 & 2,40 & 34,23 & 77,00 & 7,60 & 41,37 & $-7,27$ & 5,20 & 7,13 & 11,43 \\
\hline & & 83,17 & 3,00 & 34,97 & 85,03 & 3,10 & 35,37 & 1,87 & 0,10 & 0,40 & 1,91 \\
\hline & & 79,17 & 3,93 & 37,23 & 81,03 & 3,10 & 35,73 & 1,87 & $-0,83$ & $-1,50$ & 2,54 \\
\hline & & 87,43 & 0,13 & 27,90 & 77,97 & 3,37 & 32,70 & $-9,47$ & 3,23 & 4,80 & 11,10 \\
\hline & & 85,63 & 1,40 & 32,43 & 83,63 & 2,00 & 32,50 & $-2,00$ & 0,60 & 0,07 & 2,09 \\
\hline & \multirow{10}{*}{ Água } & 83,03 & 1,40 & 31,00 & 63,33 & 2,90 & 30,57 & $-19,70$ & 1,50 & $-0,43$ & 19,76 \\
\hline & & 85,33 & 0,00 & 25,83 & 74,37 & 4,30 & 34,80 & $-10,97$ & 4,30 & 8,97 & 14,80 \\
\hline & & 79,83 & 2,10 & 32,90 & 77,77 & 3,30 & 34,67 & $-2,07$ & 1,20 & 1,77 & 2,97 \\
\hline & & 85,37 & 1,60 & 31,60 & 75,93 & 3,13 & 33,50 & $-9,43$ & 1,53 & 1,90 & 9,74 \\
\hline & & 83,57 & 1,40 & 31,40 & 76,60 & 2,90 & 33,90 & $-6,97$ & 1,50 & 2,50 & 7,55 \\
\hline & & 84,13 & 2,60 & 33,90 & 57,33 & 3,80 & 29,83 & $-26,80$ & 1,20 & $-4,07$ & 27,13 \\
\hline & & 83,50 & 3,00 & 35,73 & 76,47 & 3,87 & 35,73 & $-7,03$ & 0,87 & 0,00 & 7,09 \\
\hline & & 84,67 & 1,50 & 31,73 & 68,57 & 3,60 & 32,33 & $-16,10$ & 2,10 & 0,60 & 16,25 \\
\hline & & 83,77 & 2,10 & 32,43 & 82,27 & 3,27 & 36,30 & $-1,50$ & 1,17 & 3,87 & 4,31 \\
\hline & & 83,73 & 1,43 & 31,43 & 70,63 & 3,80 & 32,97 & $-13,10$ & 2,37 & 1,53 & 13,40 \\
\hline
\end{tabular}




\subsubsection{Delta $E$}

A comparação das médias de Delta E é apresentada na Tabela 4 e Figuras 30 e 31.

Tabela 4 - Comparação das médias $\Delta \mathrm{E}$ (desvio padrão) dos agentes, para um mesmo material

\begin{tabular}{c|c|c|c}
\hline Material & Tempo & Terra & Água \\
\hline \multirow{3}{*}{ Resina } & 1 mês & $3,08 \pm 0,69^{\mathrm{aAB}}$ & $3,64 \pm 1,55^{\mathrm{aAB}}$ \\
& 3 meses & $1,59 \pm 0,52^{\mathrm{aB}}$ & $2,07 \pm 0,73^{\mathrm{aB}}$ \\
& 6 meses & $4,01 \pm 1,13^{\mathrm{bA}}$ & $5,28 \pm 1,52^{\mathrm{aA}}$ \\
\hline \multirow{3}{*}{ CIV } & 1 mês & $2,94 \pm 1,41^{\mathrm{aA}}$ & $7,23 \pm 3,82^{\mathrm{aB}}$ \\
& 3 meses & $4,60 \pm 3,99^{\mathrm{aA}}$ & $4,96 \pm 2,50^{\mathrm{aB}}$ \\
& 6 meses & $5,24 \pm 3,68^{\mathrm{bA}}$ & $12,3 \pm 7,50^{\mathrm{aA}}$ \\
\hline
\end{tabular}

Letras diferentes, minúsculas na linha e maiúsculas na coluna, para cada material, indicam diferença estatisticamente significante $(\mathrm{p}<0,05)$.

Considerando a alteração de cor da Resina Composta, verificou-se maior alteração após 6 meses de inumação e afogamento, resultados estatisticamente significantes $(p<0,05)$ em relação aos valores médios encontrados após 3 meses da ação dos agentes, período após o qual as amostras apresentaram as menores alterações de cor. Resultados semelhantes $(p>0,05)$ ao período de 1 mês.

Quanto ao CIV, a maior alteração de cor ocorreu quando submetido a afogamento, após 6 meses, resultado estatisticamente significante $(\mathrm{p}<0,05)$ em relação aos períodos menores a que os materiais foram submetidos, que não apresentaram diferença entre si (p>0,05). Não houve diferença $(p>0,05)$ na alteração de cor entre os materiais submetidos à inumação, para nenhum dos tempos.

Quanto ao agente causador da alteração de cor, dentro de um mesmo período de tempo (Figuras 30 e 31), não houve diferença estatisticamente significante entre eles, com exceção após 3 meses, em que houve maior alteração de cor $(\mathrm{p}<0,05)$ quando ambos os materiais foram submetidos a enterramento; quando submetidos a afogamento, a exceção ocorreu após 6 meses, quando houve maior alteração de cor $(\mathrm{p}<0,05)$. 
Figura 30 - Representação gráfica da comparação de $\Delta \mathrm{E}$ entre materiais estéticos (resina e CIV) submetidos a inumação.

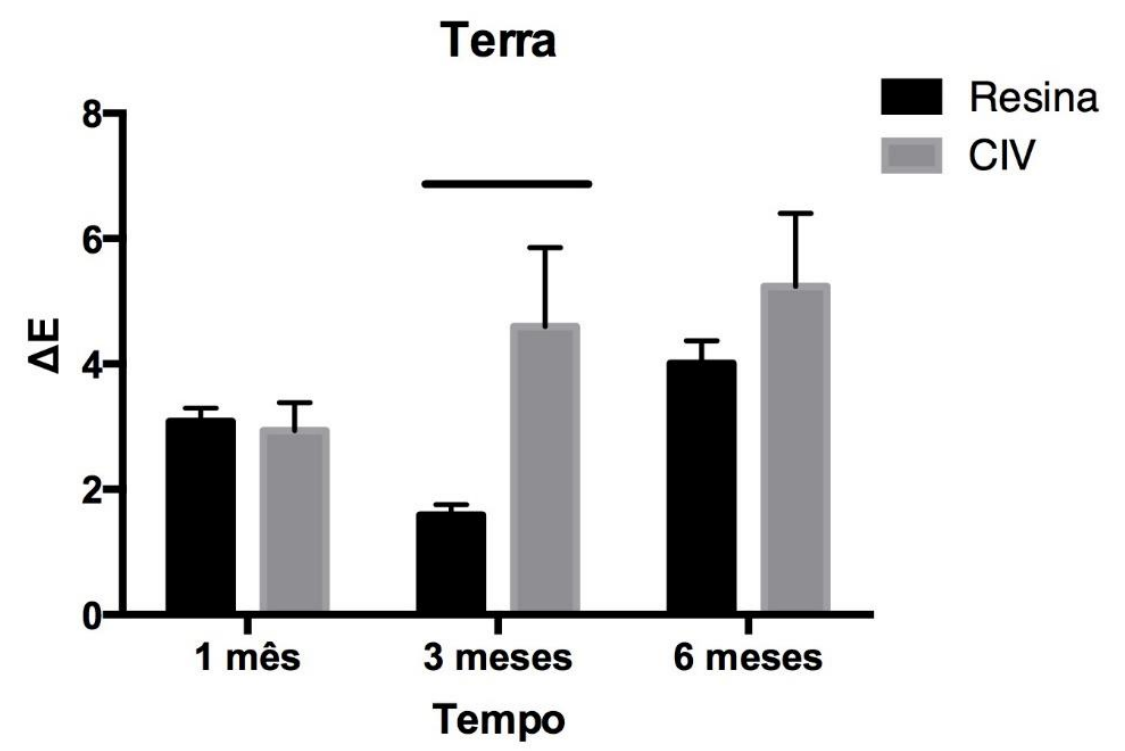

Colunas sob linhas horizontais indicam resultados estatisticamente significantes.

Figura 31 - Representação gráfica da comparação de $\Delta \mathrm{E}$ entre materiais estéticos (resina e CIV) submetidos a afogamento.

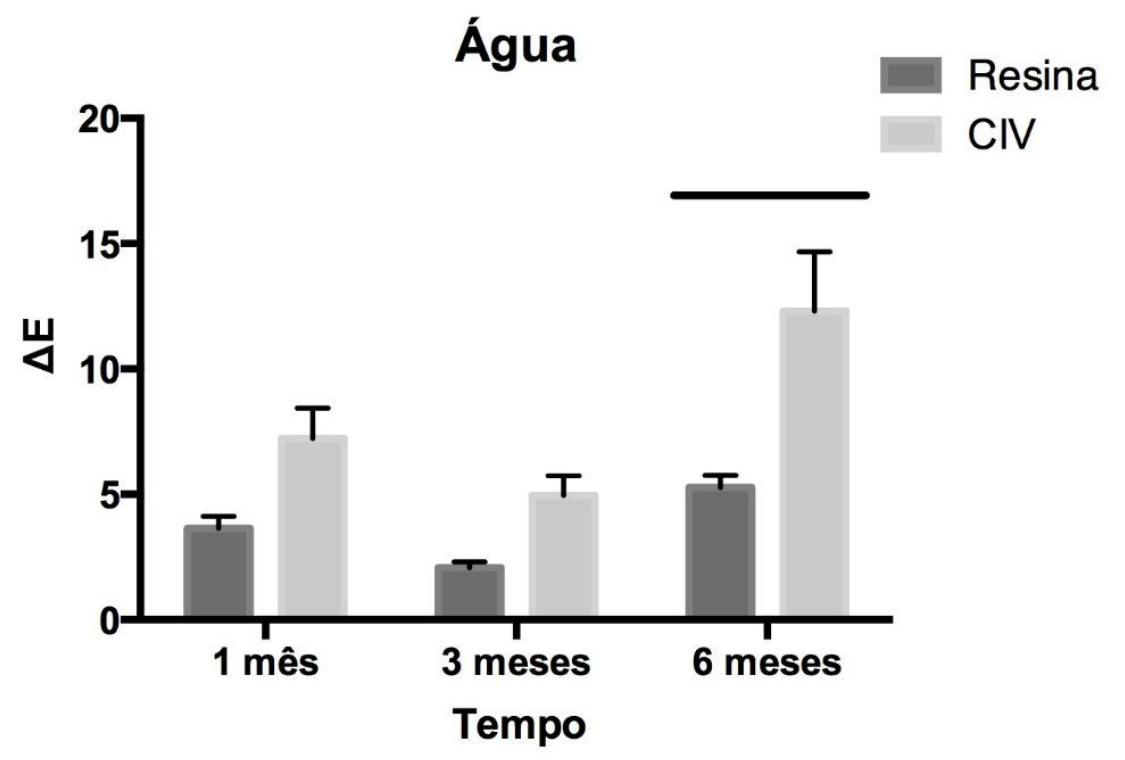

Colunas sob linhas horizontais indicam resultados estatisticamente significantes.

Comparando a alteração de cor dos materiais, após um mesmo período de tempo de ação dos agentes, verificou-se que houve diferença significante $(\mathrm{p}<0,05)$ somente após 3 meses de inumação e 6 meses de afogamento, com maior alteração de cor para CIV em ambos os casos, não havendo diferença significativa $(p>0,05)$ em nenhum dos outros tempos de ação, independente do agente. 


\subsubsection{Delta $L$}

As médias de $\Delta \mathrm{L}$ foram comparadas estatisticamente (3-way ANOVA, teste de Bonferroni, nível de significância de 95\%), e são apresentadas na Tabela 5 e Figuras 32 e 33.

Tabela 5 - Comparação das médias $\Delta \mathrm{L}$ (desvio padrão) dos agentes nos diferentes tempos de ação, para um mesmo material.

\begin{tabular}{c|c|c|c}
\hline Material & Tempo & Terra & Água \\
\hline \multirow{2}{*}{ Resina } & 1 mês & $1,19 \pm 0,93^{\mathrm{bA}}$ & $-1,88 \pm 1,53^{\mathrm{aA}}$ \\
& 3 meses & $0,27 \pm 0,70^{\mathrm{aA}}$ & $0,48 \pm 1,17^{\mathrm{aA}}$ \\
& 6 meses & $1,58 \pm 1,02^{\mathrm{aA}}$ & $1,53 \pm 0,95^{\mathrm{aA}}$ \\
\hline \multirow{2}{*}{ CIV } & 1 mês & $0,00 \pm 2,71^{\mathrm{bB}}$ & $-6,87 \pm 4,00^{\mathrm{aB}}$ \\
& 3 meses & $-3,76 \pm 4,41^{\mathrm{aA}}$ & $-3,86 \pm 3,24^{\mathrm{aB}}$ \\
& 6 meses & $-2,96 \pm 4,42^{\mathrm{bA}}$ & $-11,37 \pm 7,88^{\mathrm{aA}}$ \\
\hline
\end{tabular}

Letras diferentes, minúsculas na linha e maiúsculas na coluna, para cada material, indicam diferença estatisticamente significante $(\mathrm{p}<0,05)$.

Considerando a alteração de $\Delta \mathrm{L}$ da Resina Composta, verificou-se que houve perda de luminosidade apenas quando submetido a afogamento, após 1 mês, diferença estatisticamente significante $(p<0,05)$ em relação à inumação, após o mesmo período. Para todas as outras comparações em Resina Composta, não houve diferença estatisticamente significante $(p>0,05)$.

Quanto ao CIV, verificou-se que não houve alteração de luminosidade após 1 mês de inumação, resultado estatisticamente significante $(\mathrm{p}<0,05)$ em relação à condição de afogamento, no mesmo período. A maior alteração de luminosidade foi verificada após 6 meses de afogamento, resultado estatisticamente significante $(\mathrm{p}<0,05)$ em relação ao valor encontrado para o mesmo tempo após inumação e aos demais tempos de afogamento, que não apresentaram diferença $(p>0,05)$ entre si.

Quanto ao agente causador da alteração de luminosidade, dentro de um mesmo período de tempo (Figuras 32 e 33), verificou-se que houve diminuição da luminosidade para CIV após 3 meses de inumação, enquanto que, para a Resina Composta houve manutenção (após 3 meses) ou aumento da luminosidade (após 6 meses), com diferença estatisticamente significante $(p<0,05)$. Não houve diferença significativa $(p>0,05)$ quando os materiais foram submetidos a inumação após 1 mês. 
Quando submetidos a afogamento, em todos os tempos estudados, houve diminuição da luminosidade para CIV, sendo que verificou-se diferença estatisticamente significante $(\mathrm{p}<0,05)$ após 1 e 6 meses.

Figura 32 - Representação gráfica da comparação de $\Delta \mathrm{L}$ entre materiais estéticos (resina e CIV) submetidos a inumação.

\section{Terra}

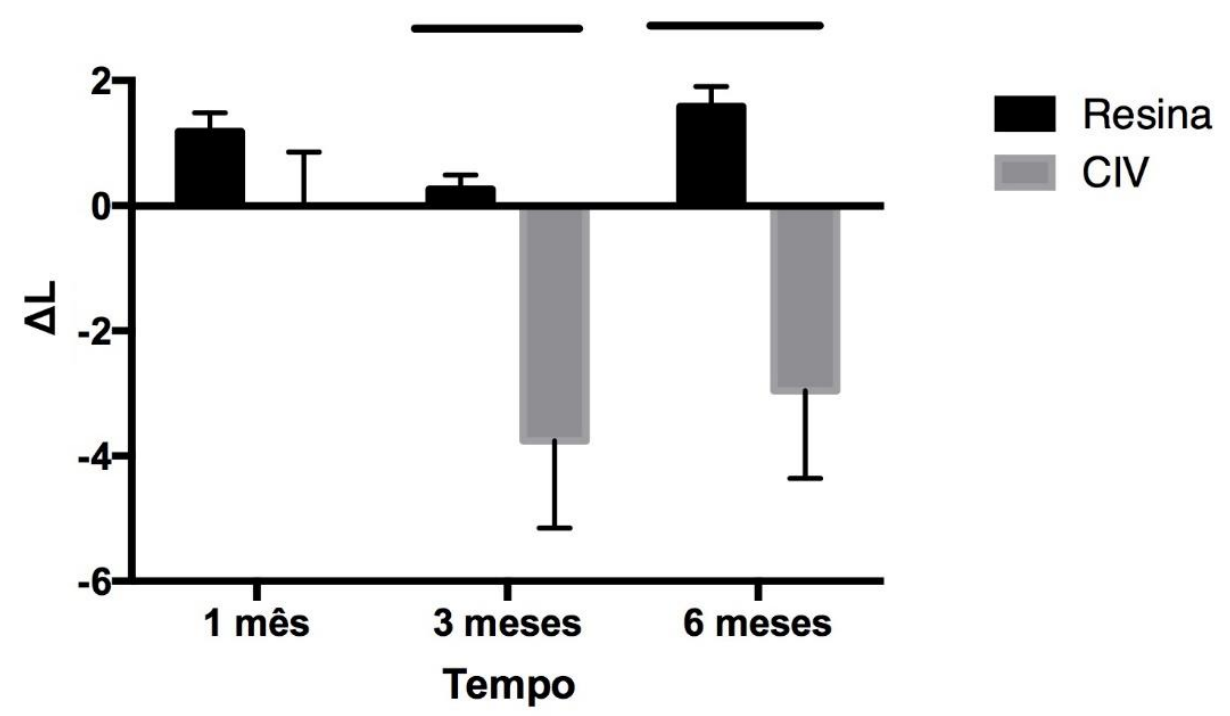

Colunas sob linhas horizontais indicam resultados estatisticamente significantes.

Figura 33 - Representação gráfica da comparação de $\Delta \mathrm{L}$ entre materiais estéticos (resina e CIV) submetidos a afogamento.

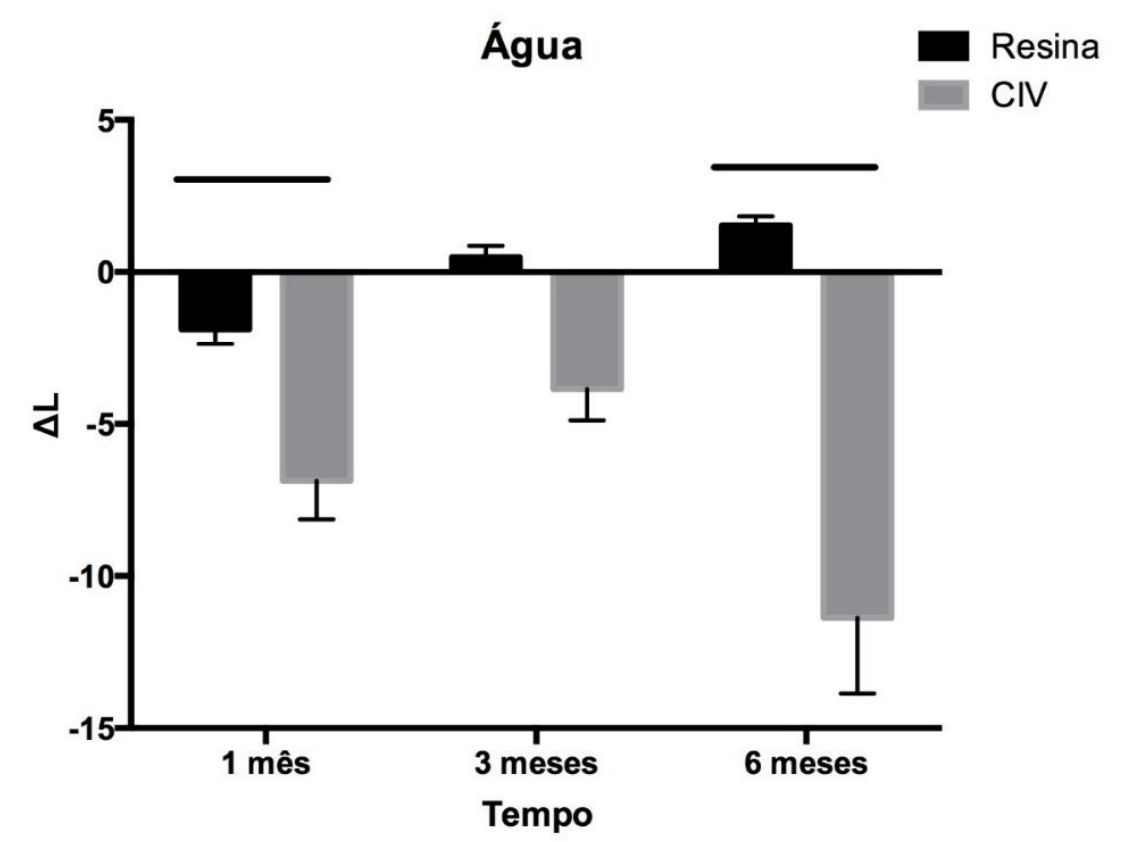

Colunas sob linhas horizontais indicam resultados estatisticamente significantes. 


\subsubsection{Delta a}

As médias de $\triangle \mathrm{a}$ foram analisadas estatisticamente (3-way ANOVA, teste de Bonferroni, nível de significância de 95\%), e as comparações são apresentadas na Tabela 6 e Figuras 34 e 35.

Tabela 6 - Comparação das médias $\Delta$ a (desvio padrão) dos agentes nos diferentes tempos de ação, para um mesmo material.

\begin{tabular}{c|c|c|c}
\hline Material & Tempo & Terra & Água \\
\hline \multirow{3}{*}{ Resina } & 1 mês & $1,98 \pm 0,26^{\mathrm{aA}}$ & $1,51 \pm 0,47^{\mathrm{aB}}$ \\
& 3 meses & $1,18 \pm 0,41^{\mathrm{aB}}$ & $1,23 \pm 0,33^{\mathrm{aB}}$ \\
& 6 meses & $2,34 \pm 0,48^{\mathrm{aA}}$ & $2,36 \pm 0,57^{\mathrm{aA}}$ \\
\hline \multirow{3}{*}{ CIV } & 1 mês & $0,01 \pm 0,68^{\mathrm{aB}}$ & $0,40 \pm 0,61^{\mathrm{aB}}$ \\
& 3 meses & $0,31 \pm 0,87^{\mathrm{aB}}$ & $0,67 \pm 0,84^{\mathrm{aB}}$ \\
& 6 meses & $1,34 \pm 1,77^{\mathrm{aA}}$ & $1,77 \pm 0,99^{\mathrm{aA}}$ \\
\hline
\end{tabular}

Letras diferentes, minúsculas na linha e maiúsculas na coluna, para cada material, indicam diferença estatisticamente significante $(\mathrm{p}<0,05)$.

Considerando as alterações ocorridas em cada material, verificou-se que nenhum dos materiais apresentou diferença estatisticamente significante $(p>0,05)$ em relação aos diferentes agentes a que foram submetidos. Comparando-se cada material submetidos a inumação, nos diferentes tempos, verificou-se maior alteração da coordenada a* após 6 meses, resultado semelhante $(p>0,05)$ ao período de 1 mês e diferente estatisticamente $(p<0,05)$ em relação aos valores médios encontrados após 3 meses da ação do agente, período após o qual as amostras apresentaram as menores alterações na coordenada. Quanto ao afogamento, verificou-se maior alteração após 6 meses, diferente estatisticamente $(\mathrm{p}<0,05)$, em relação aos demais tempos testados, que não apresentaram diferença entre si ( $p>0,05)$, sendo que após 3 meses de ação do agente, as amostras apresentaram as menores alterações.

Quanto ao CIV, a maior alteração na coordenada a* ocorreu após 6 meses de inumação e afogamento, resultados estatisticamente significantes $(p<0,05)$ em relação aos demais tempos testados, que não apresentaram diferença $(\mathrm{p}>0,05)$ entre si. As menores alterações ocorreram após 1 mês da ação dos agentes. 
Figura 34 - Representação gráfica da comparação de $\Delta$ a entre materiais estéticos (resina e CIV) submetidos a inumação.

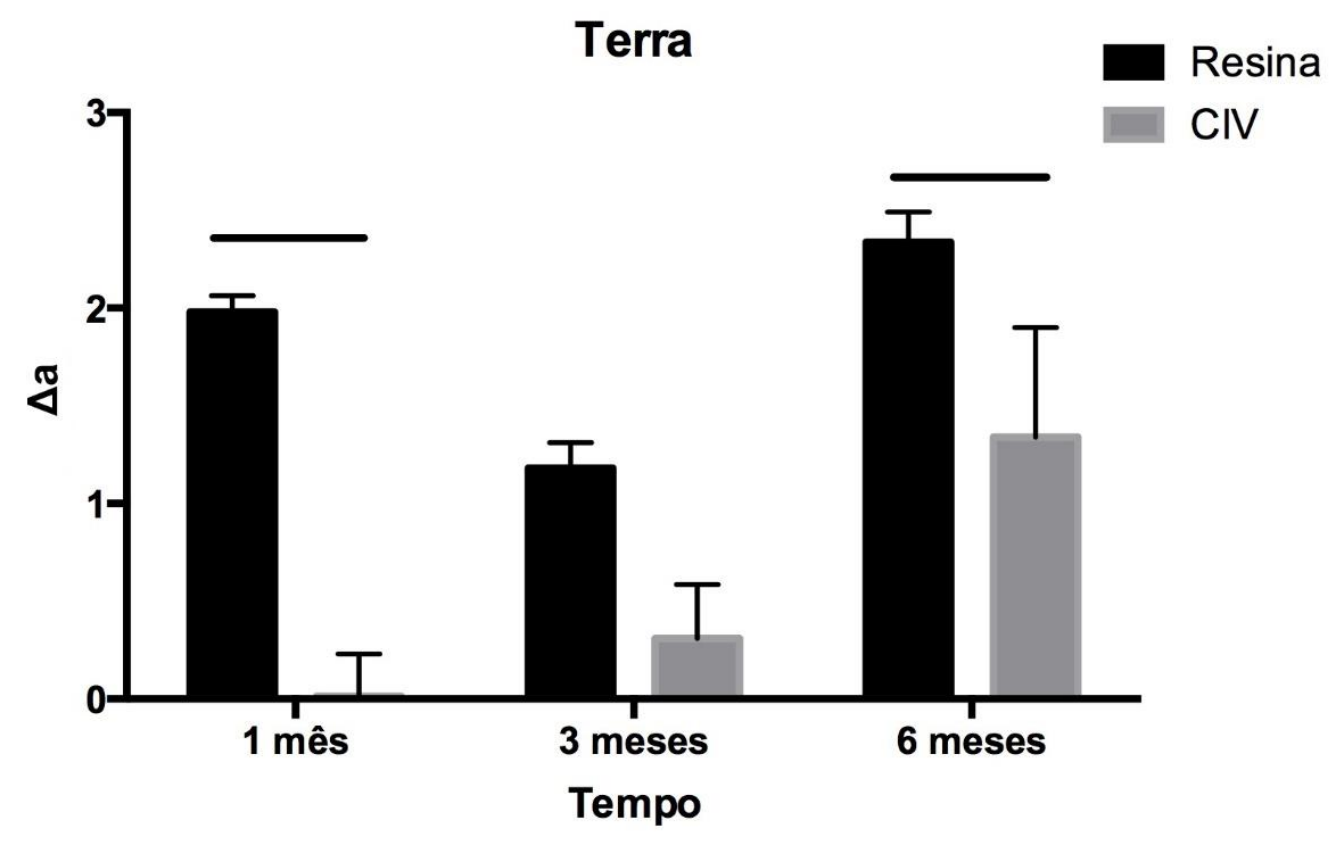

Colunas sob linhas horizontais indicam resultados estatisticamente significantes.

Figura 35 - Representação gráfica da comparação de $\Delta$ a entre materiais estéticos (resina e CIV) submetidos a afogamento.

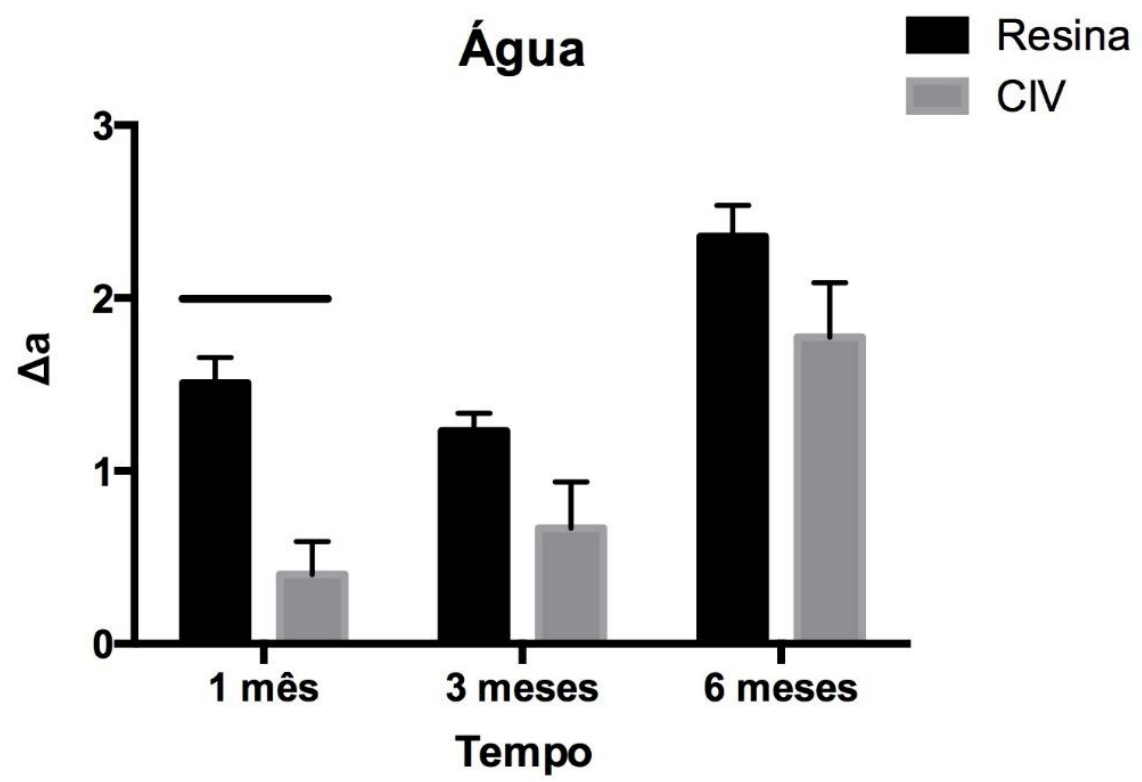

Colunas sob linhas horizontais indicam resultados estatisticamente significantes.

Comparando a alteração na coordenada $a^{*}$ dos materiais, após um mesmo período de tempo de ação dos agentes (Figuras 34 e 35), verificou-se que houve diferença significante $(\mathrm{p}<0,05)$ após 1 e 6 meses de inumação e 1 mês de afogamento, com maior alteração de cor 
para Resina Composta em ambos os casos, não havendo diferença significativa $(p>0,05)$ em nenhum dos outros tempos de ação, independente do agente.

\subsubsection{Delta $b$}

As médias de $\Delta \mathrm{b}$ Foram analisadas estatisticamente (3-way ANOVA, teste de Bonferroni, nível de significância de 95\%), e as comparações são apresentadas na Tabela 7 e Figuras 36 e 37.

Tabela 7 - Comparação das médias $\Delta \mathrm{b}$ (desvio padrão) dos agentes nos diferentes tempos de ação, para um mesmo material.

\begin{tabular}{c|c|c|c}
\hline Material & Tempo & Terra & Água \\
\hline \multirow{3}{*}{ Resina } & 1 mês & $1,85 \pm 0,62^{\mathrm{aA}}$ & $2,38 \pm 1,35^{\mathrm{aB}}$ \\
& 3 meses & $0,36 \pm 0,81^{\mathrm{aB}}$ & $1,15 \pm 0,64^{\mathrm{aB}}$ \\
& 6 meses & $2,70 \pm 0,96^{\mathrm{bA}}$ & $4,42 \pm 1,28^{\mathrm{aA}}$ \\
\hline \multirow{3}{*}{ CIV } & 1 mês & $-1,16 \pm 1,50^{\mathrm{aB}}$ & $-1,64 \pm 0,85^{\mathrm{aB}}$ \\
& 3 meses & $-0,97 \pm 1,53^{\mathrm{aB}}$ & $0,89 \pm 2,12^{\mathrm{aA}}$ \\
& 6 meses & $1,43 \pm 2,72^{\mathrm{aA}}$ & $1,66 \pm 3,34^{\mathrm{aA}}$ \\
\hline
\end{tabular}

Letras diferentes, minúsculas na linha e maiúsculas na coluna, para cada material, indicam diferença estatisticamente significante $(\mathrm{p}<0,05)$.

Considerando as alterações ocorridas para Resina Composta, comparando-se os diferentes agentes em um mesmo período de tempo, verificou-se maior alteração após 6 meses de afogamento, resultado diferente estatisticamente $(p<0,05)$ em relação aos valores encontrados para inumação. Nos demais tempos estudados, não houve diferença estatisticamente significante entre os agentes $(p>0,05)$ para Resina Composta, assim como para CIV.

Quanto à comparação das médias de Resina Composta considerando os agentes nos diferentes tempos, verificou-se que, quando submetidos à inumação, a menor alteração ocorreu após 3 meses de ação, resultado diferente $(\mathrm{p}<0,05)$ em relação aos demais tempos, que apresentaram resultados semelhantes $(\mathrm{p}>0,05)$ entre si. A maior alteração da coordenada $b^{*}$, para este material, ocorreu após 6 meses de afogamento, resultado estatisticamente significante $(p<0,05)$ em relação aos demais tempos de ação, que não apresentaram diferença $(p>0,05)$ entre si.

Quanto ao CIV, a maior alteração na coordenada $b^{*}$ foi verificada após 6 meses de inumação, resultado estatisticamente significante $(p<0,05)$ em relação aos demais tempos 
testados, que não apresentam diferença $(\mathrm{p}>0,05)$ entre si. $\mathrm{Na}$ condição de afogamento, verificou-se maior alteração da coordenada após 6 meses da ação do agente, com médias semelhantes $(p>0,05)$ aos do período de 3 meses e diferentes estatisticamente $(p<0,05)$ em relação aos valores encontrados após o período de 1 mês.

Figura 36 - Representação gráfica da comparação de $\Delta \mathrm{b}$ entre materiais estéticos (resina e CIV) submetidos a inumação.

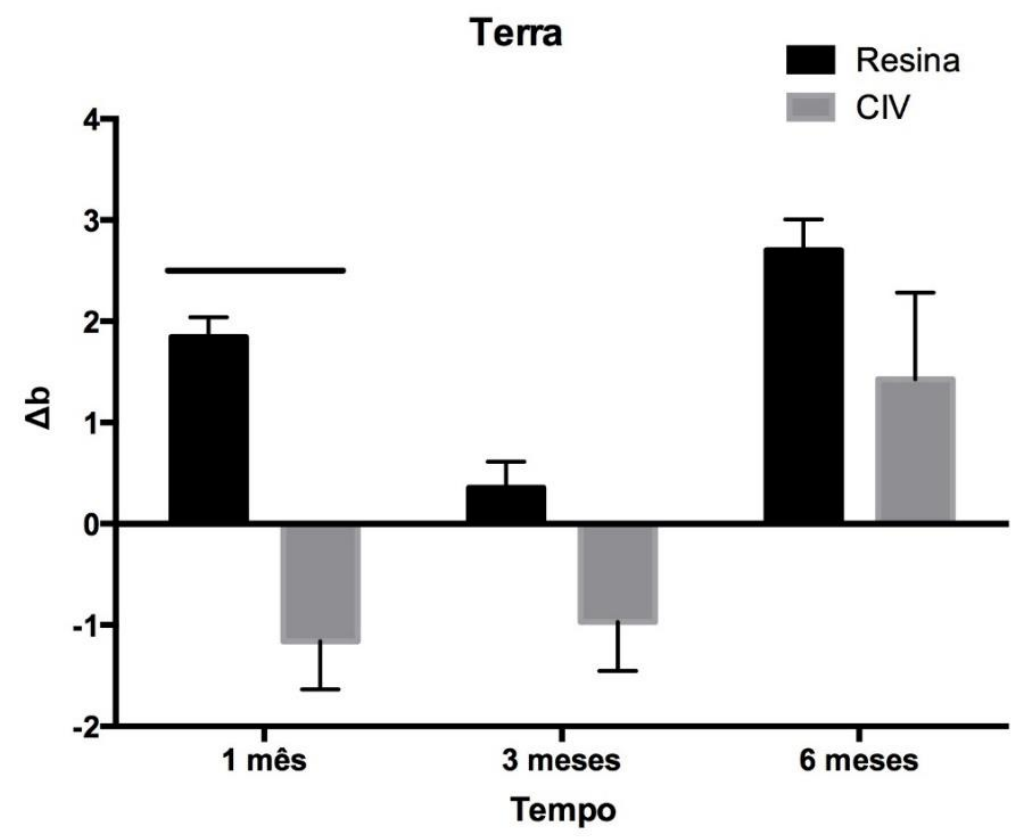

Colunas sob linhas horizontais indicam resultados estatisticamente significantes.

Figura 37 - Representação gráfica da comparação de $\Delta b$ entre materiais estéticos (resina e CIV) submetidos a afogamento.

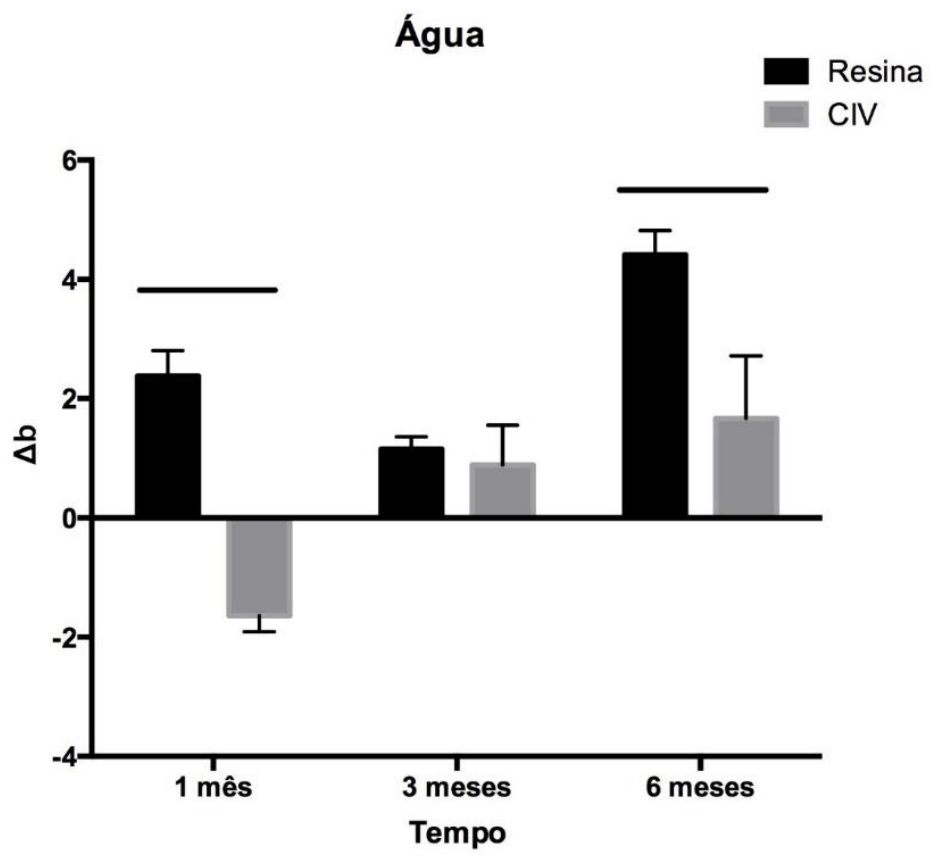

Colunas sob linhas horizontais indicam resultados estatisticamente significantes. 
Comparando a alteração na coordenada b* dos materiais, após um mesmo período de tempo de ação dos agentes (Figuras 36 e 37), verificou-se que houve diferença significante ( $\mathrm{p}<0,05)$ após 1 mês de inumação e após 1 e 6 meses de afogamento, com maior alteração de cor para Resina Composta em ambos os casos, não havendo diferença significativa ( $>0,05)$ em nenhum dos outros tempos de ação, independente do agente.

\subsection{Rugosidade de superfície}

Os valores das leituras de rugosidade média (após 3 leituras) para cada tipo de material, após cada tempo experimental, são apresentados nas tabelas 8, 9 e 10. As médias de rugosidade de superfície para os materiais estéticos foram analisadas estatisticamente segundo 3-way ANOVA (fatores de variação: material, tempo e condição ambiental), medidas repetidas, teste de Bonferroni, com nível de significância de 95\%. Para o amálgama, as médias foram analisadas estatisticamente segundo 2-way ANOVA, medidas repetidas (fatores de variação: tempo e condição ambiental), teste de Bonferroni, com nível de significância de $95 \%$.

Tabela 8 - Médias de rugosidade de superfície das restaurações de resina composta submetida a inumação e afogamento, após cada um dos tempos testados.

\begin{tabular}{ccccc}
\hline Agente & Baseline & 1 mês & 3 meses & 6 meses \\
\hline \multirow{5}{*}{ Terra } & 1,50 & 1,21 & 1,27 & 1,38 \\
& 0,92 & 1,21 & 1,41 & 1,41 \\
& 1,10 & 1,06 & 1,09 & 1,16 \\
& 2,94 & 1,98 & 1,77 & 2,36 \\
& 1,46 & 1,45 & 1,62 & 1,44 \\
& 1,22 & 1,36 & 1,22 & 1,09 \\
& 1,07 & 1,54 & 1,32 & 1,53 \\
& 0,72 & 1,00 & 0,69 & 0,70 \\
& 1,23 & 1,00 & 1,00 & 1,20 \\
Água & 2,79 & 2,38 & 1,53 & 1,88 \\
\hline & 1,79 & 1,81 & 1,84 & 2,01 \\
& 2,47 & 1,63 & 2,10 & 1,56 \\
& 1,31 & 1,36 & 1,46 & 1,41 \\
& 0,60 & 0,67 & 0,70 & 0,81 \\
& 2,11 & 1,87 & 2,02 & 1,54 \\
& 0,83 & 1,30 & 1,44 & 0,83 \\
& 1,99 & 2,33 & 1,96 & 1,77 \\
& 0,97 & 0,72 & 0,87 & 0,65 \\
& 1,90 & 1,08 & 1,31 & 1,36 \\
& 1,70 & 1,76 & 1,89 & 0,86 \\
\hline
\end{tabular}


Tabela 9 - Médias de rugosidade de superfície de cimento de ionômero de vidro submetido a inumação e afogamento, após cada um dos tempos testados.

\begin{tabular}{ccccc}
\hline Agente & Baseline & 1 mês & 3 meses & 6 meses \\
\hline \multirow{6}{*}{ Terra } & 1,46 & 2,28 & 1,84 & 2,05 \\
& 1,30 & 2,26 & 1,66 & 1,58 \\
& 0,82 & 0,89 & 1,04 & 1,14 \\
& 2,08 & 2,39 & 2,30 & 1,78 \\
& 0,80 & 1,34 & 2,01 & 1,69 \\
& 1,15 & 1,19 & 1,78 & 1,71 \\
& 1,35 & 0,89 & 0,84 & 0,87 \\
& 1,03 & 0,75 & 1,05 & 1,05 \\
& 1,37 & 3,19 & 3,01 & 3,26 \\
Água & 0,95 & 1,15 & 1,63 & 1,07 \\
\hline & 2,09 & 2,70 & 1,35 & 1,34 \\
& 1,60 & 1,78 & 1,70 & 1,39 \\
& 1,11 & 0,71 & 0,79 & 1,00 \\
& 1,13 & 1,49 & 1,50 & 1,30 \\
& 1,32 & 1,31 & 1,39 & 1,61 \\
& 1,15 & 1,23 & 1,25 & 1,31 \\
& 1,25 & 1,35 & 1,18 & 1,29 \\
& 0,93 & 1,13 & 1,03 & 1,59 \\
& 0,66 & 1,49 & 1,41 & 1,36 \\
& 1,43 & 1,33 & 1,40 & 1,46 \\
\hline
\end{tabular}


Tabela 10 - Médias de rugosidade de superfície de amálgama submetido a inumação e afogamento, após cada um dos tempos testados.

\begin{tabular}{ccccc}
\hline Agente & Baseline & 1 mês & 3 meses & 6 meses \\
\hline & 2,12 & 2,73 & 2,50 & 2,27 \\
& 1,43 & 1,73 & 1,92 & 1,47 \\
& 1,76 & 1,26 & 1,73 & 1,31 \\
& 1,32 & 1,31 & 1,27 & 1,43 \\
Terra & 1,76 & 1,57 & 1,56 & 1,90 \\
& 1,63 & 1,81 & 1,38 & 1,90 \\
& 1,44 & 1,63 & 1,68 & 1,57 \\
& 1,82 & 1,17 & 1,50 & 1,44 \\
& 3,04 & 2,32 & 2,33 & 2,28 \\
& 1,81 & 1,86 & 1,94 & 2,40 \\
\hline \multirow{6}{*}{ Água } & 1,41 & 1,39 & 1,29 & 1,14 \\
& 1,48 & 1,44 & 1,49 & 1,58 \\
& 1,50 & 1,18 & 1,15 & 1,12 \\
& 2,75 & 2,23 & 2,30 & 2,30 \\
& 2,06 & 2,14 & 2,05 & 1,97 \\
& 1,96 & 1,87 & 1,65 & 1,64 \\
& 1,28 & 1,98 & 1,55 & 1,92 \\
& 1,55 & 2,00 & 2,12 & 1,33 \\
& 1,84 & 1,69 & 1,87 & 1,60 \\
& 1,79 & 1,77 & 1,93 & 1,73 \\
\hline
\end{tabular}

A comparação das médias de rugosidade é apresentada na Tabela 11 e Figuras 38 e 39.

Tabela 11 - Comparação das médias de rugosidade de superfície (desvio padrão) analisadas segundo 3-way ANOVA, Bonferroni, $\mathrm{p}<0,05$.

\begin{tabular}{c|c|c|c}
\hline Material & Tempo & Terra & Água \\
\hline \multirow{4}{*}{ Resina } & Baseline & $1,50 \pm 0,76^{\mathrm{aA}}$ & $1,57 \pm 0,61^{\mathrm{aA}}$ \\
& 1 mês & $1,42 \pm 0,45^{\mathrm{aA}}$ & $1,45 \pm 0,53^{\mathrm{aA}}$ \\
& 3 meses & $1,29 \pm 0,32^{\mathrm{aA}}$ & $1,56 \pm 0,49^{\mathrm{aA}}$ \\
& 6 meses & $1,42 \pm 0,45^{\mathrm{aA}}$ & $1,28 \pm 0,46^{\mathrm{aA}}$ \\
\hline \multirow{3}{*}{ CIV } & Baseline & $1,23 \pm 0,38^{\mathrm{aA}}$ & $1,27 \pm 0,39^{\mathrm{aA}}$ \\
& 1 mês & $1,63 \pm 0,83^{\mathrm{aA}}$ & $1,45 \pm 0,52^{\text {aA }}$ \\
& 3 meses & $1,72 \pm 0,65^{\text {aA }}$ & $1,30 \pm 0,26^{\text {aA }}$ \\
& 6 meses & $1,62 \pm 0,70^{\text {aA }}$ & $1,36 \pm 0,17^{\text {aA }}$ \\
\hline \multirow{3}{*}{ Amálgama } & Baseline & $1,81 \pm 0,49^{\text {aA }}$ & $1,76 \pm 0,43^{\text {aA }}$ \\
& 1 mês & $1,74 \pm 0,49^{\text {aA }}$ & $1,77 \pm 0,34^{\text {aA }}$ \\
& 3 meses & $1,78 \pm 0,40^{\text {aA }}$ & $1,74 \pm 0,38^{\text {aA }}$ \\
& 6 meses & $1,80 \pm 0,41^{\text {aA }}$ & $1,63 \pm 0,37^{\text {aA }}$ \\
\hline
\end{tabular}

Para todas as comparações, em linhas e colunas para cada material, não houve diferença estatisticamente significante $(\mathrm{p}>0,05)$. 
Figura 38 - Representação gráfica da comparação de rugosidade de superfície entre materiais estéticos (resina e CIV) submetidos a inumação.

Terra

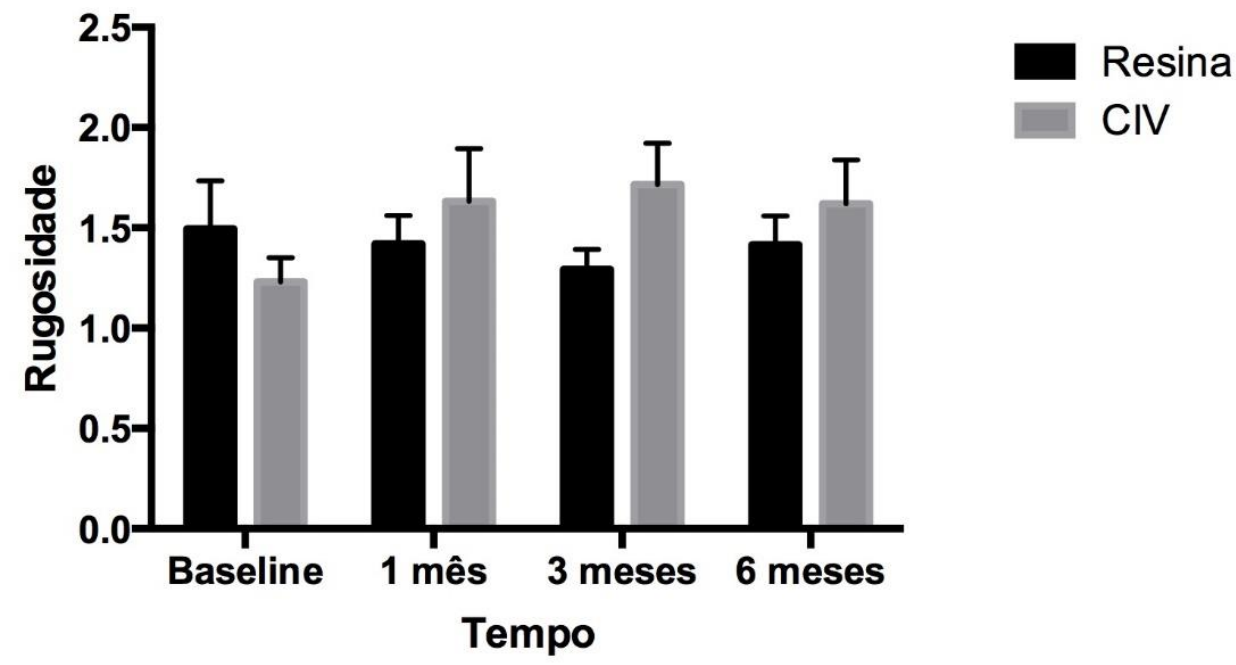

Para todas as comparações, $\mathrm{p}>0,05$.

Figura 39 - Representação gráfica da comparação de rugosidade de superfície entre materiais estéticos (resina e CIV) submetidos a afogamento.

\section{Água}

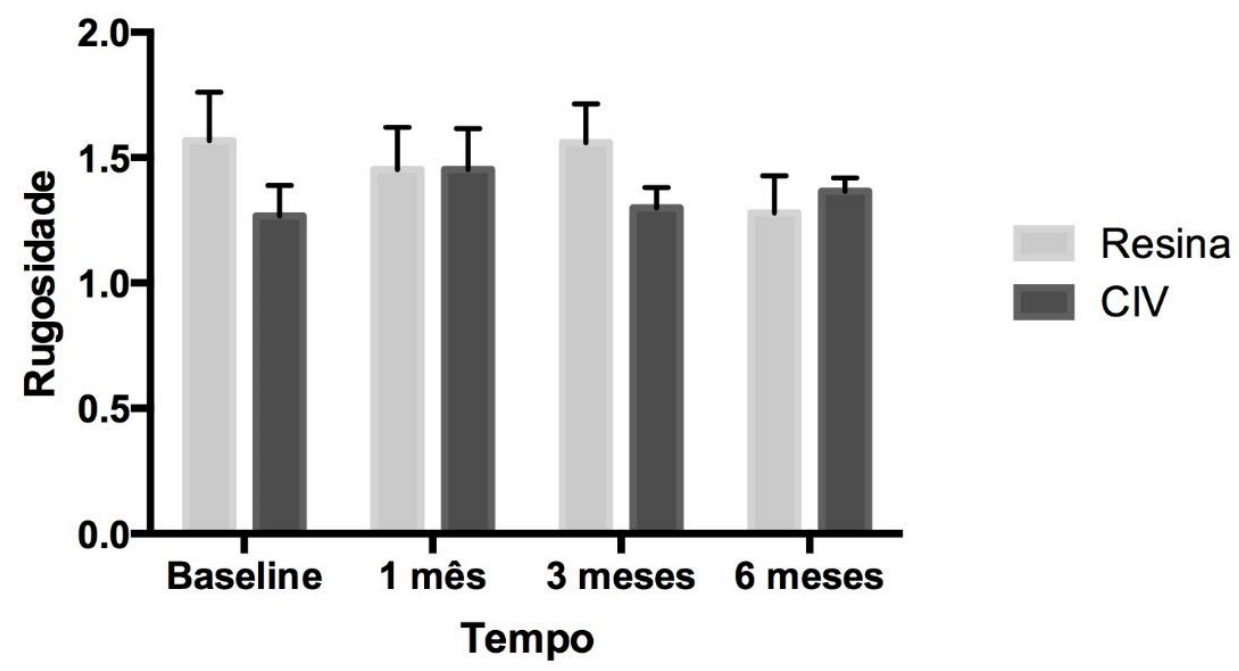

Para todas as comparações, $\mathrm{p}>0,05$.

Não houve diferença estatisticamente significante $(\mathrm{p}>0,05)$ entre as médias de rugosidade obtidas, em nenhum tempo experimental, nem entre as condições ambientais a que as amostras foram submetidas. 


\subsection{Microdureza}

Os valores médios de 3 leituras de microdureza Knoop (KHN), para cada tipo de material, após cada tempo experimental, são apresentados nas tabelas 12, 13 e 14. As médias de microdureza para os materiais estéticos foram analisadas estatisticamente segundo 3-way ANOVA (fatores de variação: material, tempo e condição ambiental), medidas repetidas, teste de Bonferroni, com nível de significância de 95\%. Para o amálgama, as médias foram analisadas estatisticamente segundo 2-way ANOVA, medidas repetidas (fatores de variação: tempo e condição ambiental), teste de Bonferroni, com nível de significância de $95 \%$.

Tabela 12 - Médias de microdureza Knoop de resina composta submetida a inumação e afogamento, após cada um dos tempos testados.

\begin{tabular}{ccccc}
\hline Agente & Baseline & 1 mês & 3 meses & 6 meses \\
\hline \multirow{6}{*}{ Terra } & 61,60 & 91,40 & 45,63 & 38,97 \\
& 76,67 & 75,20 & 71,77 & 82,63 \\
& 72,57 & 74,33 & 68,87 & 63,83 \\
& 78,83 & 92,97 & 80,37 & 91,37 \\
& 66,37 & 86,33 & 87,53 & 72,43 \\
& 68,20 & 99,07 & 68,93 & 74,73 \\
& 78,83 & 83,13 & 71,67 & 75,47 \\
& 92,77 & 106,57 & 74,90 & 54,93 \\
& 83,93 & 88,87 & 105,93 & 86,37 \\
Água & 63,70 & 84,57 & 109,87 & 76,63 \\
\hline & 88,57 & 86,70 & 75,10 & 69,13 \\
& 75,63 & 88,93 & 84,53 & 71,87 \\
& 68,23 & 82,77 & 79,43 & 78,33 \\
& 59,33 & 78,27 & 73,53 & 72,10 \\
& 73,77 & 87,33 & 90,57 & 74,87 \\
& 75,00 & 70,87 & 83,10 & 82,30 \\
& 62,00 & 58,50 & 86,63 & 77,13 \\
& 55,77 & 65,07 & 85,43 & 73,60 \\
& 80,40 & 83,37 & 85,43 & 83,27 \\
& 71,30 & 77,97 & 74,43 & 80,70 \\
\hline
\end{tabular}


Tabela 13 - Médias de microdureza Knoop de cimento de ionômero de vidro submetido a inumação e afogamento, após cada um dos tempos testados.

\begin{tabular}{ccccc}
\hline Agente & Baseline & 1 mês & 3 meses & 6 meses \\
\hline \multirow{5}{*}{ Terra } & 0,66 & 1,65 & 3,01 & 5,44 \\
& 1,03 & 3,51 & 4,40 & 7,00 \\
& 0,71 & 3,61 & 4,77 & 5,20 \\
& 0,68 & 1,38 & 3,96 & 7,36 \\
& 0,66 & 2,31 & 4,74 & 5,70 \\
& 1,71 & 4,63 & 6,66 & 9,46 \\
& 1,30 & 5,71 & 7,88 & 9,30 \\
& 0,94 & 2,35 & 3,64 & 5,93 \\
Água & 0,59 & 3,07 & 3,59 & 5,02 \\
& 1,16 & 2,85 & 3,88 & 8,32 \\
\hline & 0,48 & 2,17 & 4,85 & 3,09 \\
& 1,07 & 3,16 & 6,03 & 8,10 \\
& 1,03 & 4,47 & 7,43 & 5,83 \\
& 1,07 & 7,09 & 7,64 & 5,95 \\
& 1,15 & 3,23 & 6,63 & 9,66 \\
& 0,51 & 2,58 & 5,14 & 6,64 \\
& 1,09 & 6,02 & 6,53 & 4,16 \\
& 0,55 & 2,75 & 6,37 & 4,37 \\
& 3,05 & 4,80 & 6,85 & 9,92 \\
& 0,88 & 2,50 & 6,05 & 5,78 \\
\hline
\end{tabular}


Tabela 14 - Médias de microdureza Knoop de amálgama submetido a inumação e afogamento, após cada um dos tempos testados.

\begin{tabular}{ccccc}
\hline Agente & Baseline & 1 mês & 3 meses & 6 meses \\
\hline & 123,23 & 152,67 & 141,33 & 115,13 \\
& 136,33 & 179,00 & 142,67 & 134,33 \\
& 172,67 & 187,00 & 178,33 & 159,67 \\
& 167,67 & 156,67 & 172,00 & 145,33 \\
Terra & 117,67 & 163,00 & 186,67 & 188,33 \\
& 167,67 & 161,00 & 171,33 & 162,67 \\
& 143,67 & 170,33 & 175,67 & 152,33 \\
& 135,00 & 167,67 & 158,33 & 143,67 \\
& 180,33 & 161,00 & 145,00 & 153,00 \\
& 123,67 & 100,37 & 116,67 & 150,00 \\
\hline \multirow{5}{*}{ Água } & 107,10 & 149,67 & 166,67 & 217,33 \\
& 164,00 & 199,00 & 188,00 & 223,33 \\
& 124,00 & 149,00 & 159,00 & 155,00 \\
& 122,47 & 192,67 & 179,33 & 163,47 \\
& 125,67 & 151,33 & 201,67 & 157,10 \\
& 100,63 & 167,67 & 149,00 & 155,67 \\
& 106,67 & 109,73 & 169,83 & 175,60 \\
& 167,00 & 158,33 & 170,67 & 213,67 \\
& 123,00 & 167,67 & 170,33 & 170,67 \\
& 95,67 & 111,63 & 132,33 & 128,70 \\
\hline
\end{tabular}

A comparação das médias de microdureza Knoop é apresentada na Tabela 15 e Figuras 40 e 41.

Tabela 15 - Comparação das médias de microdureza Knoop (KHN) (desvio padrão), analisados segundo 3-way ANOVA, Bonferroni, $\mathrm{p}<0,05$, para mesmo material - comparação entre os agentes e o tempo.

\begin{tabular}{c|c|c|c}
\hline Material & Tempo & Terra & Água \\
\hline \multirow{3}{*}{ Resina } & Baseline & $74,35 \pm 9,76^{\mathrm{aA}}$ & $71,00 \pm 9,99^{\mathrm{aA}}$ \\
& 1 mês & $88,24 \pm 9,96^{\mathrm{aA}}$ & $77,98 \pm 10,18^{\mathrm{aA}}$ \\
& 3 meses & $78,55 \pm 18,83^{\mathrm{aA}}$ & $81,82 \pm 5,86^{\mathrm{aA}}$ \\
& 6 meses & $71,74 \pm 15,58^{\mathrm{aA}}$ & $76,33 \pm 4,79^{\mathrm{aA}}$ \\
\hline \multirow{3}{*}{ CIV } & Baseline & $0,94 \pm 0,36^{\mathrm{aA}}$ & $1,09 \pm 0,74^{\mathrm{aA}}$ \\
& 1 mês & $3,11 \pm 1,33^{\mathrm{aA}}$ & $3,88 \pm 1,66^{\mathrm{aA}}$ \\
& 3 meses & $4,65 \pm 1,51^{\mathrm{bA}}$ & $6,35 \pm 0,89^{\mathrm{aA}}$ \\
& 6 meses & $6,87 \pm 1,68^{\text {aA }}$ & $6,35 \pm 2,28^{\text {aA }}$ \\
\hline \multirow{2}{*}{ Amálgama } & Baseline & $146,79 \pm 23,24^{\mathrm{aA}}$ & $123,62 \pm 24,47^{\mathrm{aC}}$ \\
& 1 mês & $159,87 \pm 23,30^{\mathrm{aA}}$ & $155,67 \pm 29,23^{\mathrm{aB}}$ \\
& 3 meses & $158,80 \pm 21,87^{\mathrm{aA}}$ & $168,68 \pm 19,41^{\mathrm{aAB}}$ \\
& 6 meses & $150,45 \pm 19,03^{\mathrm{aA}}$ & $176,05 \pm 31,63^{\mathrm{aA}}$ \\
\hline
\end{tabular}

Letras diferentes, minúsculas na linha e maiúsculas na coluna, para cada material, indicam diferença estatisticamente significante $(\mathrm{p}<0,05)$. 
Não houve alteração significante $(p>0,05)$ entre a microdureza dos materiais estéticos, independente do agente e do tempo a que esses materiais foram submetidos, com exceção do CIV após 3 meses, que apresentou maior microdureza após afogamento, quando comparado a inumação $(\mathrm{p}<0,05)$.

Quanto ao amálgama, não houve diferença significativa $(p>0,05)$ na microdureza quando o material foi submetido à inumação, em qualquer um dos tempos analisados e também não houve alteração em relação ao afogamento $(p>0,05)$. Entretanto, quando submetido a essa última condição, a média de microdureza inicial (baseline) foi menor $(\mathrm{p}<0,05)$ que as encontradas após a colocação em condições de afogamento, nos diferentes tempos testados.

Após 1 mês, houve aumento na microdureza do material, semelhante $(\mathrm{p}>0,05)$ às médias encontradas após 3 meses. Porém, após 6 meses submetido a afogamento, o amálgama apresentou as maiores médias de microdureza, diferente estatisticamente $(\mathrm{p}<0,05)$ de baseline e 1 mês de afogamento.

Figura 40 - Representação gráfica da comparação de microdureza entre materiais estéticos (resina e CIV) submetidos a inumação.

\section{Terra}

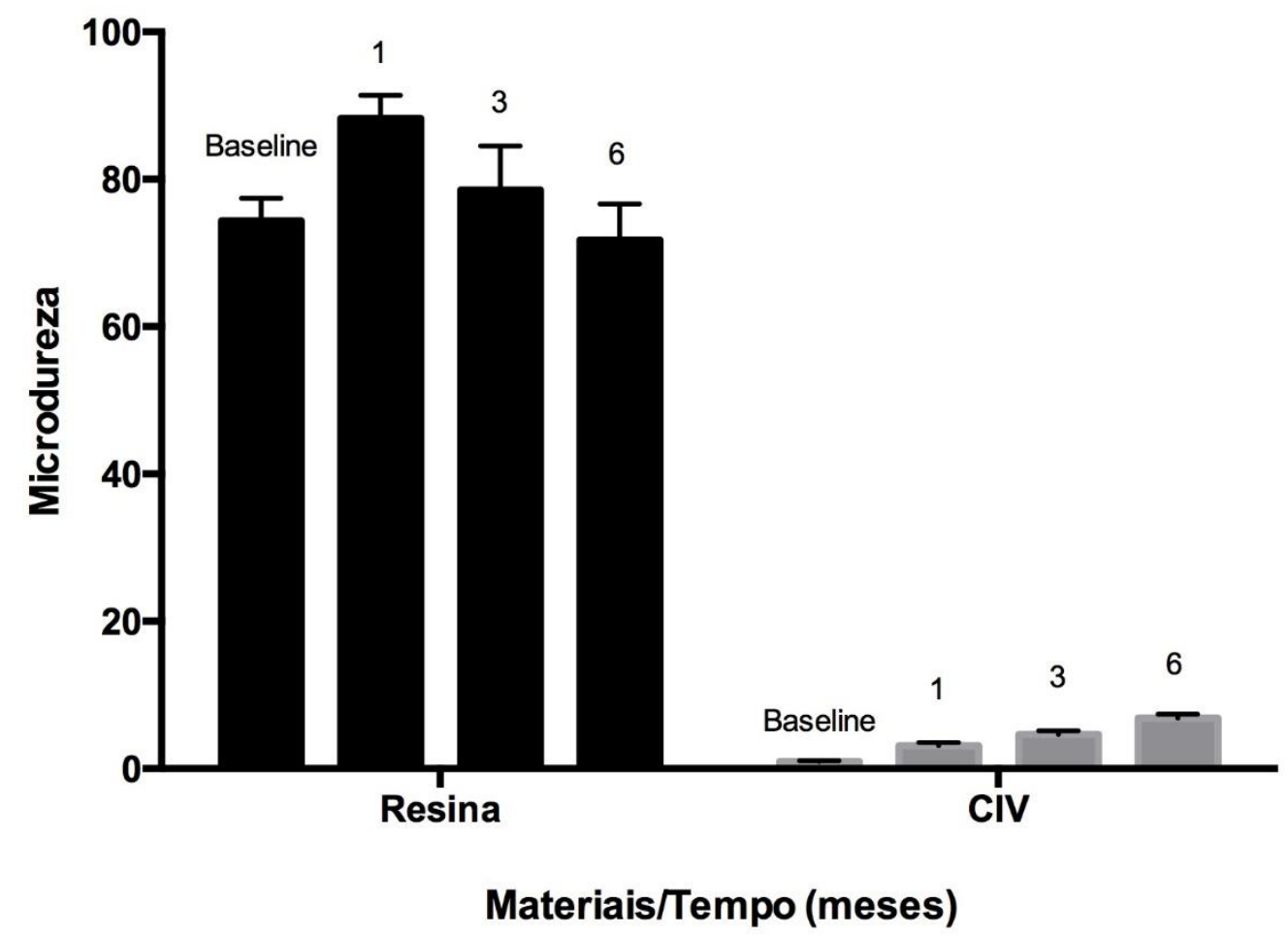

Para todas as comparações, entre os materiais, $\mathrm{p}<0,05$. 
Figura 41 - Representação gráfica da comparação de microdureza entre materiais estéticos (resina e CIV) submetidos a afogamento.

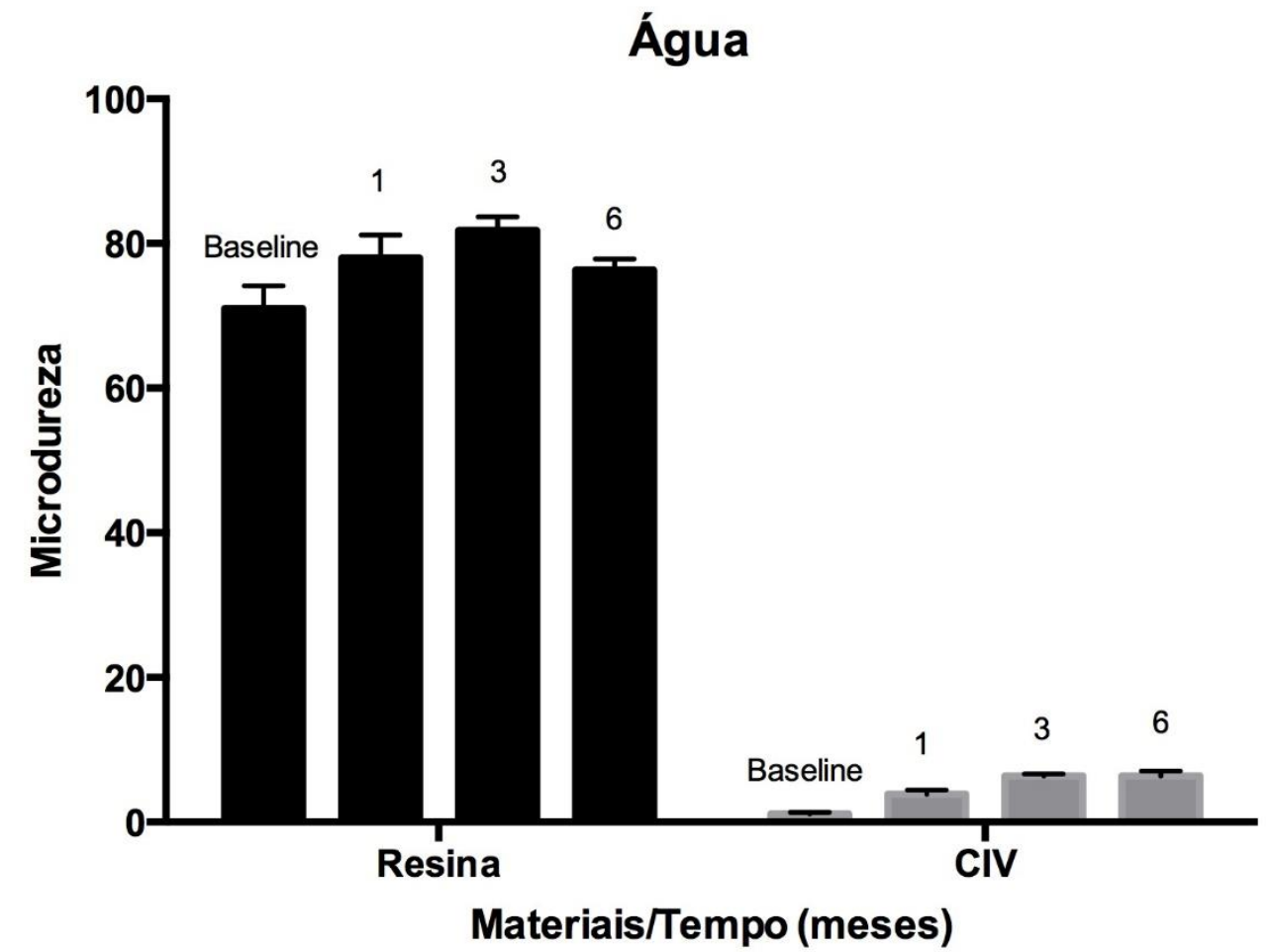

Para todas as comparações, entre os materiais, $\mathrm{p}<0,05$.

É sabido que a microdureza da resina composta é maior do que a do CIV $^{55-57}$. Assim, houve diferença significativa $(\mathrm{p}<0,05)$ entre os materiais, para todos os tempos estudados e agentes a que foram submetidos. Entretanto, não houve diferença significativa ( $p>0,05)$ quando comparados o mesmo material em diferentes tempos de ação dos agentes testados.

\subsection{Análise visual}

As fotografias obtidas, representativas de cada grupo, antes e após a submissão aos testes propostos, podem ser observadas nas figuras 42 e 43 . 
Figura 42 - Comparação visual das restaurações (resina composta, cimento de ionômero de vidro e amálgama de prata, de cima para baixo), submetidas a inumação, nos tempos referidos.

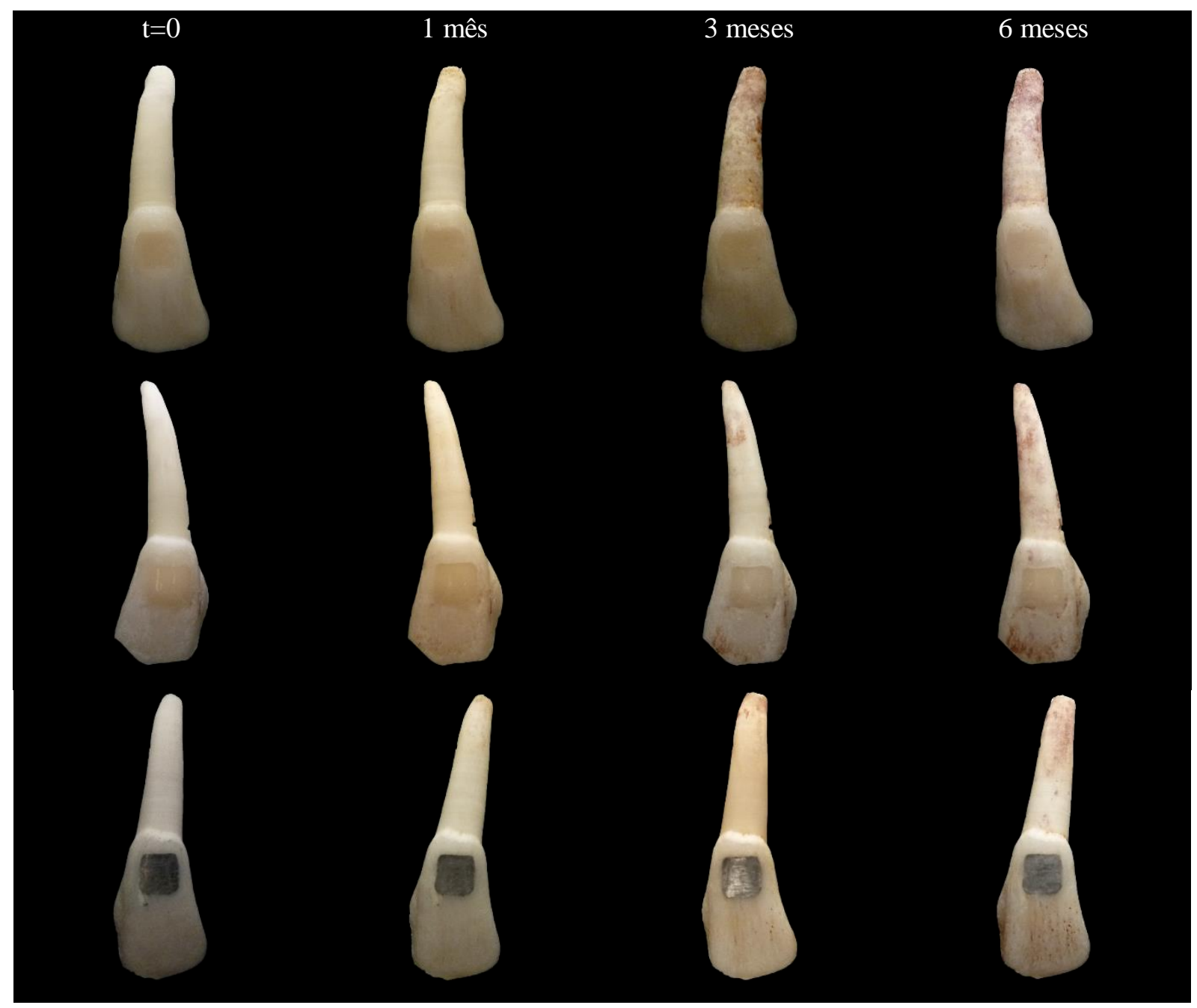

Considerando a alteração de cor da Resina Composta submetida a inumação, por meio da análise visual, verificou-se alteração após 1 mês sob a ação do agente, e se manteve estável após 3 meses. Entretanto, após 6 meses, verificou-se nova alteração significativa de cor.

Quanto ao CIV, apesar de uma perceptível perda de brilho após o primeiro mês sob ação do agente, as maiores alterações de cor puderam ser verificadas após 3 meses, e se mantiveram até 6 meses após a inumação.

O amálgama não foi analisado, instrumentalmente, no aspecto de alteração de cor. Mas, por meio da análise visual, observou-se significativa perda de brilho após 1 e 6 meses sob a ação do agente. 
Figura 43 - Comparação visual das restaurações (resina composta, cimento de ionômero de vidro e amálgama de prata, de cima para baixo), submetidas a afogamento, nos tempos referidos.

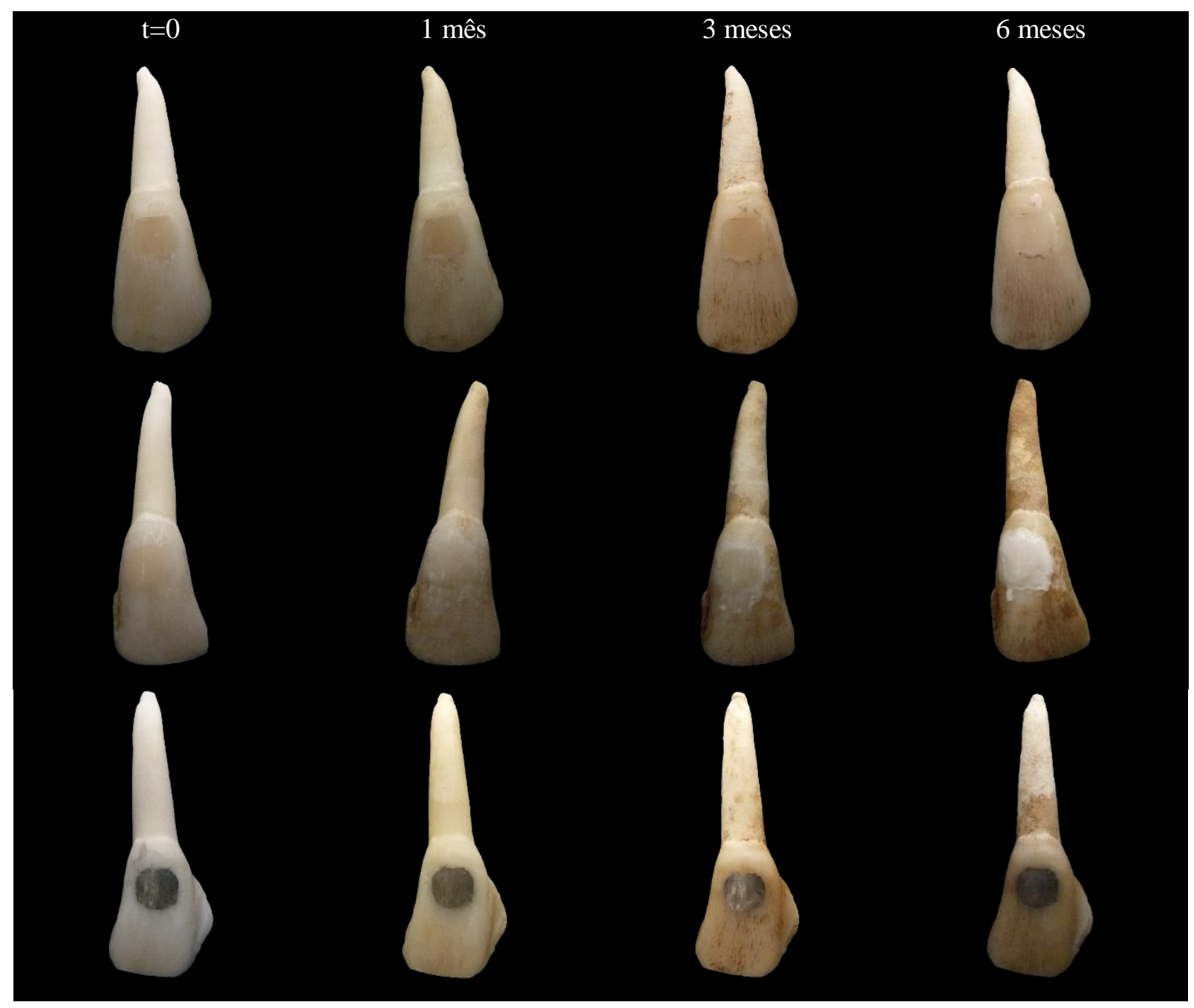

É nítida a maior alteração de cor dos dentes quando submetidos a afogamento, em relação à inumação. Percebe-se maior manchamento da estrutura dental por completo, principalmente da região coronária. A Resina Composta submetida ao afogamento, por meio da análise visual, apresentou significativa alteração de cor após 1 mês sob a ação do agente, se mantendo estável após 3 meses. Mas a maior alteração de cor foi verificada após 6 meses, apresentando-se muito mais clara em relação aos outros tempos analisados.

Quanto ao CIV, verificou-se um constante escurecimento após 1 e 3 meses sob a ação do agente, mas a maior alteração de cor foi observada após 6 meses. A restauração se apresentou significativamente esbranquiçada.

A alteração de cor do amálgama não foi analisada instrumentalmente, mas a análise visual permitiu a observação de significativa perda de brilho após 1 e 6 meses sob a ação do agente, além de significativo escurecimento após 6 meses. 



$$
\text { 5. Discusaria }
$$





\section{DISCUSSÃO}

Este trabalho teve por objetivo avaliar o efeito da terra e da água, a partir da simulação de situações de inumação e afogamento, sobre a estabilidade de cor, a rugosidade de superfície e a microdureza dos materiais restauradores odontológicos mais utilizados, ou seja, a resina composta, o cimento de ionômero de vidro e o amálgama de prata, não necessariamente nessa ordem. Para isso, partiu da hipótese nula que esses agentes não produziriam alterações em nenhuma das propriedades dos materiais, qualquer que fosse o tempo estudado; e que as diferenças entre os materiais permitiriam a diferenciação entre eles. Os resultados demonstraram que a hipótese nula não pode ser aceita, uma vez que o tempo foi fator significante para as alterações de cor dos materiais restauradores estéticos e para a microdureza do amálgama de prata. A segunda hipótese, entretanto, pode ser aceita parcialmente, uma vez que em alguns tempos estudados, não houve diferença significante ( $p>0,05)$ na alteração de cor entre os materiais estéticos, mas as diferenças $(\mathrm{p}<0,05)$ na microdureza seriam capazes de diferenciar os materiais para possível identificação. Além disso, não houve diferença estatisticamente significante $(p>0,05)$ na rugosidade de superfície entre os materiais.

É sabido que o fundo (background) sobre o qual é realizada a medição instrumental ${ }^{58}$, 59, assim como o tipo de subestrutura de uma restauração em material translucente ${ }^{60-62}$, interferem na leitura de cor. Assim, o presente estudo selecionou como substrato, para a realização das restaurações, dentes bovinos extraídos.

Os dentes bovinos foram obtidos, em detrimento aos dentes humanos, por causa da maior facilidade de obtenção e pela viabilidade de realização de preparos odontológicos, diretamente relacionada com as similaridades apresentadas entre os tecidos duros principalmente esmalte - existentes nos elementos dentais das duas espécies ${ }^{63,64}$. A composição do esmalte é muito similar entre ambos: orientação dos prismas muito semelhante; porcentagem, em peso, de cálcio equivalente, com uma gradual diminuição à medida que se aproxima da junção amelodentinária; matriz proteica composta pelos mesmos aminoácidos ${ }^{63}$. Quanto à dentina, na profundidade utilizada neste estudo, que foi de $2 \mathrm{~mm}$, sua resistência adesiva é semelhante à dentina humana, podendo, então, ser utilizada em estudos laboratoriais ${ }^{64}$. Assim, foi possível a realização de preparos cavitários com resistências, em suas paredes, próximas às apresentadas pelo dente humano. 
Ainda, foram propiciadas condições desejáveis para a execução de ataque ácido e aplicação de adesivo dentinário, nas restaurações em resina composta, e, também, para a adesividade com o cimento de ionômero de vidro.

Consequentemente, para a realização do presente estudo, não houve necessidade de submeter o projeto à Comissão de Ética no uso de Animais (CEA) da Faculdade de Odontologia de Ribeirão Preto, da Universidade de São Paulo (FORP/USP), uma vez que as amostras obtidas foram compostas por dentes bovinos obtidos em frigoríficos, em caráter de doação, após o abate dos animais para outros fins.

A alteração de cor foi determinada por meio de um espectrofotômetro, a fim de eliminar avaliações subjetivas e erros de interpretação de $\operatorname{cor}^{65}$, uma vez que os instrumentos são mais exatos que os olhos, na verificação de pequenas alterações de cor, devido à inerente percepção inconsistente de cor dos observadores ${ }^{66-69}$. Os instrumentos fazem-se, assim, precisos e confiáveis para análise de cor em estudos de materiais dentários ${ }^{70}$.

O diâmetro da ponteira do aparelho espectrofotômetro é de 6,0 mm, ou seja, a mesma dimensão das paredes do preparo cavitário, permitindo ao aparelho um perfeito posicionamento para a realização da leitura da superfície das restaurações e registro do espectro de cor L*a*b* (Figura 18). Mas o diâmetro efetivo do leitor é de 5,0 mm, o que significa que a leitura é segura e foi realizada somente dentro do espaço ocupado pelo material restaurador, não havendo possibilidade de o material ter sido lido fora da margem da restauração.

\subsection{Alteração de cor}

No estudo da alteração de cor, há três intervalos de valores de $\Delta \mathrm{E}$ que são importantes para análise da estabilidade de cor do compósito ${ }^{71-73}$ :

- $\Delta \mathrm{E}<1$ - alteração de cor não detectada pelo olho humano;

- $1 \leq \Delta \mathrm{E} \leq 3,3$ - alteração de cor detectada pelo olho humano e considerada clinicamente aceitável;

- $\Delta \mathrm{E}>3,3$ - alteração de cor detectada pelo olho humano e considerada clinicamente inaceitável, sendo indicada a substituição do material restaurador por motivos estéticos.

Considerando os resultados encontrados no presente estudo, verificou-se que as resinas compostas apresentaram níveis de alteração de cor entre "clinicamente aceitável” (após 1 e 3 
meses de inumação e 3 meses de afogamento) e "clinicamente inaceitável" (para as demais situações), o mesmo ocorrendo para o CIV, entretanto com menor prevalência para os níveis “clinicamente aceitáveis", condição encontrada somente após 1 mês de inumação. Para todas as outras situações e tempos testados, os níveis encontrados para CIV foram "clinicamente inaceitáveis".

As resinas compostas apresentam basicamente três componentes principais em sua composição: a) matriz resinosa; b) partículas de cargas inorgânicas, adicionadas com o objetivo de melhorar a estabilidade dimensional e reduzir a contração de polimerização; e c) agente de união, responsável pela união das partículas de cargas à matriz resinosa. Além desses componentes, apresentam um sistema ativador-iniciador, que atua na conversão dos monômeros em polímeros, gerando um material com maior resistência e durabilidade ${ }^{37,56}$.

Os principais compósitos existentes no mercado odontológico têm como base os monômeros metacrilatos, sendo o principal deles o Bis-GMA (bisfenol glicidil metacrilato). Sua utilização é relatada desde os primórdios das resinas compostas ${ }^{74}$. A Filtek ${ }^{\mathrm{TM}} \mathrm{Z} 350 \mathrm{XT}$, utilizada neste estudo, contém Bis-GMA, UDMA, TEGDMA, e Bis-EMA ${ }^{75}$.

Diferenças na estrutura química de compósitos - tipo de oligômeros ou monômeros utilizados, concentração e tipo de ativadores, iniciadores, inibidores na composição, o número de ligações duplas de carbono, tamanho e sistema de união entre adesivo e compósito - podem interferir em sua estabilidade de $\operatorname{cor}^{76}$.

A composição da matriz resinosa também pode ter influência na estabilidade de cor dos compósitos $^{77}$. A matriz resinosa ou mesmo interface matriz/partículas são suscetíveis à penetração de água ${ }^{78}$, que está associada à descoloração do compósito, de maneira que, quanto maior a porcentagem de matriz resinosa em sua composição, maior a possibilidade de alteração de $\operatorname{cor}^{79}$.

No presente estudo, essa alteração de cor associada à descoloração do compósito pôde ser verificada, pela análise das coordenadas que definem a cor $\left(L^{*}, a^{*}\right.$ e $\left.b^{*}\right)$, cujas diferenças serão discutidas posteriormente.

A composição da matriz resinosa pode, também, influenciar na sorção de água, pois o monômero TEGDMA absorve mais água que o monômero UDMA ${ }^{80}$, que, por sua vez, a absorve menos água que o monômero Bis-GMA ${ }^{81}$. A maior predisposição do monômero TEGDMA à absorção de água aumenta a solubilidade do polímero formado ${ }^{82}$, proporcionando 
a esses compósitos menor estabilidade de cor, quando combinados os monômeros Bis-GMA e TEGDMA, devido ao aumento do volume livre do polímero formado, e, consequentemente, a um maior espaço para as moléculas de água se difundirem no interior da estrutura polimérica ${ }^{83}$. Esse fenômeno é chamado de "plasticização" do compósito ${ }^{84}$.

Ferracane e colaboradores $(1998)^{84}$ avaliaram a ação do envelhecimento em água sobre as propriedades dos compósitos e concluíram que a degradação desses materiais em meio aquoso é limitada. Ou seja, uma vez que a rede polimérica está saturada pelo meio, a estrutura do compósito atinge uma estabilidade e não mais ocorre redução nas propriedades físicomecânicas, nem, consequentemente, degradação da interface partícula-matriz e da própria matriz polimérica, mesmo com o aumento do tempo de envelhecimento.

Os monômeros presentes na matriz resinosa são geralmente líquidos, que se solidificam durante o processo de polimerização. A extensão na qual ocorre esse processo é chamada grau de conversão, que é a medida percentual de ligações duplas de carbono consumidas durante o processo de polimerização, servindo como parâmetro indicativo da qualidade de polimerização do material ${ }^{85,86}$. UDMA e Bis-EMA são resinas com maior peso molecular do que TEGDMA e, portanto, apresentam menos ligações duplas por unidade de peso ${ }^{75}$. A presença de UDMA poderia resultar em maior e mais rápida conversão do monômero e, consequentemente, maior estabilidade ${ }^{87}$.

No presente estudo, a maior alteração de cor ocorre em 1 mês porque o material está mais suscetível à sorção de água e corantes, devido ao menor grau de conversão. Com o passar do tempo, aliado à conversão contínua dos monômeros, a alteração é menor em 3 meses, pois há uma "estabilização" dessa alteração. Após 6 meses, há um novo aumento, sugerindo que há uma alteração de cor intrínseca dos materiais. Esse mesmo padrão de alteração foi verificado nas três coordenadas que compõem o espectro CIE L*a*b*.

Os cimentos de ionômero de vidro (CIVs) são biomateriais comumente utilizados na clínica odontológica, caraterizados por uma reação ácido-base entre uma solução aquosa de ácido poliacrílico e pó de partículas de vidro de fluoraminosilicato de cálcio, resultando na formação de um sal - o polialceonoato de vidro. São materiais que se destacam devido às suas propriedades de adesão à estrutura dental e aos metais, propriedades anticariogênicas decorrentes da liberação de flúor, coeficiente de expansão térmica similar à estrutura dental e biocompatibilidade. Suas limitações de uso clínico estão relacionadas às suas propriedades mecânicas, ou seja, a resistência mecânica desse material é inferior quando comparado com 
resina composta e amálgama. Apresenta também como característica negativa uma lenta reação de $\operatorname{presa}^{56,88}$.

Outra limitação apresentada pelos CIVs é a sensibilidade inicial à perda e ganho de água, fenômenos conhecidos respectivamente como sinérese e embebição ${ }^{89}$. A suscetibilidade à perda de água é grande, mesmo após as primeiras 24 horas, período no qual o material apresenta maior resistência devido à maturação do cimento estar avançada. Com a finalidade de proteger esses cimentos, são utilizados vernizes próprios dos materiais e resinas fluidas (agentes adesivos). Recentemente foi demonstrado que o esmalte de unhas incolor apresentou o melhor desempenho na proteção superficial do CIV durante a presa ${ }^{90}$, fato que justificou o uso do mesmo no presente estudo, mesmo sabendo que os selantes de superfície também são passíveis de sofrer alterações, podendo, assim, perder efetividade na manutenção da cor dos materiais por ele protegidos ${ }^{45,91}$.

Assim, o CIV pode estar mais suscetível à embebição causada pelo afogamento do que ao manchamento intrínseco causado pela inumação. Essa característica foi confirmada pelo presente estudo, uma vez que a maior alteração de cor foi verificada quando o CIV foi submetido a afogamento, após 6 meses. Quando submetido a inumação, não houve diferença na alteração de cor, para nenhum dos tempos testados.

A comparação das coordenadas de cor $\left(\mathrm{L}^{*}, \mathrm{a}^{*}\right.$ e $\left.\mathrm{b}^{*}\right)$ permite a análise de quais contribuíram para a alteração de cor total das amostras $(\Delta \mathrm{E})$. A coordenada $L^{*}$, que se refere à luminosidade da amostra, aumentou após inumação das resinas compostas, indicando que as restaurações, em qualquer dos tempos estudados, clarearam. Para o CIV, essa coordenada diminuiu após 3 meses, se mantendo após 6 meses o que indica perda de luminosidade e consequente "escurecimento" das restaurações.

$\mathrm{Na}$ água, ambos os materiais estéticos perderam luminosidade (“escureceram”) após 1 mês, sem diferença significante ( $p>0,05)$ entre eles. Porém, enquanto a resina composta ganhou luminosidade ("clareou") nos tempos seguintes, o CIV perdeu luminosidade, sendo estatisticamente significante após 6 meses. Esse resultado pode ser decorrente da suscetibilidade do CIV à embebição ${ }^{89}$, ou até mesmo por alterações ocorridas no esmalte protetor da superfície da restauração ${ }^{45,91}$.

Quanto à coordenada a*, que varia do matiz verde ao vermelho, após a ação dos agentes, houve aumento em seus valores, ou seja, uma maior saturação do matiz vermelho, sendo a 
alteração maior para resina do que para CIV, que estava protegido pelo esmalte em sua superfície. A saturação do vermelho pode ter ocorrido devido à própria cor da terra na região.

Em relação à coordenada b*, que varia do matiz azul ao amarelo, para a resina composta a alteração sempre foi positiva, independentemente do tipo de agente a que foi submetido, o que indica um "amarelamento" do material. Quanto ao CIV, nas duas condições, houve diminuição da coordenada a* nos tempos iniciais, significando uma diminuição da saturação da cor amarela presente no material restaurador; entretanto, após 6 meses, há significativo aumento na saturação do amarelo.

\subsection{Rugosidade de superfície}

A rugosidade de uma superfície é basicamente quantificada por parâmetros relacionados à altura (amplitude) e largura (espaçamento) das irregularidades ou por uma combinação desses atributos $^{92}$. A determinação da $\mathrm{Ra}$ (roughness average), empregando o rugosímetro para detectar alteração de superfície, é, graças a sua alta resolução, o sistema de maior fidelidade ${ }^{93}$. A forma geométrica da sua ponta ativa, cuja extremidade é de diamante, apresenta-se em formato de triângulo equilátero com $5 \mu \mathrm{m}$ de lado. Por meio do deslizamento da ponta apalpadora de diamante, as irregularidades de um determinado segmento da superfície, são registradas, devendo ser representativas do restante da superfície analisada. Ainda, nessa análise, a escolha de uma escala padrão de filtragem, denominada cut-off, deve ser aplicada, evitando que as irregularidades e possíveis ondulações de superfície se sobreponham, interferindo na análise final da rugosidade de superfície ${ }^{43}$.

O parâmetro Ra retrata a média da rugosidade avaliada, considerando-se picos e vales registrados na medida de extensão. Esse parâmetro limita-se à leitura horizontal ${ }^{53,94,95}$, porém, essa medição é largamente utilizada nesse tipo de análise ${ }^{96}$ e foi adotada neste estudo para proporcionar melhores condições comparativas a outros trabalhos semelhantes ${ }^{97-99}$.

Materiais restauradores que apresentam componentes inorgânicos em sua composição podem sofrer alterações superficiais, como as resinas compostas ${ }^{100}$ e os ionômeros de vidro ${ }^{101}$. A rugosidade de superfície da resina composta aumenta com o aumento do tamanho das partículas de carga que compõem o material e, também, com irregularidades dessas partículas $^{102,103}$. Comportamento semelhante apresenta o CIV, uma vez que o tamanho e a distribuição das partículas de carga presentes no material podem alterar a superfície de maneira significante ${ }^{48}$. As alterações de rugosidade também podem ocorrer devido à maior ou menor 
incorporação de água ${ }^{104,105}$, podendo provocar alterações superficiais com o decorrer do tempo, uma vez que eles apresentam alta suscetibilidade à sinérese e embebição ${ }^{89}$.

Embora a dissimilaridade na rugosidade de superfície e resistência à abrasão dos materiais possa ser principalmente atribuída a diferenças no tamanho e volume de partículas de carga, existem outros fatores em questão, como tipo de carga e grau de conversão da matriz polimérica $^{106}$.

Há consenso na literatura de que os ionômeros apresentam maior rugosidade de superfície do que as resinas compostas e os amálgamas ${ }^{49,106}$, por ser menos resistente à abrasão. A superfície da resina composta é mais lisa, sem irregularidades significativas, quando comparada com a do CIV, que apresenta certa rugosidade inerente ao material, em decorrência de partículas de vidro de forma irregular que normalmente estão expostas ${ }^{48,49}$. Além disso, porosidades são evidentes em todos os produtos que exigem mistura de pó e líquido para iniciarem uma reação de polimerização ${ }^{49}$. Porém, o fato de o presente estudo ter verificado maior rugosidade de superfície média no amálgama pode estar relacionado com a proteção superficial de esmalte nas restaurações de $\operatorname{CIV}^{107,108}$, regularizando sua superfície.

\subsection{Microdureza}

A dureza é uma das propriedades mais utilizadas para comparar os materiais restauradores. É uma propriedade mecânica definida como a mensuração da resistência à deformação permanente e é medida por meio da relação da força aplicada pela área de indentação. As dimensões das indentações variam inversamente com a resistência à penetração do material testado. Assim, são necessárias cargas mais leves para os materiais mais macios ${ }^{36}$.

O teste de microdureza utilizado neste estudo é o convencional, que mede a diagonal da marca deixada pelo indentador, após a remoção da carga. Ou seja, o valor da microdureza é mensurado pelo grau de deformação permanente produzido na superfície do material ensaiado pela força (carga) transmitida pelo indentador ${ }^{109}$. Foi utilizada a microdureza Knoop, modalidade escolhida por ser virtualmente independente da ductilidade do material testado, possibilitando a comparação entre as durezas dos diferentes materiais restauradores ${ }^{37}$.

O teste de avaliação de microdureza é um método indireto para avaliar o comportamento mecânico da polimerização das resinas compostas que está cada vez mais utilizada na Odontologia ${ }^{38,110,111}$. As partículas de carga presentes na composição de uma resina composta 
podem se apresentar em vários tamanhos, de $0,04 \mu \mathrm{m}$ a até $3 \mu \mathrm{m}$. Essas partículas são compostas de quartzo, sílica, lítio, bário, silicato, estrôncio, zinco e outros. Quanto mais preenchido o conteúdo da resina com partículas finas, maior a resistência para que a dureza Knoop não se recupere, após a remoção da carga ${ }^{36}$. Ou seja, quanto menor o volume livre entre as moléculas, menos espaço terá para gerar novas ligações químicas, portanto menor será a deformação permanente ${ }^{112}$.

A resina composta de nanopartículas Filtek ${ }^{\mathrm{TM}} \mathrm{Z} 350$ XT (3M ESPE $\left.{ }^{\circledR}\right)$, utilizada neste estudo, é constituída por nanoaglomerados obtidos por um processo de sinterização. As partículas de carga desses compósitos são uma combinação de sílica com tamanho de 20nm não-aglomeradas/não agregadas; zircônia com tamanho de 4-11nm não-aglomeradas/nãoagregadas e aglomerados de partículas agregadas de zircônia/sílica (combinação de partículas de sílica com 20nm e zircônia com 4-11 nm) $)^{75}$.

É sabido que a microdureza da resina composta é maior que a do $\operatorname{CIV}^{55,57}$. A diferença nos resultados de microdureza entre os dois grupos de materiais pode ser explicada pela sua diferença de composição. A dureza superficial mais elevada das resinas compostas está relacionada com a maneira como a matriz polimérica foi formada, sua densidade e microestrutura; são compósitos que apresentam grande heterogeneidade na sua superfície, com partículas de durezas distintas e, dessa forma, a microdureza varia de acordo com a dureza dessas partículas quando atingidas pelo indentador ${ }^{113-115}$. Isso explica porque, neste estudo, houve diferença significativa entre os materiais, para todos os tempos estudados e agentes a que foram submetidos, porém não houve diferença significativa quando comparado o mesmo material em diferentes tempos de ação dos agentes testados, ou seja, os agentes não são capazes de produzir alteração na microdureza dos materiais, independentemente do tempo testado.

O amálgama, apesar de não ser um material restaurador estético, ainda é utilizado na clínica e principalmente em serviços sociais, devido ao seu baixo custo, durabilidade e facilidade de manipulação ${ }^{116}$.

O amálgama utilizado neste estudo foi o gs-80 (SDI $\left.{ }^{\circledR}\right)$, pré-capsulado com partículas esféricas e com alto teor de cobre. Sua composição apresenta 40\% de prata, 31,3\% de estanho e $28,7 \%$ de cobre ${ }^{112}$. Os maiores valores de microdureza são obtidos nos amálgamas com alto teor de cobre, quando comparados ao amálgama convencional ${ }^{50,116,117}$.

Pelo menos em período inicial, a microdureza dos amálgamas é uma propriedade tempodependente $^{50}$. Ou seja, ela aumenta com o tempo, devido à reação de cristalização ${ }^{118}$. Após a 
cristalização inicial do material, quando se torna possível realizar a escultura do material, a reação de cristalização do amálgama continua $a^{50,118} \mathrm{e}$, com isso, há melhores propriedades mecânicas desse material, incluindo sua microdureza ${ }^{119}$. Os resultados do presente estudo confirmam esse fato, uma vez que, nos primeiros tempos estudados, foi pequeno o aumento de microdureza do amálgama, em ambas as condições a que foi submetido. Porém, após 6 meses submetidos a afogamento, ele apresentou as maiores médias de microdureza, diferente estatisticamente de baseline e 1 mês de afogamento.

Poucos são os estudos que relacionam a corrosão do amálgama com sua microdureza, e os achados são controversos. Enquanto alguns relataram não haver relação significativa entre corrosão e microdureza $^{120}$, outros demonstraram que a corrosão diminui a microdureza ${ }^{121}$. Entretanto, os dados do presente estudo contradizem esses achados. Isso pode ter ocorrido pois o tempo de estudo pode não ter sido suficiente para produzir corrosão do material metálico.

Uma das principais contribuições que o presente estudo pode oferecer aos serviços periciais, em relação à identificação humana, está relacionada com a possibilidade de diferenciar os materiais estéticos, quando presentes na cavidade bucal de cadáveres não identificados, que foram inumados ou encontrados na água. Essa eventual diferenciação pode auxiliar no confronto entre as informações ante mortem, contidas no prontuário odontológico do suspeito, se existente, com informações post mortem, colhidas e descritas pelos peritos odontolegistas responsáveis. Assim, os resultados do presente estudo permitem afirmar que a microdureza inerente a cada material é fator determinante para essa diferenciação.

Analisada separadamente, a microdureza, por si só, não é capaz de diferenciar os mesmos materiais, nos diferentes tempos estudados, em nenhuma das condições ambientais, uma vez que não houve diferença significante $(p>0,05)$ na alteração dessa propriedade físicomecânica. Porém, os diferentes materiais estudados apresentam microdurezas características para cada um, mas muito distintas entre eles. Essa diferença significante $(p<0,05)$ possibilita a diferenciação entre materiais estéticos que, como foi observado, em alguns tempos estudados, não apresentem diferença significante $(\mathrm{p}>0,05)$ na alteração de cor.

Em relação à rugosidade de superfície, não houve diferença estatisticamente significante ( $p>0,05)$ entre os materiais, em nenhum dos tempos estudados, e nem entre as condições a que foram submetidos. Ao contrário da microdureza, os materiais restauradores não apresentam uma rugosidade individual característica, que possa ajudar em uma diferenciação complementar, após a análise de outras propriedades, como cor e dureza, pois a lisura 
superficial de uma restauração depende muito mais do polimento realizado pelo cirurgião dentista durante a confecção da restauração ${ }^{50}$. Essa constatação inviabiliza o emprego da análise de rugosidade de superfície em uma eventual perícia odontolegal que tenha por finalidade auxiliar na identificação de um cadáver.

Outro aspecto que seria relevante para a perícia de identificação humana é o tempo a que os materiais restauradores estariam submetidos aos agentes terra e água. Apesar de a tafonomia estudar essencialmente as alterações ocorridas em materiais orgânicos, e o presente estudo ter analisado as modificações ocorridas em materiais sintéticos, seria possível correlacioná-lo à cronotanatognose, caso os resultados obtidos fornecessem dados seguros para tal. Essa análise poderia oferecer um parâmetro para estipular a data aproximada a que os cadáveres foram inumados ou afogados, auxiliando na investigação policial e, até mesmo, confirmando ou excluindo suspeitos. Mas a ausência de padrão nas alterações de cor e microdureza, além da exclusão completa da rugosidade de superfície, inviabilizam esse tipo de análise. 
sec 



\section{CONCLUSÃO}

Com base nos resultados encontrados no estudo, concluiu-se que:

- A inumação e o afogamento produzem alteração de cor nos materiais restauradores estéticos, mas essa alteração não é tempo dependente;

- Não há interferência dos agentes testados sobre rugosidade de superfície dos materiais, independentemente do tempo testado;

- Apenas a microdureza do amálgama é modificada em 6 meses de inumação e afogamento. Não houve diferença na microdureza dos materiais restauradores estéticos em função dos agentes e tempos testados, apesar de apresentarem diferenças inerentes quanto à essa propriedade;

- A contribuição desse método para as perícias de identificação humana após inumação ou afogamento só é possível considerando-se a microdureza, sendo auxiliada pela análise da alteração de cor do material;

- A análise da rugosidade de superfície não oferece parâmetros para comparação de materiais restauradores odontológicos, sendo descartada como critério auxiliar em procedimentos de identificação;

- Não é possível predizer o tempo de inumação ou afogamento de um indivíduo apenas com base nos parâmetros estudados. 



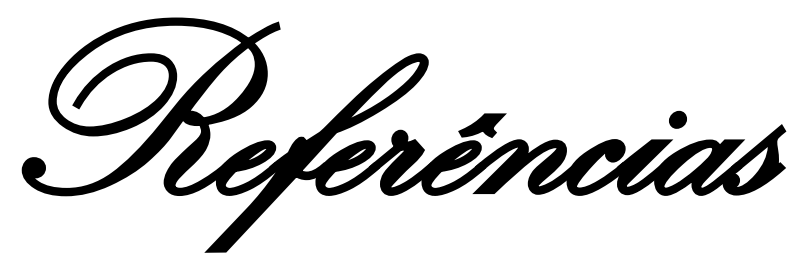





\section{REFERÊNCIAS}

1. Consolidação das Normas para Procedimentos nos Conselhos de Odontologia. Aprovada pela Resolução CFO 63/2005.

2. Brasil. Lei $\mathrm{n}^{\circ}$ 5.081, de 24 de agosto de 1966. Regula o exercício da Odontologia. Disponível em <http://www.planalto.gov.br/ccivil_03/leis/15081.htm>; Acessado em 25 de julho de 2014.

3. Vanrell JP. Odontologia Legal \& Antropologia Forense. 2 ed. Rio de Janeiro: Guanabara Koogan; 2009.

4. Espíndula A. Perícia Criminal e Cível: uma visão geral para peritos e usuários da perícia. 4 ed. Campinas: Millennium; 2013.

5. Almeida Jr. A, Costa Jr. JBQ. Lições de Medicina Legal. 14 ed. São Paulo: Nacional; 1977.

6. Clark DH. Practical forensic odontology. Butterworth-Heinemann; 1992.

7. Keiser-Nielsen S. Teeth that told. Department of Forensic Odontology, Royal Dental College; 1988.

8. Leite VG. Odontologia Legal. Salvador: Nova Era; 1962.

9. Gruber J, Kameyama MM. O papel da Radiologia em Odontologia Legal. Pesqui Odontol Bras. 2001; 15(3):263-8.

10. França GV. Medicina Legal. 9 ed. Rio de Janeiro: Guanabara Koogan; 2011. 694 p.

11. Jobim LF, Costa LRS, Silva M. Identificação Humana - Identificação medicolegal, perícias odontológicas, identificação humana pelo DNA. 2 ed. Campinas: Millennium; 2012.

12. Couto RC. Perícias em Medicina \& Odontologia Legal. Rio de Janeiro: Med Book; 2011.

13. Galvão LCC. Medicina Legal. São paulo: Santos; 2012.

14. Arbenz GO. Medicina Legal e Antropologia Forense. São Paulo: Atheneu; 1988.

15. Oliveira RN, Melani RFH, Antunes JLF, Freitas ER, Galvão LCC. Perda dentária post mortem em processos de identificação humana. Odontologia e Sociedade. 1999; $1(1 / 2): 35-8$.

16. Tilstone WJ, Savage KA, Clark LA. Forensic science: An encyclopedia of history, methods, and techniques: ABC-CLIO; 2006.

17. Jackson ARW, Jackson JM. Forensic Science. 3 ed. Pearson: Prentice Hall; 2011.

18. INTERPOL. Disaster Victim Identification Guide. Lyon: OIPC/ICPO - INTERPOL 2013. 
19. Silva SCP. A contribuição da perícia odontológica na identificação de cadáveres. [Dissertação de mestrado]. Porto: Universidade do Porto; 2007.

20. Rodríguez Cuenca JV. Introducción a la Antropología Forense. Análisis e interpretación de restos óseos humanos. Bogotá: Anaconda Editores; 1994.

21. Senn DR, Stimson PG. Forensic Dentistry. 2 ed. New York: CRC Press - Taylor \& Francis; 2010.

22. Dahberg AA. Dental traits as identification tools. Dent Prog. 1963; 3:155-60.

23. Porto IM, Laure HJ, Sousa FB, Rosa JC, Gerlach RF. New techniques for the recovery of small amounts of mature enamel proteins. Journal of Archaeological Science. 2011; 38(12):3596-604.

24. Rothwell BR. Principles of dental identification. Dental Clinics of North America. 2001; 45(2):253-70.

25. Glass RT, Von Fraunhofer JA. Practical Forensic Dentistry - theory and practice of forensic dentistry. Deutschland: VDM; 2009.

26. Okoye MI, Wecht CH. Forensic investigation and management of mass disaster. Tucson: Lawyers \& Judges Publishing Company, Inc; 2007.

27. Herschaft EE, Alder ME, Ord DK, Rawson RD, Smith ES. Manual of Forensic Odontology. 4 ed. Saratoga Springs, NY: American Society of Forensic Sciense; 2006.

28. Paranhos LR, Caldas JCF, Iwashita AR, Scanavini MA, Paschini RC. A importância do prontuário odontológico nas perícias de identificação humana. RFO. 2009; 14(1):14-7.

29. Hinchliffe J. Forensic odontology, part 2. Major disasters. British Dental Journal. 2011; 210(6):269-74.

30. Clark DH. An analysis of the value of forensic odontology in ten mass disasters. Int Dent J. 1994; 44:241-50.

31. Fereira JL, Fereira AE, Ortega AI. Methods for the analysis of hard dental tissues exposed to high temperatures. Forensic Science International. 2008; 178(2-3):119-24.

32. Spadácio C. Análise dos principais materiais dentários restauradores submetidos à ação do fogo e sua importância no processo de identificação. [Tese de doutorado]. Piracicaba: Universidade Estadual de Campinas; 2007.

33. Moreira RP, Freitas AZVM. Dicionário de odontologia legal. Rio de Janeiro: Guanabara Koogan; 1999.

34. Hercules HC. Medicina Legal - Texto e Atlas. São Paulo: Atheneu; 2011.

35. Pires-de-Souza FCP, Garcia LFR, Hamida HM, Casemiro LA. Color stability of composites subjected to accelerated aging after curing using either a halogen or a light emitting diode source. Brazilian Dental Journal. 2007; 18(2):119-23. 
36. Sakaguchi RL, Powers JM. Craig - Materiais dentários restauradores. Rio de Janeiro: Elsevier; 2012. 416 p.

37. Anusavice KJ, Shen C, Rawls HR. Phillips Materiais Dentários. 12 ed. Rio de Janeiro: Elsevier; 2013.

38. Rode KM, Freitas P, Lloret PR, Powell LG, Turbino ML. Microhardness evaluation of a microhybrid composite resin light cured with halogen light, light-emitting diode and argon ion laser. Lasers Med Sci. 2009; 24(1):87-92.

39. Mundim FM, Garcia LFR, Pires-de-Souza FCP. Effect of staining solutions and repolishing on color stability of direct composites. Journal of Applied Oral Science. 2010; 18(3):249-54.

40. Alandia-Román CC. Análise da estabilidade de cor e rugosidade de superfície de compósitos submetidos à fumaça de cigarro. [Dissertação de mestrado]. Ribeirão Preto: Universidade de São Paulo; 2011.

41. Roselino LMR. Efeito da escovação e do envelhecimento artificial acelerado sobre a alteração superficial de materiais restauradores estéticos. [Dissertação de mestrado]. Ribeirão Preto: Universidade de São Paulo; 2012.

42. Mundim FM. Estudo longitudinal da influência da ação de soluções fluoretadas sobre alteração de cor e rugosidade de superfície de compósitos odontológicos. [Tese de doutorado]. Ribeirão Preto: Universidade de São Paulo; 2011.

43. Martínez MAJA. Avaliação do desgaste e da rugosidade superficial de uma resina composta, após escovação simulada, em função de diferentes energias e fontes de luz usadas na polimerização. [Dissertação de mestrado]. Bauru: Universidade de São Paulo; 2004.

44. Mundim FM. Influência do envelhecimento artificial acelerado sobre a estabilidade de cor, opacidade e densidade das ligações cruzadas de compósitos odontológicos armazenados em diferentes ambientes e tempos de armazenagem. [Disertação de mestrado]. Ribeirão Preto: Universidade de São Paulo; 2007.

45. Aguilar FG. Avaliação da cor e opacidade de compósitos diretos protegidos com selantes de superfície submetidos ao envelhecimento artificial acelerado. [Dissertação de mestrado]. Ribeirão Preto: Universidade de São Paulo; 2008.

46. Zanin FR, Garcia LFR, Casemiro LA, Pires-de-Souza FCP. Effect of artificial accelerated aging on color stability and surface roughness of indirect composites. The European journal of prosthodontics and restorative dentistry. 2008; 16(1):10-4.

47. Silame FDJ. Efeito do envelhecimento artificial acelerado na estabilidade de cor de cimentos resinosos para cimentação de laminados cerâmicos. [Dissertação de mestrado]. Ribeirão Preto: Universidade de São Paulo; 2013.

48. Yap AUJ, Lye KW, Sau CW. Surface characteristics of tooth-colored restoratives polished utilizing different polishing systems. Operative Dentistry. 1997; 22(6):260-5. 
49. Momoi Y, Hirosaki K, Kohno A, McCabe JF. In vitro toothbrush-dentifrice abrasion of resin-modified glass ionomers. Dental Materials. 1997; 13(2):82-8.

50. Nonaka T, Gabrielli F, Ribeiro SA, Centola ALB, Sá DN. Amálgama Dental - Estudo da microdureza superficial. Efeito da brunidura. Semina: Ciências Biológicas e da Saúde. 1996; 17(2):206-13.

51. Commission Internationale de l'Eclairage. Colorimetry-technical report. 15. Viena, Austria: CIE Publication; 1986.

52. Wyszecki G, Stiles WS. Color science. New York: Wiley; 1982.

53. Leitao J, Hegdahl T. On the measuring of roughness. Acta Odontologica Scandinavica. 1981; 39(6):379-84.

54. Pires-de-Souza FCP, Casemiro LA, Garcia LFR, Cruvinel DR. Color stability of dental ceramics submitted to artificial accelerated aging after repeated firings. Journal of Prosthetic Dentistry. 2009; 101(1):13-8.

55. Brosh T, Ganor Y, Belov I, Pilo R. Analysis of strength properties of light-cured resin composites. Dental Materials. 1999; 15(3):174-9.

56. Reis $\mathrm{A}$, Loguercio $\mathrm{AD}$. Materiais dentários diretos - dos fundamentos à aplicação clínica. São Paulo: Santos; 2009. 423 p.

57. Bertolini MM, Oliveira G, Charone S, Soares RMA, Souza IPR, Portela MB. Avaliação in vitro da microdureza de cimentos de ionômero de vidro modificados por resina submetidos a biofilme de Candida albicans. Pesquisa Brasileira em Odontopediatria e Clínica Integrada. 2010; 10(2):249-55.

58. Lee YK, Lim BS, Kim CW. Effect of surface conditions on the color of dental resin composites. Journal of Biomedical Materials Research. 2002; 63(5):657-63.

59. Lee YK, Lim BS, Kim CW. Difference in the colour and colour change of dental resin composites by the background. Journal of Oral Rehabilitation. 2005; 32(3):227-33.

60. Stevenson B, Ibbetson R. The effect of the substructure on the colour of samples/restorations veneered with ceramic: A literature review. Journal of Dentistry. 2010; 38(5):361-8.

61. Nakamura T, Saito O, Mizuno M, Tanaka H. Changes in translucency and color of particulate filler composite resins. International Journal of Prosthodontics. 2002; 15(5):494-9.

62. Stavridakis MM, Papazoglou E, Seghi RR, Johnston WM, Brantley WA. Effect of different high-palladium metal-ceramic alloys on the color of opaque and dentin porcelain. Journal of Prosthetic Dentistry. 2004; 92(2):170-8.

63. Turssi CP, Messias DF, Corona SM, Serra MC. Viability of using enamel and dentin from bovine origin as a substitute for human counterparts in an intraoral erosion model. Braz Dent J. 2010; 21(4). 
64. Anido-Anido A, Amore R, Lewgoy HR, Anauate-Netto C, Silva TM, Gonçalves SEP. Comparative study of the bond strength to human and bovine dentin in three different depths. Brazilian Dental Science. 2012; 15(2):56-62.

65. Kolbeck C, Rosentritt M, Lang R, Handel G. Discoloration of facing and restorative composites by UV-irradiation and staining food. Dental Materials. 2006; 22(1):63-8.

66. Ragain JC, Johnson WM. Color acceptance of direct dental restorative materials by human observers. Color Research and Application. 2000; 25(4):278-85.

67. Della Bona A, Barrett AA, Rosa V, Pinzetta C. Visual and instrumental agreement in dental shade selection: Three distinct observer populations and shade matching protocols. Dental Materials. 2009; 25(2):276-81.

68. Ozat PB, Tuncel I, Eroglu E. Repeatability and reliability of human eye in visual shade selection. Journal of Oral Rehabilitation. 2013; 40(12):958-64.

69. Bahannan SA. Shade matching quality among dental students using visual and instrumental methods. Journal of Dentistry. 2014; 42(1):48-52.

70. Zimmerli B, Koch T, Flury S, Lussi A. The influence of toothbrushing and coffee staining on different composite surface coatings. Clinical Oral Investigations. 2012; 16(2):46979 .

71. Ruyter IE, Nilner K, Moller B. Color stability of dental composite resin materials for crown and bridge veneers. Dental Materials. 1987; 3(5):246-51.

72. Seghi RR, Hewlett ER, Kim J. Visual and instrumental colorimetric assessments of small color differences on translucent dental porcelain. Journal of Dental Research. 1989; 68(12):1760-4.

73. Johnston WM, Kao EC. Assessment of appearance match by visual observation and clinical colorimetry. Journal of Dental Research. 1989; 68(5):819-22.

74. Bowen RL, inventor. Dental filing material composising vinyl siliane treated fused silica and a binder consisting of a reaction product of bisphenol and glycidyl acrylate. US3066; 1962.

75. Kobussen GA, Craig BD, Halvorson RH, Doruff MC, Bigham WS. Optical properties of highly aesthetic composite restoratives. J Dent Res. 2009;88 (Spec Iss A):1508.

76. Nasim I, Neelakantan P, Sujeer R, Subbarao CV. Color stability of microfilled, microhybrid and nanocomposite resins - An in vitro study. Journal of Dentistry. 2010; 38:E137-E42.

77. Inokoshi S, Burrow MF, Kataumi M, Yamada T, Takatsu T. Opacity and color changes of tooth-colored restorative materials. Operative Dentistry. 1996; 21(2):73-80.

78. Oysaed H, Ruyter IE. Water sorption and filler characteristics of composites for use in posterior teeth. Journal of Dental Research. 1986; 65(11):1315-8. 
79. Papadopoulos T, Sarafianou A, Hatzikyriakos A. Colour stability of veneering composites after accelerated aging. Eur J Dent. 2010; 4(2):137-42.

80. Braden M. Water-absorption characteristics of dental microfine composite filling materials. 2. Experimental materials. Biomaterials. 1984; 5(6):373-5.

81. Pearson GJ, Longman CM. Water sorption and solubility of resin-based materials following inadequate polymerization by a visible-light curing system. Journal of Oral Rehabilitation. 1989; 16(1):57-61.

82. Bagheri R, Burrow MF, Tyas M. Influence of food-simulating solutions and surface finish on susceptibility to staining of aesthetic restorative materials. Journal of Dentistry. 2005; 33(5):389-98.

83. Choi MS, Lee YK, Lim BS, Rhee SH, Yang HC, Lim YJ. Changes in color and translucency of porcelain-repairing resin composites after thermocycling. J Biomed Mater Res. 2006; 78(Part B: Appl Biomater):1-6.

84. Ferracane JL, Berge HX, Condon JR. In vitro aging of dental composites in water - Effect of degree of conversion, filler volume, and filler/matrix coupling. Journal of Biomedical Materials Research. 1998; 42(3):465-72.

85. Carvalho Júnior OB. Avaliação in vitro da dureza superficial, da contração de polimerização e da rugosidade de 29 resinas compostas. [Dissertação de mestrado]. São Paulo: Universidade de São Paulo; 2002.

86. Anfe TEA, Caneppele TMF, Agra CM, Vieira GF. Microhardness assessment of different commercial brands of resin composites with different degrees of translucence. Brazilian Oral Research. 2008; 22(4):358-63.

87. Kim JH, Lee YK, Powers JM. Influence of a series of organic and chemical substances on the translucency of resin composites. Journal of Biomedical Materials Research Part B-Applied Biomaterials. 2006; 77B(1):21-7.

88. Van Noort R. Introdução aos materiais dentários. 3 ed. Rio de Janeiro: Elsevier Brasil; 2010. 292 p.

89. Louro RL. Influência do ultra-som na resistência à abrasão e na rugosidade de superfície dos cimentos de ionômero de vidro submetidos à escovação. [Tese de doutorado]. Bauru: Universidade de São Paulo; 2007.

90. Mandarino F. Cimentos de ionômero de vidro. Disponível em: www.forp.usp.br/restauradora/dentistica/temas/cim_ion_vid/cim_ion_vid.pdf. Acessado em 27 de Outubro de 2014.

91. Pires-de-Souza FCP, Contente MMMG, Casemiro LA. Cianoacrilato como protetor superficial de restaurações de cimento de óxido de zinco e eugenol e de cimento de ionômero de vidro: avaliação da infiltração marginal. Ciênc odontol bras. 2006; 9(1):4753. 
92. Rios D. Avaliação do desgaste e rugosidade superficial de materiais utilizados para selante, submetidos à escovação com dois diferentes dentifrícios. [Dissertação de mestrado]. Bauru: Universidade de São Paulo; 2000.

93. Batista WVB. Avaliação da eficiência do polimento efetuado em superfícies de vidro e de amálgama, por pontas de "borracha abrasiva" ou pastas para polimento, em relação à perda de massa e à rugosidade [Dissertação de mestrado]. Bauru: Universidade de São Paulo; 2003.

94. Whitehead SA, Shearer AC, Watts DC, Wilson NHF. Comparison of methods for measuring surface-roughness of ceramic. Journal of Oral Rehabilitation. 1995; 22(6):4217.

95. Whitehead SA, Shearer AC, Watts DC, Wilson NHF. Surface texture changes of a composite brushed with "tooth whitening" dentifrices. Dental Materials. 1996; 12(56):315-8.

96. Ehrnford L, Derand T, Larsson LA, Svensson A. An abrasion test for composite resins. Journal of Dental Research. 1980; 59(4):716-20.

97. Powell JM, Phillips RW, Norman RD. In vitro wear reponse of composite resin, amalgam, and enamel. J Dent Res. 1975; 54(6):1183-95.

98. Wang L. Avaliação comparativa da resistência à abrasão de resinas compostas condensáveis, submetidas à escovação simulada, através da alteração de massa e da rugosidade superficial. [Dissertação de mestrado]. Bauru: Universidade de São Paulo; 2001.

99. Prakki A. Resistência ao desgaste de cimentos resinosos submetidos à ciclagem de $\mathrm{pH}$ e escovação simulada. [Dissertação de mestrado]. Bauru: Universidade de São Paulo; 2003.

100. Papagiannoulis L, Tzoutzas J, Eliades G. Effect of topical fluoride agents on the morphologic characteristics and composition of resin composite restorative materials. Journal of Prosthetic Dentistry. 1997; 77(4):405-13.

101. El-Badrawy WA, McComb D. Effect of home-use fluoride gels on resin-modified glassionomer cements. Operative Dentistry. 1998; 23(1):2-9.

102. Scheibe K, Almeida KGB, Medeiros IS, Costa JF, Alves CMC. Effect of different polishing systems on the surface roughness of microhybrid composites. Journal of Applied Oral Science. 2009; 17(1):21-6.

103. Marghalani HY. Effect of filler particles on surface roughness of experimental composite series. Journal of Applied Oral Science. 2010; 18(1):59-67.

104. Mathis RS, Ferracane JL. Properties of a glass-ionomer resin-composite hybrid material. Dental Materials. 1989; 5(5):355-8. 
105. Maneenut C, Tyas MJ. Clinical evaluation of resin-modified glass ionomer restorative cements in cervical "abrasion" lesions: one-year results. Quintessence Int. 1995; 26(10):739-43.

106. Turssi CP, Magalhaes CS, Serra MC, Rodrigues AL. Surface roughness assessment of resin-based materials during brushing preceded by $\mathrm{pH}$-cycling simulations. Operative Dentistry. 2001; 26(6):576-84.

107. Nahsan FPS. Influência da aplicação de selantes na rugosidade de resinas compostas. Bauru: Universidade de São Paulo; 2009.

108. Catelan A, Lima MO, Giorgi MCC, Miranda DA, Ambrosano GMB, Aguiar FHB, Lima DANL. Influência do selamento de superfície na rugosidade e microdureza de compósitos dentais antes e após o clareamento dental. Prosthes Lab Sci. 2014; 3(11):191-6.

109. McCabe JF, Walls AWG. Applied dental materials. 8 ed. Oxford: Blackwell Science; 1998.

110. Rueggeberg FA, Ergle JW, Mettenburg DJ. Polymerization depths of contemporary lightcuring units using microhardness. J Esthet Dent. 2000; 12(6):340-9.

111. Price RBT, Ehrnford L, Andreou P, Felix CA. Comparison of quartz-tungsten-halogen, light-emitting diode, and plasma arc curing lights. Journal of Adhesive Dentistry. 2003; 5(3):193-207.

112. Soprano V. Estudo de parâmetros para ensaios de microdureza em amálgama de prata, resina composta, dentina e esmalte bovinos. [Dissertação de mestrado]. São Paulo: Universidade de São Paulo; 2008.

113. Oliveira TMMG. Efeito das variáveis microestruturais nas propriedades mecânicas de cimento ionômero de vidro convencional. [Tese de doutorado]. Rio de Janeiro: Universidade Federal do Rio de Janeiro; 2005.

114. Oréfice RL, Pereira MM, Mansur HS. Biomateriais: Fundamentos e Aplicações. Rio de Janeiro: Cultura Médica; 2006. 536 p.

115. Ulhoa MPM, Santana LRS, Bianchi EC, Cruz CED, Aguiar PR, Freitas CA, Freitas MFA. Comparação da influência entre tempos de polimerização em resinas compostas polimerizadas com led e luz incandescente Polímeros: Ciência e Tecnologia. 2007; 17(3):258-62.

116. Donassollo TA, Leivas LL, Osinaga PWR, Demarco FF. Microdureza do amálgama: influência da liga e do tratamento superficial. Rev Pós Grad. 2003;10: 204-10.

117. Patsurakos A, Möberg LE. Corrosion behavior and microhardness of three amalgams. Scand J Dent Res. 1988; 96:376.

118. Silva AB, Centola ALB, Turbino ML, Froner IC, Nascimento TN. Microdureza de amálgama: efeito da brunidura pós-escultura e da brunidura pré e pós-escultura Rev Odontol Univ São Paulo. 1994; 8(3):193-7. 
119. Mandarino F. Ligas para Restaurações de Amálgama 2003. Disponível em: http://www.forp.usp.br/restauradora/dentistica/temas/amalgama/amalgama_04/amalgam a_04.html. Acessado em 30 de Outubro de 2014.

120. Johansson BI, Mjor IA. Marginal degradation and corrosion of a dispersed high copper amalgam. Scandinavian Journal of Dental Research. 1988; 96(1):75-82.

121. Ilikli BG, Aydin A, Isimer A, Alpaslan G. In vitro corrosion behaviour and microhardness of high-copper amalgams with platinum and indium. Journal of Oral Rehabilitation. 1999; 26(2):170-6. 

Anesco 

ANEXO

Autorização para utilização do lago do campus de Ribeirão Preto, da Universidade de São Paulo

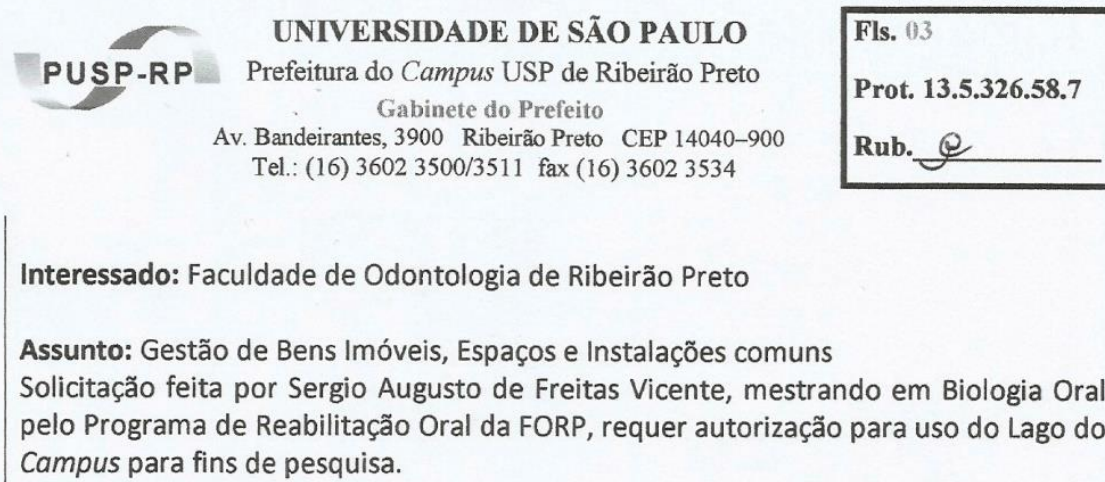

Autorizamos a solicitação do mestrando Sergio Augusto de Freitas Vicente, referente à utilização do Lago do Campus para fins de pesquisa, devendo o mesmo entrar em contato com o Eng. Florestal Devanir Jerônimo Del'Arco para as devidas orientações de acesso ao local.

Após, encaminhem-se os autos à DVMANOP/PUSP-RP. Em seguida, ao SVGUAUN/PUSP-RP para ciência, retornando ao Gabinete/PUSP-RP.

Ribeirão Preto, 17 de dezembro de 2013.

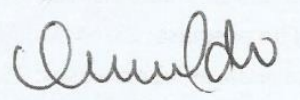

Prof. Dr. Osvaldo Luiz Bezzon Prefeito de Campus USP

$$
\text { Ciente: }
$$

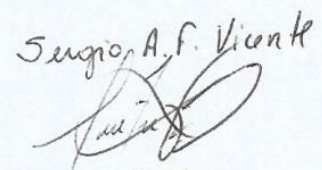

$17 / 12 / 13$ 


\section{PUSP-RP UNIVERSIDADE DE SÃO PAULO \\ Prefeitura da USP-RP \\ Divisão de Manutenção e Operação}

- Informação: 37/2014

- Protocolado: 13.5.326.58.7

- Interessado: FORP

- Assunto: solicitação feita por Sérgio Augusto de Freitas Vicente, mestrando em Biologia Oral pelo Programa de Reabilitação Oral da FORP, requer autorização para uso do lago do Campus para fins de pesquisa

Após as devidas orientações ao Sr. Sérgio Augusto de Freitas Vicente conforme registro da ciência fls. 03 e inclusão do cronograma fls. 04 , encaminhe-se à Guarda Universitária para providências cabíveis.

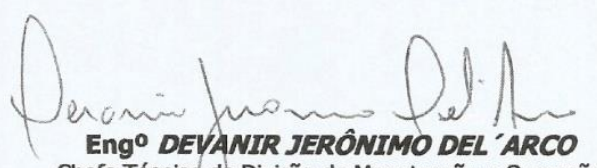

Chefe Técnico da Divisão de Manutenção e Operação

$$
\text { 22.01.14 }
$$


UNIVERSIDADE DE SÃO PAULO

PUSP-RP

Prefeitura do Campus USP de Ribeirão Preto

Serviço de Guarda Universitária - Seção de Segurança

Fone: $3602-3600$ / 3700

Int: Comissão de Meio ambiente

Assunto: Autorização para uso do lago do Campus para fins de pesquisa - Prot. 13.5.326.58.7

AO SVGUAUN

Conforme solicitação, informo que todos os agentes já foram informados sobre a solicitação feita pelo mestrando Sérgio Augusto de Freitas Vicente para autorização para uso do lago do Campus para fins de pesquisa.

Ribeirão Preto, 30 de janeiro de 2014

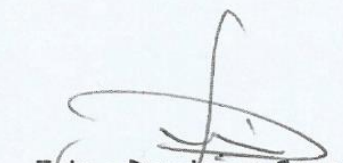

Jaime Domingos Cruz Filho

Chefe da Seção de Segurança/PUSP-RP

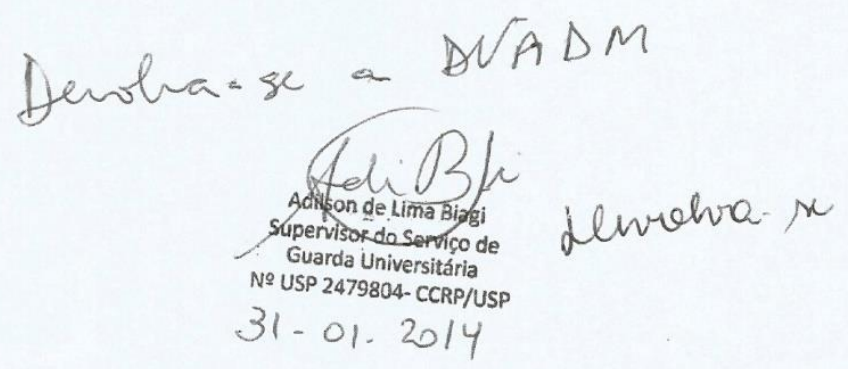




\begin{tabular}{cc|c|} 
UNIVERSIDADE DE SÃO PAULO & Fls. 07 \\
PUSP-RP & $\begin{array}{c}\text { Prefeitura do Campus USP de Ribeirão Preto } \\
\text { Gabinete do Prefeito }\end{array}$ & Prot. 13.5.326.58.7 \\
& $\begin{array}{c}\text { Av. Bandeirantes, } 3900 \text { Ribeirão Preto CEP } 14040-900 \\
\text { Tel.: (16) } 36023500 / 3511 \text { fax (16) } 36023534\end{array}$ & Rub.
\end{tabular}

Interessado: Faculdade de Odontologia de Ribeirão Preto

Assunto: Gestão de Bens Imóveis, Espaços e Instalações comuns

Solicitação feita por Sergio Augusto de Freitas Vicente, mestrando em Biologia Oral pelo Programa de Reabilitação Oral da FORP, requer autorização para uso do Lago do Campus para fins de pesquisa.

Ciente. Encaminhem-se os autos à FORP, para conhecimento e prosseguimento.

Ribeirão Preto, 13 de fevereiro de 2014.

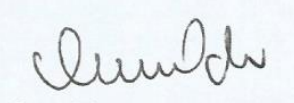

Prof. Dr. Osvaldo Luiz Bezzon

Prefeito de Campus USP 
Ciente.

Encaminhe-se à secretaria do Programa de

Reabilitação Oral desta Faculdade, para ciência

dos interessados e demais providências que couberem, retornando para arquivo.

Ribeirão Preto, 18 de fevereiro de 2014.

$\checkmark$ alder

aldemar R 3 an 7.

Rrof. Dr. Valdemar Maliet da Roche Barros

Diretor da FORP/USP
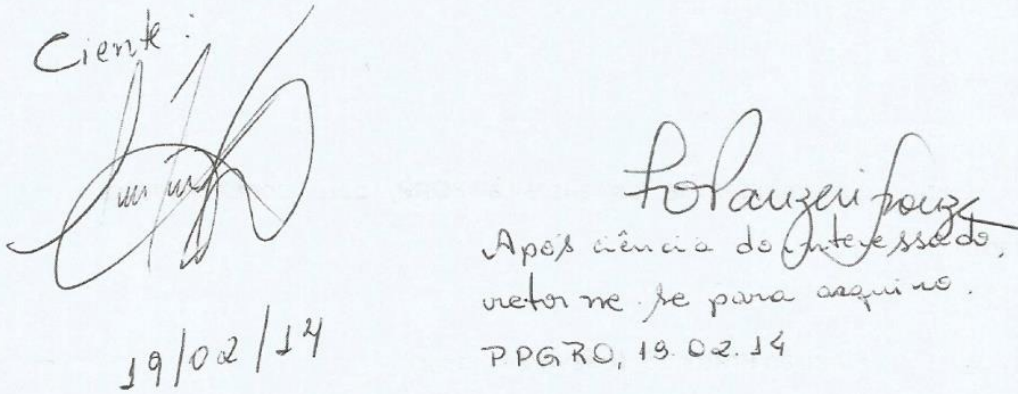
